JUTTA ASSEL / GEORG JÄGER

\title{
Zur Ikonographie des Lesens - Darstellungen von Leser(inne)n und des Lesens im Bild
}

\section{Lesebilder als Quelle für die Lese(r)geschichte}

\subsection{Quellenwert des Bildes}

„Ein Bild sagt mehr als tausend Worte“ - dieser Satz erfaßt doppelbödig die Eigenart von Bildern, auf der ihr Quellenwert beruht. Während Worte allgemeine Begriffe für ganze Klassen von Sachverhalten sind, hat es eine bildliche Darstellung mit einer je bestimmten Gestaltung zu tun. Auf dieser sciner Eigenart beruht wesentlich sein Quellenwert: Es bereichert unser historisches Wissen, indem es dieses konkretisiert, und stellt dabei Buch und Leser in bedeutungstragende Zusammenhänge. Zur Kontextbildung tragen Personen, Konstellationen mit spezifischen Örtlichkeiten, Tageszeiten, Tätigkeiten oder Gegenständen bei, die sich mit Leseakten und Lesestoffen verknüpfen.

Obwohl die meisten Lese(r)bilder allseits bekannte Situationen von Menschen mit Büchern schildern, die klar verständlich scheinen, gilt es zu fragen: Geben die Darstellungen ein Abbild der Wirklichkeit - oder ist ihnen ein verborgener Sinn eigen? Beides ist möglich. Bei einem Teil der Bilder kann sich eine Interpretation auf das unmittelbar im Bild Anschauliche beschränken. Bei dem größeren Teil jedoch wird die Deutung der verschlüsselten Botschaften je nach Kenntnisstand des Betrachters in verschiedenen Sinnschichten erfolgen, so daß mehrere Lesarten unterschiedlicher Komplexität nebeneinander möglich sind. Porträts von Lesenden können sich z.B. auf historische, mythologische oder christliche Vorbildgestalten beziehen, um sich deren Sinngehalt anzueignen, wie in Rembrandts ,portrait historié " Lesende Alte“ (Prophetin Hannah, Kap. 4.4). Dem Interpreten, der die ,Sprache der Bilder "kennt, erschließt sich in der ikonographischen Analyse - außer der Klärung der formalen Gestalt (Komposition, Lichtführung, Farbe etc.) - ihr Thema bzw. Gehalt. Eine Werkanalyse, welche die Bedeutungsvielfalt eines bestimmten Lese(r)bildes - seinen Typus, seine Motivik, Attribute sowie den religiösen, philosophischen, politischen Hintergrund etc. - erforschen möchte, muß sich zur Dekodierung des Fundus tradierter Texte bedienen: der umfangreichen emblematischen Literatur, der Bibel, der antiken Mythologie, der historischen, philosophischen, theologischen Literatur u.v.m.

Den Kontextualisierungen von Buch und Leser/in lassen sich die alltagsweltlichen und kulturellen Bezugsfelder entnehmen, in die Buch und Lesen gestellt sind. Im wesentlichen sind dies drei Bezugsfelder.

(1) Christliche Heilsgeschichte: Zum Bereich der Heilsgeschichte gehören die Darstellungen von Jesus und der Heiligen Sippe, der Propheten, Evangelisten, Apostel, Kirchenväter und Heiligen (Kap. 2), der Eremiten, Mönche, Ordensleute und Geistlichen (Kap. 3), von Anna, Maria (Kap. 4.1 u. 4.2) sowie aller die Bibel, den Katechismus, Andachts- und Erbauungsbücher lesenden Laien (Kap. 4.4 u. 5.2). 
(2) Bildung und Wissen: In diesen Kontext gehören die Darstellungen der Herrscher- und Standespersonen beiderlei Geschlechts, der kirchlichen und weltlichen Gelehrten, Philologen und Wissenschaftler/innen wie deren Schüler, aber auch der Schreiber, Dichter/innen, Künstler/innen, Kaufleute und anderer Berufsgruppen und lesender Privatpersonen (für den Mann Kap. 3, für die Frau Kap. 4.3). Schilderungen des häuslichen Lebens, der Unterhaltung, Erziehung und Freizeit rücken verstärkt die lesende Frau ins Blickfeld (Kap. 4.4 u. 5.1). Durch die Geltung, die dem Buch sowohl in der christlichen Religion wie in der alten Gelehrsamkeit zukommt, wie auch durch die Hierarchie zwischen Priester und Laien, Prediger und Hörern, Lehrer und Schülern hat das Buch die Aura des Autoritativen. Hier schließen die Darstellungen von Unterrichts- und Gerichtsszenen, Trauungen und sonstigen amtlichen Vorgängen an, bei denen (Gesetzes)Bücher befragt werden oder Eintragungen in Bücher erfolgen.

(3) Sinnengenu $\beta$ und Sexualität: Bis heute verbinden sich in vielen Situationen Lesefreuden mit Genüssen anderer Art, mit Hör- (Musik) und Gaumengenüssen (Getränken, Rauchwaren, Naschwerk; Nies 1991a), aber auch mit Stimulantien wie Duft (Blumen), Kunst, bequemen Lesemöbeln und speziellen Licht- und Wärmequellen. Verstärkt seit Mitte des 19. Jahrhunderts dokumentieren Bilder der (verbotenen) Freizeitlektüre ,wohlige', sinnlich anregende Lesesituationen. So entstand ein Bildtyp, in dem das Buch, meist ein Roman, lässig lagernden Mädchen und Frauen Anreiz zu erotischen Träumereien gibt und zu verbotenen Genüssen verlockt (Kap. 5.3). Von der Möglichkeit, differente Zustände zu überblenden, macht der Bildtypus der Büßenden Magdalena Gebrauch, in dem die Rolle der Dirne und der Heiligen verschmelzen. Von der Darstellung der Büßenden Magdalena führt ein direkter Weg zum Frauenakt mit Buch (Kap. 4.5). Auch in Bildern mit Lesern ist das Buch mit Sinnenfreuden gekoppelt: Neben lesenden Rauchern, Trinkern und Verliebten findet sich der onanierende Leser bzw. Leserinnen. Bilder bilden mithin eine hervorragende Quelle für Fragen nach dem assoziativen Umfeld und der emotionalen Besetzung des Buches und des Lesens.

Mit der Entwicklung der neuen Reproduktionstechniken Lithographie, Stahl- und Holzstich, der Heliogravüre sowie der photo- und chemographischen Verfahren hörte der Bildbesitz im 19. Jahrhundert auf, ein Privileg der oberen Schichten zu sein, und wurde jedem zugänglich. Dank der seit der Mitte des Jahrhunderts sich entwickelnden Kunstverlage und der bald voll industrialisierten Bilderfabriken kommt es zu einer Flut auch von Lese(r)bildern. Die Produktion stellt sich auf die Nachfrage ein, variiert alle Bildtypen, reizt sie aus, ironisiert und karikiert sie schließlich in den beliebten Witzblättern. Über Zeitungen und Zeitschriften, Kunstvereine, Bildpostkarten etc. werden die Bilder in weiteste Schichten verbreitet. Sozialgeschichtlich gesehen, erreicht die Verbreitung von Lese(r)bildern im 19. Jahrhundert bis zum Ersten Weltkrieg ihren Höhepunkt. Im Gegenzug scheinen die überlieferten Bildtypen jedoch an kultureller Geltung und prägender Kraft zu verlieren.

\subsection{Quellenkritik des Bildes}

Den Bildzeugnissen von Lesenden kommt ein sehr unterschiedlicher Quellenwert zu. Die Spannweite reicht vom Abbild, das zeigt, wie es früher um das Lesen bestellt war, bis zum dogmatischen Gehalt eines religiösen Bildes. Die über Jahrhunderte 
tradierte christliche Ikonographie bezeugt das konventionalisierte Wissen um die Rolle von Buch und Lektüre in der Heilsgeschichte, läßt sich jedoch nur mit Vorsicht auf die historische Realität beziehen. Viele Lesebilder der Frühen Neuzeit sind Dokumente der Selbstrepräsentation einer sozialen Gruppe, die belegen, wie sie sich in ihrem Umgang mit dem Buch sah und wie sie gesehen werden wollte. Die enge Verbindung des Lesens mit Bildung, Humanität und Individualität, welche die bürgerliche Gesellschaft prägt, führte zu einer Hochschätzung von Lesebildern. Sie sind Zeugnis einer umfassenden Pädagogisierung des Lesens und entwerfen häufig ideale Lesesituationen, an denen sich der Betrachter im positiven oder negativen Sinn ein Beispiel nehmen soll. Um den Aussagewert der Bildquelle einschätzen zu können, ist mithin ihr Funktionszusammenhang im religiösen und kulturellen Leben zu berücksichtigen.

Die Funktion der Lesebilder nimmt in der Kommunikations- und Verwendungssituation konkrete Gestalt an. Die christlichen Lesebilder waren Teil eines kirchlichen Ritus oder einer religösen Praxis (Belting 1991, 1995) oder hatten Vorbildcharakter. Porträts mit Buch dienten der (Selbst)Repräsentation der Dargestellten und ihrem Andenken, Genrebilder der nostalgischen Verklärung von Alltagsszenen, der beschaulichen Betrachtung wie auch dem Schmuck der Wohnung, Illustrationen und Karikaturen in der Presse der amüsanten Unterhaltung, Postkarten der beziehungsreichen Kommunikation usw. Neben die religiösen Bilder, an die sich für Gläubige Aussagen von existentieller Bedeutung knüpfen, die immer wieder neu aktualisiert werden, treten die Produkte einer Unterhaltungsindustrie, die nur mit einer oberflächlichen Aufmerksamkeit rechnen und für den aktuellen Verbrauch bestimmt sind. Den unterschiedlichen Funktionen entspricht somit ein sehr ungleicher Stellenwert der Bildzeugnisse in ihrer Herkunftskultur, der bei der Bestimmung ihres Quellenwertes in Rechnung zu stellen ist.

Nach Funktion und Kommunikationssituation bilden künstlerischer Stil und ästhetische Qualität einen dritten Referenzrahmen bei der Beschreibung von Lesebildern. Die Darstellung einer Lesesituation in der Kunst verweist stets mehr oder weniger stark auf den Stil der Epoche, der künstlerischen Bewegung oder des Künstlers. In dem Maße, in dem sich die bildende Kunst im Übergang zur Neuzeit verselbständigte, gewannen künstlerische Stile, Techniken und Motive an ästhetischem Eigenwert.

\section{Bücher und Lesende in der christlichen Ikonographie}

Wie das Judentum, aus dem es hervorgegangen ist, so ist auch das Christentum eine Schrift- und Buchreligion. Juden wie Christen wurden von den arabischen Nachbarn „Volk des Buches" genannt. Die Tafeln mit den Geboten und die Schriftrollen, handschriftlichen Codices und gedruckten Bücher, in denen die Heilige Schrift aufgezeichnet ist, sowie eine Typologie von Schreibenden und Lesenden zählen zum grundlegenden Inventar der christlichen Bildwelt.

Sowohl Gottvater wie Gottsohn finden sich mit Buch dargestellt, das aufgeschlagen zuweilen das Alpha und Omega, den ersten und letzten Buchstaben des griechischen 
Alphabets, zeigt und damit auf Gott als den Anfang und das Ende aller Dinge hinweist. Im byzantinischen Bildtypus ,Christus Pantokrator“ (Allherrscher) präsentiert der thronende Gottessohn ein geschlossenes oder ein frontal zum Beschauer hin aufgeschlagenes Buch, in dem ein unterschiedlicher Text zu lesen steht, etwa „Ego sum lux mundi“" (Ich bin das Licht der Welt; Joh. 8,12, auch Joh. 10,9 und 15,17) oder „Jesus alpha omega“ (Anfang und Ende). Die Propheten, Apostel, Evangelisten, Kirchenväter sowie Ordensgründer werden in vielfältiger Weise mit dem Buch dargestellt. Dazu gehören auch die zahlreichen Heiligen, Märtyer und Engel, denen das Buch als Attribut beigegeben ist, sowie Päpste und Kleriker (Braun 1992). Hier ist das Buch Hinweis auf das Heilswissen, die Schriftgläubigkeit, -gelehrsamkeit und -lehre.

Der ,Triumph ' des Thomas von Aquin, des großen Scholastikers des Hochmittelalters, auf dem Tafelbild von Francesco Traini in der Dominikanerkirche Santa Catharina in Pisa 1344 (Van Winckel/Van Grethem, 154 f.; Zuschreibung umstritten) verdeutlicht die zentrale Stellung des Buches in der christlichen Wissensordnung. Im Zentrum des Bildes thront Thomas von Aquin, der neben anderen Schriften sein Werk „Summa contra Gentiles“ mit dem Zitat aus den Sprüchen Salomos VIII,7 „Veritatem meditabitur guttur meum et labia mea detestabuntur impium“ (Denn mein Mund soll die Wahrheit reden, und meine Lippen sollen hassen, was gottlos ist.) geöffnet auf dem Schoß hält. Über ihm sind Christus in der Mandorla, von Engeln umringt, sowie die vier Evangelisten mit Moses und Paulus - alle mit geöffneten Schriften in Händen - dargestellt. Zur Rechten von Thomas steht Aristoteles, zur Linken Plato, unter ihnen bilden Priester unterschiedlicher Orden zwei Gruppen. Der arabische Aristoteliker Averroes und seine Lehre liegen besiegt am Boden, wie das neben ihm mit den Seiten zur Erde gewendete Buch anzeigt. Strahlen bezeichnen die Inspirationsquellen. Sie gehen vom Mund des Gottessohnes zu den Evangelisten, Moses und Paulus, sowie von deren Schriften wie auch direkt von Jesu zum Kopf des Thomas und betonen hiermit die göttliche Offenbarung als wichtigste Inspirationsquelle. Auch von den Büchern der antiken Philosophen gehen Strahlen zum Mund des Aquiners. Das Werk des Thomas ist von einem Strahlenbündel umgeben, weil in ihm alle Worte ihre wahre Bedeutung finden. Die von den Strahlen berührten Ordensleute beziehen sich in ihren Disputationen auf seine Schriften. Somit zeigt das Bild eine durch das göttliche Wort inspirierte, durch mündliche Verkündigung und Disputation, schriftliche Tradierung und Auslegung im Buch geprägte Gesellschaft von Heiligen, Philosophen und gelehrten Klerikern.

Die frühen Bildformulierungen lesender Evangelisten, Kirchenlehrer und Ordensgründer werden in den profanen Gelehrtendarstellungen aufgenommen. Der Bildtypus des studierenden hl. Hieronymus im Gehäuse (Jan van Eyck, Abb. 3), der auf frühe Darstellungen der Evangelisten und Kirchenlehrer (vor allem des hl. Gregor, vgl. Eberlein 1995) zurückgeht, führt zu den Gelehrtendarstellungen in der Studierstube (z.B. Dürer, Erasmus von Rotterdam, Kupferstich 1526). Im Kapitelsaal des Dominikanerklosters von San Nicolo in Treviso (1352; Gibbs 1989, 50-87) verherrlichte Tomaso da Modena herausragende Ordensmitglieder - unter ihnen die Päpste Innocenz V und Benedikt XI, Vincenz von Beauvais und Thomas von Aquin - und variierte 
dabei in 40 Darstellungen die Situation lesender und schreibender Mönche in ihren Zellen. Hier findet sich auch die älteste Bildquelle einer Lesebrille (Mann 1992, 31). Lehrend, predigend und lesend zeigen sich außer Christus und den Kirchenvätern zahlreiche Heilige, Kleriker und Ordensleute mit Büchern.

Mit den Büßern in der Einöde (Hl. Hieronymus, Hl. Magdalena, Eremiten, vgl. Kap. 3.2 und 4.5), dem hl. Johannes dem Täufer in der Wüste (z.B. im Gehen lesend gemalt vom Berner Nelkenmeister, Ende des 15. Jahrhunderts; Zürich, Kunsthaus) und Szenen des Christus-, Marien- und Heiligenlebens werden Lesesituationen in die freie Natur verlegt (z.B. Giovanni Cariani, La Madonna Cucitrice, um 1525; Genius of Venice, Nr. 31 mit Abb., wo Maria mit der das Buch eingemerkt haltenden Elisabeth im Freien zwischen Rosen und Zitronenbäumchen dem spielenden Jesusknaben mit Johannes zuschauen). Die ersten, die nachts bei Mondschein oder dem Licht einer Kerze bzw. Laterne über dem Buch meditierend gezeigt wurden, dürften die Büßer/ Eremiten gewesen sein. Die erste Gruppe von buchbesitzenden und lesenden Laien ging in Gestalt der Dedikations-Adressaten, Auftraggeber, Autoren und Stifter in die Bildgeschichte ein (Chroniken, Altargemälde - vgl. beispielhaft den Stifter Nicolas Rolin, einen hochrangigen Notabeln, auf Jan van Eycks „Madonna des Kanzlers Rolin“, 1436. Paris, Musée du Louvre; Norbert Schneider 1994, 36-39 mit Abb.).

Die Ikonographie der lesenden und lehrenden Frau nimmt von den Schilderungen der seit Augustinus den Propheten gleichgeordneten Sibyllen, der hl. Katharina von Alexandrien und einigen anderen weiblichen Heiligen, der hl. Anna und hauptsächlich Maria ihren Ausgang. Denn im Gestus des Lesens steht in unzähligen Szenen des Marienlebens Maria dem Betrachter vor Augen; in vielen ist das Buch nicht nur Sinnbild, sondern Objekt tatsächlicher Lektüre. Ein Bildtypus mit Nachfolge ist z.B. die Verkündigung (Kap. 4.1) oder der Tod Mariens, deren Sterbebett die Apostel umstehen, ihr das Buch vorhalten, (Sterbegebete) vorlesen, lesen und disputieren etc. (vgl. z.B. den Marientod des Wiener Meisters, um 1430; Dom- und Diözesanmuseum Wien). Die Prophetin Hannah, eine der bedeutendsten Frauen des Alten Testaments, präfiguriert mit geöffnetem Buch die lesende alte Frau, die besonders im 17. Jahrhundert in den Niederlanden und im 19. Jahrhundert in Deutschland zahlreiche Ausprägungen fand (Kap. 4.4). Wie aus dieser Auswahl zu ersehen, hat die christliche Ikonographie eine typenreiche und wirkungsmächtige Bildwelt mit Büchern und Lesenden geschaffen.

\section{Mann und Buch}

\subsection{Das Buch als Attribut des Mannes: Ausweis von Gelehrsamkeit, Bildung und Wissen}

Seit den Anfängen der Porträtdarstellung ließ sich der „homo doctus“ meist mit Buch oder Büchern abbilden, wobei die Rollen von Autor und Leser kaum zu trennen sind (z.B. Tizian, Männerporträt, um 1511/12; Genius of Venice, Nr. 116 mit Abb., oder Lucas Cranach d.Ä., Dr. Johannes Cuspinian, 1502/03; Norbert Schneider 1994, 82). Das Buch in den Händen eines Gelehrten dient zur Charakterisierung seines Berufs- 
standes, seiner Gelehrsamkeit und seiner Zugehörigkeit zur geistigen Elite. In den Porträts von Astronomen, Ärzten und anderen Wissenschaftlern gesellen sich zum fachspezifischen Buch oft die jeweiligen Arbeitsinstrumente wie Astrolabium, Zirkel, Sextant, Phiolen, optische und chemische Instrumente etc. Die Entwicklung der Naturund Technikwissenschaften löste die Verbindung von Wissenschaft und Buch zunächst nicht auf.

Porträts sowie Genrebilder von Geistlichen beider Konfessionen und Mönchen mit Büchern als Attributen oder Requisiten sind ubiquitär. Lutherporträts wurden vorbildhaft für die Bildnisse protestantischer Geistlicher, einer die deutsche Lesekultur bis ins 19. Jahrhundert tragenden Gruppe. Luther wird als Brustbild oder in ganzer Gestalt im Studierzimmer dargestellt. In der Bildsprache der Lutherporträts ist die Bibel das zentrale Sinnbild, das auf keiner Darstellung fehlt. „Die Bibel ist der Inbegriff seiner Verkündigung und der lebende Christus der Inhalt seines Glaubens“ (Luther im Porträt 1983, 14). Luther hält ein Buch in Händen, weitere Folianten liegen auf seinem Schreibpult und auf dem Fenstersims und stehen in der Bücherwand (Abb. 6). Auf den geöffneten Seiten der Bibel sind für das protestantische Schriftverständnis zentrale Zitate zu lesen, wie „Suchet in der Schrift“ (Joh. 5,39; Luther im Porträt 1983, 14). Die populäre Druckgraphik des 19. Jahrhunderts zeigt Luther mit geöffnetem Buch in der Linken, die Rechte auf das Herz gelegt und den Blick nach oben gerichtet (ebd., 69 f.). Dieser Demutsgestus verbildlicht Luthers Bewußtsein, $\mathrm{da} ß$ all seine Beschäftigung mit der Schrift nur durch die Gnade Gottes und Gott zu Ehren erfolgt.

\subsection{Vom Hieronymus im Gehäuse zum Gelehrtenporträt}

Von Hieronymus, der die erste Bibel (Vulgata) zusammenstellte und ins Lateinische übersetzte und darum als der gelehrteste der Kirchenväter galt, gibt es zwei Darstellungsstränge, die sich im 15. Jahrhundert herauskristallisierten: der eine zeigt den Kirchenvater als meditierenden Einsiedler in der Wüste, der zweite den Bibelübersetzer in der Abgeschiedenheit seiner Studierstube, umgeben von den Requisiten seiner Gelehrsamkeit. Die Ikonographie beider Versionen - des studierenden und des büßenden Hieronymus - wurde im Laufe der Zeit für unterschiedliche Bildtypen (z.B. Humanistenporträt, Eremiten-Genre) und Positionen (z.B. der Reformation und der Gegenreformation) verwendet.

Die Darstellungen des Hieronymus und von Eremiten in der Einöde bieten eine breite Skala von intensiv im Buch lesenden und blätternden, studierenden oder in das Buch versunkenen alten Männern - und verweisen auf die Vorbildlichkeit der vita contemplativa (vgl. z.B. Hendrick Bloemart, Der hl. Hieronymus, 1624; Leselust 1993, Nr. 5 mit Abb.; Lorenzo Lotto, San Girolamo penitente, 1506; Berenson, Tav. 17; s. auch Dürer, Der hl. Antonius vor der Stadt, Kupferstich, 1519 - zur nazarenischen Adaption vgl. Ost, 66 ff.). Zu den gängigen Attributen des häufig halb entblößten Büßers Hieronymus und seiner ideellen Nachfolger zählen neben dem Buch Totenschädel, Stundenglas und Kreuz - Mahnungen an die Hinfälligkeit und Erlösungsbedürftigkeit des Menschen. In den Schilderungen des Heiligen in seiner Studierstube als Halb- oder Ganzfigur (vgl. Dürers Gemälde von 1521 bzw. seinen Kupferstich 
Hieronymus im Gehäuse, 1514) ergänzt diese ein stillebenhaftes Arrangement von Pergamentrollen, Folianten, Schreibzeug und heruntergebrannter Kerze - Zeichen für Nachtstudium. Tier-Attribut ist der Löwe, dem der Heilige nach der Legende einen Dorn gezogen hat (vgl. Dürers Holzschnitt von 1492, mit je einer aufgeschlagenen Bibel in hebräischer, griechischer und lateinischer Schrift). Die Folianten, die der Kirchenvater, teils aufgeschlagen, um sich liegen oder gestapelt hat, weisen darauf hin, daß hier Bücher aus Büchern entstehen, Lesen und Schreiben somit aufs engste verknüpft sind.

In Hieronymus sahen die Humanisten ein Idealbild philologischer Gelehrsamkeit, mit dem sie sich identifizierten. Auf den Bildtypus des Hieronymus im Gehäuse, geprägt besonders durch Dürer, wurde daher bei den Porträts, die Gelehrte in ihrer Studierstube zeigen, zurückgegriffen. Lucas Cranach d.Ä. stellte Kardinal Albrecht von Brandenburg, einen Kirchenfürsten der Reformationszeit, 1525 als hl. Hieronymus in enger Anlehnung an Dürers Stich dar, Wolfgang Studer benutzte den Stich in seitenverkehrter Verkleinerung für ein Lutherbild von ca. 1580 und strich durch diese Parallelisierung die Leistung der Bibelübersetzung ins Deutsche heraus (Hofmann 1983, 208). Die von Dürer entworfene Stube mit Holzbalkendecke, Fensterbank mit Polstern und Butzenscheiben ging als Ausdruck deutscher Gemütlichkeit in spätere Lesebilder altdeutscher Prägung cin.

Die Ikonographie des Gelehrten in seiner Studierstube lebt fort bis in die historisierenden und parodierenden Schilderungen im 19. Jahrhundert von Don Quichote (Adolph Schrödter, 1834; Eduard Grützner, 1904) sowie Mephisto und dem Schüler (z.B. Julius Oldach, 1828; Eduard Grützner, 1897, mit vielen weiteren Beispielen bei Boehn 1924 und Neubert 1932). Auf Schrödters „Don Quijote in der Studierstube“ liest der Ritter, den Mund staunend geöffnet und in eine Ecke des mächtigen Lehnsessels gekauert, in dem Folianten „Amadis von Gaula“. In der unordentlichen Stube lagern auf Tisch, Boden und Bücherbord weitere Folianten, deren Titel ins Bild gesetzt werden. Da Schrödter in seiner weitverbreiteten Darstellung das „rührend Lächerliche“ des von den Idealen seiner Bücher getäuschten Ritters im Kampf gegen die Realität betont, lud er die kritischen Zeitgenossen, die - wie Heine - den vergeblichen Kampf gegen die Restauration als ,Donquixotismus ' empfanden, zur Identifikation ein (Hartau 1987, 145-157, Zitat 155). Noch zur Zeit des auf die Märzrevolution folgenden Neoabsolutismus war für Caspar Scheuren der (faustische) Gelehrte, der im Lehnstuhl in seiner Studierstube beim Schein der Öllampe über seinen vielen Büchern sitzt und „über Leben und Tod, Natur und Geschichte nachdenkt,“ das Sinnbild des „Deutschen“ schlechthin (Hartau 1987, Abb. 121, Zitat 156).

$\mathrm{Da}$ das Thema des männlichen Lesens häufig in engem Zusammenhang mit dem Gelehrtenbildnis steht, lassen sich hier bedeutende Porträts von vornehm standesgemäßer Haltung in großer Zahl benennen, zum Beispiel von Raffael „Leo X.“ (1518/19) und „Kardinal Bibbiena“, von Tizian „Pietro Aretino“ (1545), von Anthonis van Dyck „Kardinal Bentivoglio“ (1623), von Rubens „Justus Lipsius und seine Schüler“ (1611/12) aus der Galleria Pitti in Florenz usw. Ihnen stehen die intimen Leserbildnisse Rembrandts gegenüber (zahlreiche Radierungen, z.B. „Jan Sixt am Fenster“, 1647, oder das Gemälde seines Sohnes „Titus“, um 1655; Wien, Kunsthistorisches 
Museum). Ähnlich verhält sich das Berufs-Porträt zum privaten Leserbildnis: Dem immer noch, jedoch seltener mit Buch- oder anderen Berufsattributen vertretenen (bürgerlichen) Gelehrten- und Literatenporträt (vgl. z.B. Brucker/Haid 1741-55), das die geistig bedeutende Persönlichkeit nunmehr durch ausgeprägte Charakterisierung der Gesichtszüge zu kennzeichnen sucht, treten - verstärkt seit Mitte des 18. Jahrhunderts und vorzüglich in der Graphik - die oft sehr persönlichen und intimen Formulierungen des manchmal im Freien (z.B. Leibniz in einem Lustwäldchen; Wunderlich, fig. 4) oder ruhig für sich Lesenden bzw. über die Lektüre Nachdenkenden an die Seite (z.B. Ludwig Stern, Franz Ludwig Erthal als junger Mann, 1753, Aschaffenburg, Staatsgalerie, Bergmann 1976, Tl. 2, Abb. 6; Georg Friedrich Kersting, Der elegante Leser, 1812; Weimar, Kunstsammlungen; Adolf Menzel, Bildnis des Dr. Eitner, Aquarell, 1850; Franz Defregger, Der Leser; Defregger 1983, Bd. 1, Abb. S. 68). $\mathrm{Zu}$ einem Porträtisten der Romantiker wurde Emil Ludwig Grimm u.a. mit Bildern seines Bruders Jacob Grimm (am Fenster lesend, 1814, Grimm 1990, Bd. 1, P 92; über dem Zettelkasten, 1817, Bd. 2, K 31), des Juristen Friedrich Carl von Savigny (1809; Bd. 1, Nr. P39) oder des Dichters Clemens Brentano (1837; Bd. 1, Nr. P354; Reichsdruck 886).

\section{Frau und Buch}

Die Sibyllen mit ihren in Spruchsammlungen niedergelegten Weissagungen werden seit dem 6./7. Jahrhundert in Gemeinschaft mit den Propheten dargestellt. Auch von der hl. Katharina von Alexandrien, der Patronin der Gelehrten und Universitäten, wie von einigen anderen Heiligen finden sich frühe Darstellungen mit Buch-Attribut. Die Prototypen der mit Buch abgebildeten oder lesenden Frau sind aber Maria und ihre Mutter Anna. Von der ,Unterweisung Mariens“ bis zur ,Mariä Himmelfahrt', der Maria im ,Paradiesgärtlein“ bis zu den Bildern der hl. Sippe zeigen Darstellungen Mariens und des Marienlebens vielfältigste Buch- und Leseszenen, wobei der Gestus des Lesens manchmal sogar das Leitmotiv ist; einige der Bildformulierungen wurden vorbildhaft auch für die profane abendländische Kunst. Ob als einzelne, nahsichtig gegebene Figur zur privaten Andacht oder in einem mehrfigurigen Altarbild - die Heilige Schrift oder ein anderes Buch ist im Umfeld Mariens häufig zu finden. Sie liest sogar auf einer Schilderung der ,Flucht nach Ägypten', mit ihrem Kindchen auf dem von Josef geführten Esel reitend (für das Spätmittelalter Büttner, Abb. 1; auch bei Schreiner 1990, Abb. 35).

\subsection{Maria in der Verkündigungsszene}

In der Verkündigungsszene wird Maria meist lesend oder vor dem Buch betend und handarbeitend und dem Engel Gabriel demütig bzw. erschreckt zugewandt dargestellt. Maria liest den Psalter oder im Buch des Propheten Isaias die Stelle (Is. 7,14), die auf die Geburt des Messias durch eine Jungfrau vorausweist. Sie hält das zuweilen von einem Tuch geschützte Buch in der Hand, oder es liegt in ihrem Schoß bzw. auf 
einem Lesemöbel oder dem Boden. Häufig finden sich weitere Bücher auf oder in ihrem Pult und Zimmer, und weiße Lilien sind ihr als Attribut zugeordnet. Lesend, betend und manuell tätig wurde Maria im Mittelalter zur „Symbolgestalt“ einer zunächst Frauen des Adels vorbehaltenen Bildung (Schreiner 1990, 335). Daß Frauen sich durch Beiordnung oder Selbstidentifikation mit Maria in der Verkündigungsszene ins Heilsgeschehen einbezogen, zeigen Miniaturen des Spätmittelalters (Büttner 1972, Abb. 11-12, und Polleross 1988, Abb. 36, wo die Königin Margarethe von Spanien und ihre Tochter als Maria und Verkündigungsengel figurieren). Als „Inbegriff einer bücherhungrigen, lesefreudigen und wissenschaftlich gebildeten Frau“ wurde die lesende Maria als „normgebendes Vorbild für erzieherische Zwecke“ eingesetzt (Schreiner 1990, 317, 339) und als Prototyp der intensiv lesenden frommen und tugendhaften Frau geschildert - so z.B. wenn unter einem kleinen Andachtsbild mit dem Halbporträt der am Pult lesenden Maria steht (Stahlstich von Carl Mayer, um 1840): „Ich will forschen in deinem Gesetze, und es beobachten von meinem ganzen Herzen“ (Ps. 118, 34). Augenfällig wird dies, wo die Handlung in einen häuslichen Innenraum - oft ihr Schlafgemach - verlegt ist und die bürgerliche Alltagswelt sowie menschliche Empfindungen in die Situation einfließen.

\subsection{Anna lehrt Maria, Maria das Jesuskind Lesen - die häusliche Erziehung durch die Mutter}

Der Bildtypus der Frau als häusliche Lehrerin im Lesen wird durch die sowohl in der Hoch- wie in der Volkskunst äußerst verbreiteten Annen- (Kleinschmidt 1930, Fastner 1986) und Marien-Darstellungen geprägt: Anna unterrichtet Maria (Abb. 15, 17), Maria das Jesuskind (Abb. 13). Es ist die geduldige und zärtliche Mutter, die sich dem Kind zuneigt und es schützend umfaßt und hält. Die Ikonographie zeigt zahlreiche Varianten, die sich über die Jahrhunderte wiederholen.

Das Motiv der Anna als Erzieherin war besonders beliebt in der Barockkunst in Deutschland. „Das Buch wird geradezu zu ihrem Attribut oder Symbol“" (Kleinschmidt 1930, 371). In einem verbreiteten Typus, den Murillo und Rubens (Kleinschmidt, Taf. 11 u. 16) aufgenommen haben, steht bzw. kniet die kleine Maria neben der sitzenden Anna und blickt ins offene Buch, das Anna im Schoß, auf den Knien oder in Händen hält, um sie durch Unterweisung im Lesen (der Heiligen Schrift) auf ihre Berufung vorzubereiten. Die Situationen, in denen die sitzende Gottesmutter dem Jesusknaben das geöffnete Buch hinhält bzw. dieser es fassen will (z.B. Maria mit Kind von Quentin Massys, vor 1500; Bruxelles, Musées Royaux des Beaux-Arts, bzw. Sandro Botticelli, um 1490; Mailand, Museum Poldi-Pezzoli), sind insofern verschieden, als hier ein Kleinkind nach dem Buch der manchmal lesenden Mutter greift, um sie abzulenken, darin zu blättern, die Bilder zu beschauen oder auch die Seiten zu zerknüllen - letzteres ein Zeichen dafür, daß der Jesusknabe als das ,fleischgewordene Wort" Gottes eines Buches nicht bedarf (z.B. Rogier van der Weyden, um 1440; Madrid, Prado).

Die Annendarstellungen geben das Vorbild ab für die liebevolle Leseunterweisung von Mädchen, die Marienbilder für die Erziehung des kleinen Knaben, ehe er aus den Händen der Mutter in den Unterricht eines Lehrers gegeben wird. Schon in der 
religiösen Kunst wird das Motiv zu intimen häuslichen Mutter-Kind-Szenen im Haus und im Freien ausgestaltet. Julius Schnorr von Carolsfeld läßt den Jesusknaben bei der stürmischen Umarmung der lesenden Mutter sogar auf das Buch treten (,Maria mit dem Kinde“, Abb. 14). Daß Friedrich Wasmann (Die Frau des Künstlers mit ihren beiden älteren Kindern, um 1860, Hamburg, Kunsthalle; Nathan, Nr. 122 mit Abb.) die Bildformulierung für das Porträt von Frau und Kindern verwandte, belegt die Übergänglichkeit der Bildtypen im religiösen und säkularen Bereich: Die Mutter sitzt im Freien, das Kleine steht auf ihrem linken Schenkel und tritt mit einem Fuß auf das offen in ihrem Schoß liegende Buch, während das größere Mädchen sich rechts an die Mutter schmiegt und ihren Arm umfaßt. Das viel jüngere Anna-SelbdrittThema faßt die Gruppe von Großmutter, Mutter und Kind in einer Komposition zusammen; im 19. Jahrhundert finden sich modifiziert und säkularisiert dergleichen Familiengruppierungen im Genrebild.

Auf Marienszenen wird bereits die Verbindung von Lektüre und häuslicher Handarbeit, von Nähen, Spinnen und Stricken (z.B. Nürnberger Meister, Maria und Elisabeth mit den Kindern Jesus und Johannes, um 1400; Nürnberg, Germanisches Nationalmuseum und Schreiner 1990, 345 f. u.ö.) gezeigt, die das Lesen der Frau - im Unterschied zum Studium der Gelehrten - an ihre häuslichen Pflichten zurückbindet. Im Zuge der Säkularisierungsprozesse wird die Situation als ,mütterliche Unterweisung ‘ umgedeutet und verallgemeinert. Eine Reproduktion nach einer Unterweisungsszene mit Anna und Maria (Berlin, Kgl. Gemäldesammlungen) - Rembrandt (HanfstaenglDruck um 1900) bzw. Govert Flinck (Stahlstich von J. Geyer), zugeschrieben - trägt die Unterschrift „Unterweise dein Kind und gib dir Mühe mit ihm (Sir. 30,13).“ Der Bibelspruch hebt den exemplarischen, zur Nachahmung auffordernden Charakter solcher Darstellungen, die als Wandschmuck in Wohnungen, Schulräumen usw. dienten, heraus. Der Bildtypus der sitzenden Mutter, vor der das zu unterrichtende Kind - meist ein Mädchen - steht, wird zum Programmbild häuslicher Erziehung, wie aus Illustrationen und Titelblättern der Kinder- und Jugendliteratur hervorgeht.

Nach den Bildzeugnissen erfolgt die erste Begegnung mit Büchern (Bibel, ABCund Bilderbuch etc.) bis in unser Jahrhundert hinein durch die Mutter bzw. Frauen, die Mutterstelle vertreten, wie die Großmutter, die ältere Schwester oder Gouvernante. Die höheren Töchter werden bis weit ins 19. Jahrhundert hinein oft ausschließlich im Hause unterrichtet. Dem Annen-Typus folgt die Szene „L'Éducation de la Reine“ aus Rubens Medici-Zyklus (1622-25), der in 22 Gemälden Leben und Taten der Königin Maria Medici, Gattin Heinrichs IV., schildert. In der antikisch-allegorischen Erziehungsszene führt Minerva die kleine Maria, welche an ihren Schenkel gelehnt ins Buch schaut und schreibt, in die Wissenschaft ein. Weitverbreitete mütterliche Erziehungsszenen schufen Jean-Baptiste Chardin (Wildenstein 1969, Farbtafel 7, 36), Philippe Mercier oder Nikolaus Daniel Chodowiecki. Auf Chodowieckis Ölbild „Häusliche Lektion“ (um 1775; Geismeier, 39) werden vier Töchter verschiedenen Alters von der Mutter im Haus unterwiesen. Die dominante Stellung der Mutter mit dem Buch in der Hand, nach dem sie die vor ihr stehende Kleinste abhört, wird durch die kreisförmige Komposition unterstrichen, in der die Mädchen ihr untergeordnet sind. Den häuslichen Unterricht zeigen auch zahlreiche Genrebilder von Franz van 
Mieris (1662/63, wo hinter dem im Buch auf dem Schoß der Mutter lesenden Knaben im Dunkel schon der Erzieher wartet, der ihn die folgenden Jahre unterrichten wird; Leselust, Nr. 58 mit Abb.) bis Benjamin Vautier (Der Hauslehrer, 1865, Nürnberg, Germanisches Nationalmuseum).

Vom 17. bis ins 19. Jahrhundert häufig sind Szenen informellen Unterrichts, in dem Mutter, Großmutter oder ältere Schwester Bibel, ABC- oder Bilderbuch halten und ein Kind daneben steht oder sitzt und ins Buch schaut, es hält oder zuhört, wenn ihm erklärt, vorgelesen oder erzählt wird. So zeigt ein anonymes Porträt Isabella Leutz mit ihrem Sohn Viktor, der - an sie gelehnt und von ihr mit der Rechten umfaßt - ein naturkundliches Buch mit koloriertem Kupferstich aufgeschlagen auf ihrem Oberschenkel hält (1827; Düsseldorf, Stadtmuseum); ein Holzstich nach Paul Wagner mit dem Titel „Das neue Bilderbuch“ (Daheim, 1896) stellt eine glücklich lächelnde Mutter dar, die mit ihrem Töchterchen, das auf der Sessellehne bei ihr am Fenster sitzt, das Buch anschaut. Besonders beliebt ist die Einübung der Kleinsten ins Gebet (z.B. Das Morgen-Gebet, Stahlstich von Johann Georg Serz nach Heinrich Löwenstein, um 1840; Verlag von Carl Mayer's Kunst-Anstalt in Nürnberg - wobei das Gebet im kleinen verzierten Buch in der Hand der Mutter zu lesen ist).

Eine Erweiterung erfahren die Buchszenen mit Mutter und Kind, für die der enge körperliche Kontakt bzw. der innige Gefühlsbezug charakteristisch sind, wenn der Vater im Hintergrund schlafend, arbeitend oder beide belauschend einbezogen ist. Auf Bildern der Heiligen Familie findet sich dieser Bildtypus z.B. auf einem Stich von Franziska Schöpfer (1792, nach van der Werff) oder auf einer Zeichnung von Josef Obwexer (Abb. 19) aus der Mitte des 19. Jahrhunderts, wo Joachim durch das Fenster die im Schoß Annas lesende kleine Maria auf die Gesetzestafeln des Alten Bundes an der Wand verweist. In vergleichbarer Komposition zeigt eine Kitschpostkarte der Jahrhundertwende (Abb. 20), wie Mutter und Töchterchen, die sich vor das Haus gesetzt haben, von dem durchs Fenster schauenden Vater überrascht werden. Dem von der Mutter umschlungenen Mädchen wird vorgelesen, während es ins Buch schauen darf. Hier ist dem Vater besonders deutlich die Position des Dritten zugewiesen, der die Szene als Beobachter konstituiert, aber von ihr ausgeschlossen bleibt.

\subsection{Das Buch als Attribut der Frau: Ausweis von Frömmigkeit, Sitte und Bildung}

Obwohl Frauen schon an der antiken Lesekultur teilhatten und im Frühmittelalter die Literalität unter den Laien fast ausschließlich bei ihnen lag, war das Studium, die ernsthafte Lektüre von Büchern, sofern es sich nicht um religiöse Schriften handelte, bis ins 18. Jahrhundert vorzugsweise den Männern zugeordnet. So finden sich unter den wenigen Darstellungen gelehrter Frauen vom Typus des Gelehrtenporträts die Bildnisse einiger Dichterinnen und Ordensfrauen, z.B. der hl. Brigitta (um 453-523), Gründerin des Brigidenordens in Irland, der Mystikerin Hildegard von Bingen (1098-1179) oder der Dichterin Christine de Pisan (1363-1431). Dedikationsblätter wie z.B. Dürers Holzstich für die erste gedruckte Ausgabe der Werke von Hroswitha von Gandersheim oder Porträts von Schriftstellerinnen mit Büchern - wie z.B. der ,Gottschedin', Übersetzerin und Verfasserin von Theaterstücken - verweisen meist 
auf eigene Werke bzw. auf die wissenschaftliche oder belletristische Lektüre der Dargestellten. Ein eigener Bildtypus, der von der französischen Malerei geprägt wurde, verbindet sich mit dem ,gelehrten Frauenzimmer" des 18. Jahrhunderts (Abb. 26). François Bouchers „Mme. Pompadour“ (1756, München, Alte Pinakothek) repräsentiert die gelehrte Mätresse am absolutistischen Hof, die am literarischen und wissenschaftlichen Diskurs ihrer Zeit teilnimmt.

Frauenporträts mit Buch sind seit den vorbildlichen Darstellungen des 16. Jahrhunderts allgegenwärtig. Das religiöse Buch, als Attribut einem weiblichen Bildnis beigegeben, verweist auf ein frommes und gesittetes Leben - ein Leben, das den kirchlichen und sozialen Normen genügt; ein weltliches Buch in entsprechender Umgebung signalisiert Bildung. Der Gestus des Buch-in-Händen-Haltens, des wirklichen Lesens, der unterbrochenen Lektüre, des über einem Buch nachdenklichen Sinnens sind Hauptmotive in der Gattung Porträt durch viele Jahrhunderte; daneben ist das Buch auch bloßes Accessoire oder Requisit. Seit den Stifterdamen-Bildnissen auf Miniaturen in Stundenbüchern (Büttner, Abb. 15 mit Maria von Burgund) oder auf Altartafeln erfaßt der Bildtypus nach und nach Frauen aller Schichten, von der Herrscherin bis zur Gattin des Kaufmanns und zuletzt auch die Bäuerin. Die sitzende oder stehende Frau hält das Buch geschlossen, manchmal geöffnet in Händen, hat häufig einen Finger im Buch - so als ob sie die Stelle, an der sie unterbrochen wurde, festhalten möchte -, stützt sich auf das Buch, das auf einer Balustrade oder einem Tischchen aufruht, oder hat es darauf abgelegt. Meist ist das Buch kleinformatig, häufig ist es als Andachtsoder Gesangbuch erkennbar, doch trifft man seit dem 18. Jahrhundert zunehmend auf Almanache und Taschenbücher sowie Prachtbände, die zu beliebten Geschenkartikeln für Frauen wurden (z.B. Edward Burne-Jones, Bildnis der Maria Theresa Zambaco, 1870; Neuss, Clemens-Sels-Museum). Das Porträt um 1800 zeigt die lesende Frau - nach englischem Vorbild - oft vor Landschaftshintergrund (z.B. Friedrich Heinrich Füger, Bildnis der Gattin, um 1797, Wien, Österreichische Galerie; Georg Karl Urlaub, Bildnis einer Dame im Park, Karlsruhe, Kunsthalle), was für die Gattung bis ins 20. Jahrhundert - neben den Interieur-Szenen - Geltung behält.

Mitte des 19. Jahrhunderts hat die Porträtphotographie den Bildtypus Frau mit Buch aufgenommen. Massen von alten Fotos und Postkarten verdeutlichen, wie die Darstellung der Frau mit Buch zur klischeehaften Konvention wurde, für die die Ateliers die nötigen Requisiten, etwa einen antikisierenden Hintergrund mit Säule und Balustrade sowie Bücher aller Art, bereithielten. Ambitionierte Photographen arrangierten Bildkompositionen mit der ein Buch haltenden oder in der Lektüre unterbrochenen Frau vor gemalten Hintergrundkulissen.

\subsection{Die Frau als Trägerin religiöser Überlieferung und Sitte: Großmutter, Mutter und Tochter mit Bibel, Gebet- und Gesangbuch}

Wie in den Szenen des Marienlebens, findet sich in Darstellungen einzelner ,Stationen' im Leben der Frau das Buch als ihr steter Begleiter. Von ihrer Wiege, an der die Mutter lesend sitzt, dem Taufgang, den ersten Leseübungen mit der Großmutter, den Schreibversuchen nach der großen, alten Bibel, der Firmung, den Schul- 
und Handarbeitsstunden, über Braut- und Hochzeit, Kindererziehung, Krankheit und Genesung, als Witwe, bei der stillen Erbauung und anderen Frömmigkeitsübungen bis zu ihrer Todesstunde ist ihr ein religiöses Buch beigeordnet. All dies sind seit dem 17. Jahrhundert beliebte und durch die Printmedien des 19. Jahrhunderts weitverbreitete Themen des Volks- und Bauern-Genre mit vielfältigen anekdotischen Ausschmückungen. In ihnen werden reale Ereignisse aus dem Leben der Frau verklärt nachgebildet und ihr zugleich die gesellschaftliche Rollenerwartung vorgestellt. Auch Sonderformen wie die (Typen)Porträts der festlich gekleideten Kirchgängerin, Rosenkranzbeterin und Andächtigen - meist idealschöne, in sich gekehrte junge Mädchen in altertümlichem Gewand oder Tracht, vervollständigen das Repertoire der Vorbilder frommen und sittlichen Lebens.

Sehr verbreitet war speziell vom 17. bis ins 19. Jahrhundert das Thema der alten Frau mit Buch. Die Bildformulierung geht auf einen Prototyp Rembrandts von 1631 zurück, der im Stich rasche Verbreitung und Nachfolge bei Zeitgenossen und Rembrandtisten auch des 18. Jahrhunderts fand. Im 19. Jahrhundert wurde der Bildtypus aufgegriffen und in zahlreichen Varianten hauptsächlich in der Druckgraphik und auf Bildpostkarten verbreitet. Die „Alte lesende Frau“ von Rembrandt, die in kostbarem Mantel und Haube in einem dunklen, nicht näher definierten Innenraum auf einem Stuhl sitzt und ein großformatiges Buch liest, auf dem ihre Hand liegt (Leselust 1993, Nr. 69), wurde lange Zeit als „Rembrandts Mutter“ bezeichnet. Doch es ist die Prophetin Hannah, die Gott „mit Fasten und Beten Tag und Nacht diente“ (Lukas 2,57 ) und im Jesusknaben Gottes Sohn erkannte - eine Vorbildfigur für alte Frauen. In diesem ,portrait historié" stellte Rembrandt die individuell erfaßte Persönlichkeit einer alten Frau mit Hilfe einiger Attribute in einen historisierenden Kontext und schuf damit eines der einflußreichsten Bilder einer Lesenden überhaupt. Auch in den vergleichbaren Porträts lesender alter Frauen von Gerrit Dou (Leselust 1993, Nr. 23 mit Abb.) und Ferdinand Bol (Leselust 1993, Nr. 7) wird durch die auf das Buch konzentrierte Lichtführung und den neutralen Hintergrund eine ähnlich intensive Lesesituation geschaffen. Dous populär gewordene „Lesende“ (St. Petersburg, Eremitage) - nach dem gleichen Modell wie bei Rembrandt - ist in weltvergessener Konzentration beim Betrachten einer Illustration im Lukasevangelium zu sehen.

Im 19. Jahrhundert ist es häufig die von Nicolaes Maes, einem weiteren Rembrandtschüler, geprägte Genreszene mit lesender alter Frau, die Nachfolge findet (vgl. seine „Lesende“ sowie „Schlafende alte Frau“, um 1660; Bruxelles, Musée Royaux des Beaux-Arts). Gezeigt wird ein kleiner Raumausschnitt, wo in einem bequemen Armstuhl am teppichverhängten Tisch mit Büchern und allerlei Gegenständen eine alte Frau intensiv lesend sitzt. Diese Bildtradition nimmt z.B. Johann Peter Hasenclever in der "Betschwester“ auf (1833, Privatbesitz; Soiné 1990, 38-42 mit FarbAbb. I). In der Bildmitte sitzt eine alte Frau mit Kneifer, gesenktem Kopf und niedergeschlagenen Augenlidern vor einem Tisch mit aufgeschlagenem Buch - vermutlich einer Bibel -, einer Kanne, einem Milchkännchen, einer Tasse und Schale. Das prächtige Buch, das komfortable Mobiliar und der pralle Beutel der Frau deuten auf Wohlhabenheit, ihr Dahindämmern auf gedankenlos „frömmelnde Religiosität“. Auf dem Stahlstich von Lazarus G. Sichling nach Peter Wickenberg (1837/44) wird die 
Bildkompositon von Maes in die einfache Stube einer alten Frau transponiert, die in ihrer großen, zweispaltigen Bibel liest, neben sich ihr Strickzeug im Körbchen am Boden. Wie der sonstige spärliche Hausrat ist auch die Bibel ein von Generation zu Generation vererbter Hausrat. In einer ähnlich komponierter Szene liest auch „Die Mutter des Künstlers im Stübchen“ von Hans Thoma (1871; Winterthur, Stiftung Oskar Reinhart) in einer großen alten Bibel. Der Maler hat seine Mutter auf mehreren Gemälden als intensive Bibelleserin charakterisiert. Sie verkörpert den Typus der Frau, die in die Konvention erbaulicher Lektüre einübt, indem sie sie musterhaft vorlebt.

Die Einsamkeit der alten Frau, die mit ihren Erinnerungen und ihrem Gebetbuch lebt, dokumentiert eine Autotypie von Aenny Löwenstein aus dem Anfang unseres Jahrhunderts. Abgeschlossen von der Welt sitzt sie am Tisch, hinter ihr an der Wand die Photos ihrer Lieben um ein größeres Bild gruppiert. Der Buchschutz spricht von dem sorgsamen Umgang der Frau mit ihrem einzigen Lesestoff, der ihr nach arbeitsreichem Leben - auf das die abgearbeiteten Hände weisen - Trost und Erbauung gewährt. Unter das Bild sind Verse der seinerzeit beliebten Trivialautorin Anna Ritter gesetzt: „Großmutter sitzt für sich allein,/Die Abendsonne hüllt sie ein ...“.

\subsection{Das Buch und die, fleischliche Sünde": Von der büßenden Magdalena zum weiblichen Akt}

Die Verschmelzung von drei neutestamentlichen Frauengestalten - der Maria Ägyptica, einer Dirne und bekehrten Büßerin; der Maria von Bethanien, die Christus die Füße salbte, sowie Maria Magdalena, der Jüngerin Christi, welcher er sieben Teufel ausgetrieben hat - bot reichen Stoff für bildliche Darstellungen (vgl. die Bildtypen in La Maddalena). In der Entwicklung vom Andachtsbild zum neuen Bildtypus der Büßerin in der Einöde, deren ikonographische Ausprägung in Italien erfolgte, sind entscheidend die Kompositionen Correggios (z.B. Maria Magdalena, liegend in einem Buch lesend, ehemals Dresden, Gemäldegalerie) und - weit wirkungsvoller - Tizians. Diese geben Magdalena als nah zum Betrachter gerückte Halbfigur mit entblößter Schulter und fließendem Haar, deren sinnliche Präsenz (so in den Gemälden von 1550 und 1560 und zahlreichen Varianten und Kopien) mit ihren Attributen Totenkopf (Zeichen für Eitelkeit und Hinfälligkeit des Lebens) und aufgeschlagenem Buch (Hinweis auf ihre ,vita contemplativa') kontrastieren.

Die Betonung des sinnlichen Aspekts der Maria Magdalena durch Tizian, welche im 16. Jahrhundert (nach Ingenhoff-Dannhäuser 1984, 63) „Modell und Sinnbild der Kurtisane" war, rückte in den meisten der nachfolgenden Darstellungen immer stärker in den Vordergrund, wozu die häufig nächtliche, leidenschaftliche Bußpraxis in der Einöde beiträgt (vgl. z.B. Francesco Furinis fast entblößte, höchst sinnliche „Büßende Magdalena“ von 1633, die vor einem Buch kniet; La Maddalena, 200). Durch Zurückdrängen der christlichen Symbole und Betonung der Ekstase und der sinnlichen Ausstrahlung des Frauenkörpers - dessen Nacktheit zur Ikonographie der Sünderin und Büßerin gehört - wurde das Sujet zunehmend profaniert. Der Bedeutungsgehalt - tätige und segensreiche Reue und Buße - geriet in Vergessenheit vor der schönen Sünderin (z.B. Stich um 1850 von Stein nach A. van der Werff, München, Bayerische 
Staatsgemäldesammlungen), die sich schließlich im populären Schlafzimmerbild zur Verführerin wandelte. Eine religiös verzückte Inszenierung wurde für die Magdalenen-Darstellungen charakteristisch, wie sie z.B. das weit verbreitete Bild von Carlo Dolci zeigt. Durch den körperlichen Orgiasmus - Maria Magdalena greift sich an den Busen und blickt sehnsuchtsvoll gen Himmel - wird die göttliche Ekstase verbildlicht. Den Transfer des Profanen ins Sakrale zeigen umgekehrt einige in der Gestalt der hl. Magdalena porträtierte Damen der Gesellschaft vom Ende des 15. bis ins 18. Jahrhundert (vgl. Polleross 1988, Abb. 69.74), z.B. Katharina von Aragon, Margarete und Magdalena von Österreich. Seit etwa 1660 gab es in Frankreich eine Modewelle, sich ,à la Madeleine“ darstellen zu lassen, erwähnt doch Bardon (302, Anm. 111) allein acht Bildnisse der Madame de la Vallière ,en Madelaine (penitente)“.

Für die in freier Natur liegenden Magdalenen wurde nach Correggios und Lorenzo Lottos Vorbild auch Pompeo Batonis Formulierung wegweisend (1842; Clark 1985, Platte 56). Hier liest die entblößte Büßende mit schmerzlichem Gesichtsausdruck, auf Fels ausdrucksvoll hingestreckt, in dem auf den Totenschädel gestützten Buch. Das ehemals in der Dresdner Gemäldegalerie ausgestellte Werk war deutschen Künstlern zugänglich, so daß weite Verbreitung möglich war (vgl. die seitenverkehrte Kopie von Christian Gottfried Schultze von 1810, die Kopie von Kersting von 1830 und die Lithographie von Nepomuk Muxel, 1820). Als Wandbild der Firma May war diese „Spezialität des erotischen Genres“ (Ost, 93) in der Version von 1894 in Preußen noch 1908 verboten (Brückner 1973, Abb. 120). Vom Bildtypus der erotisch evozierenden Maria Magdalena führt eine Linie zu Aktkompositionen, bei der die Lesesituation nur noch als Motiv für weibliche Nacktheit fungiert. So im Falle von Fenner-Behmers „Bücherwurm“ (Kaiser 1976, 61; weiteres Beispiel 130), die nackt lesend auf dem Bett liegt, statt sich anzukleiden und zu frühstücken.

\section{Sozialformen des Lesens}

Die Bilder überliefern alltagsweltliche Lesesituationen in einer realistischen, wenngleich häufig nostalgischen Sichtweise und historistischen Stilisierung. Deutlich wird dies hauptsächlich in den vielen das ländliche Leben verklärenden Genrebildern und den altdeutschen oder rokokohaften Szenerien aus der zweiten Hälfte des 19. Jahrhunderts. Die dargestellten Lesesituationen dokumentieren die Imaginationen der bürgerlichen Gesellschaft vom Lesen und überliefern dessen ,Sitz im Leben': mit welchen Personenkreisen, Situationen und Orten es in Verbindung gebracht, in welche sozialen Zusammenhänge es gestellt wurde und welche gefühlsmäßigen oder gesellschaftlichen Werte man ihm zuschrieb.

Als Leserin geistlicher und schöngeistiger Literatur dominiert die Frau. Es gibt wohl kaum einen Künstler des 19. Jahrhunderts, der nicht Mutter, Frau, Schwester, Tochter oder andere Mädchen und Frauen lesend gemalt oder gezeichnet hat. In der deutschen Malerei begegnen sie häufig etwa bei Ludwig Emil Grimm, Alfred Anker, Franz Defregger, Hans Thoma oder Fritz von Uhde, in der französischen Malerei bei 
Ernest Meissonier, Francois Bonvin, Henri Fantin-Latour oder Auguste Renoir usw. In der modernen Kunst wird das Motiv der lesenden Frau weitergeführt (Max Beckmann, Picasso u.v.m.).

Im Verhältnis zu den massenhaften, in ihre Lektüre vertieften Frauen und Mädchen gibt es im Genrebild oder (genrehaften) Porträt nur wenige Buch-Leser, z.B. von Johann August Krafft (Der Müller Wilder in Landkirchen, 1819; Schön 1987/1993, 14), Peter Schwingen (Herr Peter de Weerth, um 1845; Koetschau 1926, Abb. S. 148), Edouard Manet (Le Liseur, 1861) oder Adolf Menzel (Wartender Besuch, 1901; Berlin, R. Wagner - FarbAbb. der Jugend, wo Menzel das Bildnis des lesenden Dr. Eitner von 1850, s. oben, in ein Genrebild umgestaltete). Wohl aber finden sich unter den Freundschafts-, Familien- und Selbstporträts intime Darstellungen von Lesern, unter anderem von Franz Heesche (Bildnis des lesenden Emil Jansen, 1830; Pauli 1925, Abb. 60), Wilhelm Trübner (Martin Greif, 1876; Frankfurt, Städelsches Kunstinstitut) oder Max Slevogt (Karl Voll, 1898; München, Bayerische Staatsgemäldesammlungen). Beliebt waren Leser im historisierenden Kostüm nach dem Vorbild der zahl- und erfolgreichen Leser-Darstellungen von Ernest Meissonier (Abb. 11), die seine Genremotive ,Raucher' und ,Kunstliebhaber “ ergänzten. Aus dem bäuerlichen Milieu stammen die Leser von Franz Defregger oder Wilhelm Leibl.

Die von allem Beiwerk befreite, existentielle Situation des Lesens hat Ernst Barlach in den berühmten Figuren „Lesender Klosterschüler“ (Holz, 1930; Barlach 1960, Nr. 367 mit Abb.) und „Der Buchleser (Lesender Mann im Wind)“ (Bronze, 1936; Barlach 1960, Nr. 473 mit Abb.) gestaltet. Der „Klosterschüler“ zeigt einen meditierenden Jüngling, die Hände aufgestützt, geneigten Kopfes über einem Buche sitzend, das aufgeschlagen auf seinem Schoß liegt. Gregor, der Widerstandkämpfer in Alfred Anderschs Sansibar oder der letzte Grund (1957), sieht in ihm die Ikone eines kritischen Intellektuellen, der „ohne Auftrag“ lebt: „Er las ganz einfach. Er las aufmerksam. Er las genau. Er las sogar in höchster Konzentration. Aber er las kritisch. Er sah aus, als wisse er in jedem Moment, was er da lese. Seine Arme hingen herab, aber sie schienen bereit, jeden Augenblick einen Finger auf den Text zu führen, der zeigen würde: das ist nicht wahr."

An Lesesituationen mit einzelnen Leser/innen sind insbesondere zu beachten, (a) inwieweit der/die Lesende sich auf die Lektüre konzentriert oder die Augen/den Kopf erhoben hat, über dem Buch ins Sinnen oder (Tag)Träumen geraten ist bzw. den Blick-Kontakt mit dem Betrachter sucht; (b) inwieweit das Lesen zu einer eigenwertigen und in sich abgeschlossenen Situation ausgestaltet ist, sich mit anderen Beschäftigungen (etwa Handarbeiten der Frau) verbindet oder sich zur Umwelt im Haus/zur Natur hin öffnet; (c) welche Beschaffenheit und Merkmale diese Umwelt des Lesens aufweist. Lesergruppen, die sich über einem Buch zusammenfinden, weisen auf die Funktion des Lesens für Gruppenbildungen und -prozesse hin. Dabei kommt es darauf an, (a) inwieweit die soziale Beziehung durch die Lektüre selbst aufgebaut oder (wie beim Vorlesen am Krankenbett) nur sekundär für das Lesen genutzt wird bzw.ob umgekehrt eine genuine Lesesituation für andere Zwecke (z.B. im Trachtenbild) instrumentalisiert wird; (b) inwieweit die Situation durch die Zuordnung des 
Buches zu Autoritätspersonen (Vater, Mutter, älteren Geschwistern, Lehrer/in, Geistlichen etc.) hierarchisch (vor)strukturiert ist oder sich in freier Geselligkeit entfaltet; (c) welche Reaktionen das gemeinsame Lesen oder Vorlesen bei den Beteiligten auslöst (zur Typologie und Wandel der „Interaktionssituationen“ beim Lesen vgl. Schön 1987/1993, 194-204).

\subsection{Leserinnen im Innenraum}

Für die Interieurs sind bequeme und entspannte Lesesituationen charakteristisch, manchmal mit Blick ins Freie. Zu unterscheiden ist zwischen dem bäuerlichen, kleinstädtischen und bürgerlichen oder adeligen Milieu der Leserin. Bei letzteren ist das Lesen des öfteren verbunden mit dem Genuß eines Getränkes (Tee, Kaffee), seltener mit dem von Obst, vervollständigt wird die Szene gern durch Haustiere (Hund oder Katze). Möbel, Nippes, Blumensträuße oder Zimmerpflanzen sowie die an den Wänden hängenden (Familien-)Bilder dienen der Charakterisierung des Wohnmilieus. Auf Gemälden der Jahrhundertwende findet sich die Lesende zuweilen in einem üppig mit Blumen, Pflanzen und - wie im Salonbild - mit Kunstwerken ausgestatteten Interieur (z.B. Rudolf Alt, Blumenstilleben mit Louise Alt im Hintergrund, 1895; Wien, Historisches Museum; Lovis Corinth, Dame am Goldfischbassin, Wien, Kunsthistorisches Museum; Childe Hassam, The Room of Flowers, 1894; Finocchi 1992, Abb. 58).

Die Lesenden sitzen auf einem Stuhl (Lehnstuhl, Schaukelstuhl oder Sessel) frei im Raum oder an einem Lesemöbel (Wohnzimmer-, Näh-, Schreibtisch), sitzen oder liegen auf dem Kanapee oder Sofa (z.B. Max Unold, Auf dem Sofa, um 1920, bequem hingelagert mit ausgezogenen Schuhen, oder das Gemälde von Max Beckmann, Liegende Frau mit Schwertlilien, 1931; Wien, Museum des 20. Jahrhunderts), strecken sich auf dem Bett aus (z.B. Eugen Spiro, Lesendes Mädchen, 1929), liegen auf dem Boden usw. Gelesen wird (Leselicht!) am geschlossenen oder offenen Fenster (z.B. Friedrich Wasmann, Abb. 27; Peter Krafft, Die Tochter des Künstlers am Schreibtisch, um 1830; Wien, Österreichische Galerie des 19. Jahrhunderts), im Erker oder an der geöffneten (Balkon-, Veranda-)Tür (z.B. Fritz von Uhde, An der Verandatür, 1902; Uhde, 239), nachts bei der Kerze (z.B. Lesende, nach G. Romney, um 1790, Reichsdruck, Nr. 940), Lampe, am (Kachel-)Ofen oder offenen Kamin etc.

Ganz nahe an den Betrachter gerückt ist die häufig groß in Dreiviertel- oder Halbfigur dargebotene Leserin, z.B. in Vittorio-Matteo Corcos „Unterbrochene Lektüre“ (Holzstich; Gartenlaube, 1893, Nr. 2, 25). Der sie hinterfangende Landschaftsgrund scheint gemalt auf einen Paravant im Innenraum und öffnet sich rechts zum ,ideal gegebenen ' Naturraum. Zwischen Hintergrund und Betrachter gefangen, blickt die jugendliche Schöne verschleiert nach rechts - der „Störung“ entgegen -, den Lesefinger im geöffneten Buch im Schoß.

\subsection{Frömmigkeitsübungen}

Ins traditionsverhaftete Milieu bäuerlicher und (klein)bürgerlicher Kreise führen Leseszenen, in denen eine Frau im Sonntags- oder Feiertagsfrieden, in aufgeräumter Stube und feiertäglich gekleidet, intensiv liest. Sie greifen zum Teil auf holländische 
Vorbilder zurück - wie z.B. auf das früher Pieter de Hooch und jetzt Pieter Janssens Elinga zugeschriebene und als „Holländische Wohnstube“ bzw. „Die lesende Frau“ betitelte Bild (München, Alte Pinakothek; kopiert z.B. von Bonvin, Weisberg 1980, 25 und Nr. 329). In der Diktion des 19. Jahrhunderts werden solchen Kompositionen Stimmungswerte wie „Behagen, stille Sammlung, schöne Ruhe, stiller Friede, festliche Sauberkeit"1 zugeordnet.

Als Szenen erbaulicher Lektüre schließen sich die Hausandachten bzw. „Erbauungsstunden" an (z.B. Adolf Hoelzel, Hausandacht, um 1890/91, München, Bayerische Staatsgemäldesammlungen). Mädchen und junge Frauen als Rosenkranzbeterinnen, auf dem Weg zur/vor der/betend in der Kirche - oft versunken in ihre Lektüre sind ein überaus häufig dargestelltes Genrethema besonders in den Familienblättern, von Künstlern der Münchner Schule (z.B. Robert Beyschlag, Hermann Kaulbach, Walter Firle u.v.m.) und des Wiener Biedermeier (Franz Eybl, Der Gang aus der Kirche, um 1849, Die Alte in der Kirche, 1849, beide Wien, Privatbesitz; Wiener Biedermeier, Nr. 103-04, mit Abb.). Wilhelm Leibls „Drei Frauen in der Kirche“ (1878-81; Hamburg, Kunsthalle), ein Meisterwerk der realistischen Malerei, wurde für die einzeln oder in der Generationenfolge andächtig betende Frau ein vielfältig variiertes Vorbild bis ins 20. Jahrhundert. Auch in Kapellen und an Marterln wird mit Buch gebetet, einzeln oder in Gruppen (z.B. Johann Matthias Ranftl, Rast der Wallfahrer, 1852, mit einem laut (vor)betenden alten Mann; Wien, Österreichische Galerie; Wiener Biedermeier 1992, Nr. 183 mit Abb.). Traditionelle Frömmigkeitsübungen (Andacht, Kirchgang, Prozession, Wallfahrt) werden zu Trachtenstücken und zur Wiedergabe bäuerlicher Kultur genutzt. Szenen mit Frauen, die sich für den Kirchgang festlich herrichten, weisen auf die Verknüpfung der rituellen Handlung mit der sozialen Repräsentation der Frau in der Öffentlichkeit hin.

\subsection{Romanlektüre}

Allermeist wird jungen Mädchen und Frauen die Lektüre von Romanen, daneben auch von Lyrik-Anthologien und Pulikumszeitschriften zugeordnet. Bilder mit Titeln wie „Spannende Lektüre“, ,Der erste Roman“, „Der neue Roman“ (Kaiser 1976, 68), „Der neueste Roman“ (von Conrad Kiesel, Aquarell-Facsimile von Rich. Bong in Berlin, um 1890) oder „Der dritte Band“ (des dreibändigen Romans, Abb. 31), - alle aus dem letzten Drittel des 19. Jahrhunderts - schildern die Frau als eifrige Leserin belletristischer Literatur. Die literarische Sozialisation höherer Töchter illustriert das Blatt „Die neue Nummer“ (von J. R. Wehle, „Steyrermühl“, vorm. L. C. Damarski): Bei Lampenschein studiert ein Mädchen mit aufgestütztem Kopf die „Neue Illustrirte Zeit"; ein Kunstblatt und zwei Prachtbände mit Goldschnitt liegen neben ihr.

Diese Szenen leiten über zu zwei eigenen Typen von Lesesituationen, nämlich der „heimlichen Lektüre“ (Holzstich nach Emanuel Spitzer, Abb. 39) und des „verbotenen Buches“ (z.B. Kaiser 1976, 18 u. 159 sowie die Bildergeschichte von Ferdinand von

1 Paula Monjé: Sonntagsmorgen. In: Sonntags-Zeitung für Deutschlands Frauen, II. Jg., 1898/99, H.36; 551 mit Text 562. 
Reznicek, Das verbotene Buch, 1896, Simplicissimus, Jg. 1, Nr. 4, 5) bzw. des „verbotenen Romans" (Der verbotene Roman, Farblithographie von Bernhard Mohrhagen nach Hermann Raunheim, um 1858; Bürgerliches Wandbild 1975, 40; D. J. Bles, Het verboden romannetje, Lithographie nach F. H. Weissenbruch; Romantische liefde, Abb. 38). Sie zeigen zum einen Frauen, die sich erregender Lektüre bewußt hingeben (z.B. V. Marais-Milton, „Müssigkeit“" Kaiser, 154 -, wo sich eine Nackte neben Buch und Kaffee und mit Zigarette genüßlich vor dem Kamin auf dem Bärenfell räkelt). Zum anderen sind es unschuldige Mädchen, denen das Lesen von Liebesgeschichten oder als freizügig geltenden Romanen von Eltern und in Pensionaten häufig und vergeblich untersagt war. Unter dem Titel „Höhere Töchter“ stellt F. von Reznicek (Simplicissimus, 7. Jg., 1902/03, Nr. 49, 389) eine sichtlich gelangweilte junge Dame beim Aufstehen dar, der als Text in den Mund gelegt wird: „Seitdem mich Mama aus dem Institut genommen hat, habe ich kein unanständiges Buch mehr gelesen.“

$\mathrm{Da}$ die Lesende über dem Buch ins Grübeln, Sinnen oder Träumen gekommen ist, führen Bilder vor Augen mit Titeln wie „In Gedanken“ oder „Träumerei“ (Postkarten bei Kaiser, 66, 71 u. 174; Dante Gabriel Rossetti, The Daydream, 1856; Vittorio Matteo Corcos, Sogni, 1896; Finocchi 1992, Abb. 7). Die Mädchen und Frauen haben ihre Lektüre unterbrochen, ihr Blick ist in unbestimmte Ferne gerichtet, ins Innere zurückgenommen oder dem Beschauer zugewandt.

Diese identifikatorische Lesehaltung wurde seit dem ,Wertherfieber' immer wieder verspottet. Die Wirkung von Goethes Roman illustriert Chodowiecki in zwei kompositorisch eng aufeinander bezogenen Bildern (Abb. Plaul 1983, 103 f.): Auf dem ersten ist die Frau, in die Ecke eines Sofas gelehnt, ganz in das Buch versunken, auf dem zweiten ist sie mit offenem Mund bestürzt aufgesprungen und hält sich weinend eine Hand vor die Augen. Das Hündchen, das sich neben ihr zusammengerollt hatte, springt nun aufgeregt zu ihren Füßen, ein Schemel ist umgefallen. Als Musterbeispiel für diesen Bildtypus gilt Johann Peter Hasenclevers „Die Sentimentale“ (1846; Soiné 1990, Abb. 22). Das Bild zeigt von hinten die sitzende Gestalt eines Mädchens mit tränenden Augen und blosser Schulter, das aus nächtlicher Stube zum vollen Mond aufschaut. Über dem Bett hängt das Bildnis des geliebten Husaren, dessen mit den Worten „Innigstgeliebte Fanny“ beginnender Brief mit seinem Porträt im Medaillon auf dem Tisch liegt. Daneben aufgeschlagen sind Goethes „Werther“ und - mit einer Rose als Lesezeichen - Heinrich Claurens „Mimili“, ein von Liebe handelndes Lieblingsbuch der Zeit. Das Arrangement hebt hervor, wie persönliches Erleben mit literarischen Mustern überformt wird und wie sich dabei Rührung mit Erotik mischt.

In den Bildern von Mädchen und jungen Frauen mit Buch, in denen sich die Grenzen zwischen Fiktion und Wirklichkeit verwischt zeigen, sind Ernst und Satire gegen Ende des 19. Jahrhunderts nicht zu trennen. Das im populären Wandschmuck endlos variierte Thema „Hochzeitstraum“ erreicht auf einer im üppigen Neurokoko von Hans Tzatzkas Bildern gestalteten „Münchner-Kunst“-Karte einen Höhepunkt: Das Mädchen ist im Bett über einem (Liebes?)Roman entschlummert, und nun verwirklichen sich im Traum ihre Wünsche: Der Bräutigam steht wartend in der Tür, um sie zur Trauung in die Kirche zu führen; sie empfängt den Segen der Mutter, Amoretten umspielen die Träumerin. Das Titelbild der Anthologie „Heidenröslein. Lieder von 
Liebeslust und Frühlingsfreud“2 verbildlicht ein trivialliterarisches Programm: Amor begegnet der Leserin auf ihrem einsamen Spaziergang und schenkt ihr Rosen der Poesie und Liebe. Die Satire darauf hat Olaf Gulbransson 1907 im „Simplicissimus“ (Jg. 12, Nr. 7, Titelseite) geliefert: Alle Kreatur erwacht im Frühling mit neuen Kräften und paart sich nach Herzenslust, nur die "höhere, unschuldige“ Tochter geht allein mit ihrem Buch spazieren und ist unerfahren in den kreatürlichsten Dingen. Der Text wendet sich gegen die Religion, doch könnte das Mädchen genauso gut in einer der Anthologien ,für die Jungfrau“ lesen.

\subsection{Dienstbotenlektüre}

Eine Bilderfindung des 19. Jahrhunderts sind die lesenden Zofen, Dienstmädchen und Haushälterinnen, Ammen und Kindermädchen, die vor dem Bücherschrank ihrer Herrschaften schmökern und an deren Lesestoffen partizipieren. Unter Titeln wie „Pflichtvergessen“, „Die Zofe“ oder „Verbotener Zeitvertreib“ werden junge Mädchen vom Land oder aus der Unterschicht dargestellt, denen sich hier die Welt des Buches zu erschließen beginnt. Auf einer Karikatur von F.B. Dörbeck (Lithographie, Berlin um 1830) zieht das Schicksal Rinaldo Rinaldinis, des edlen Räubers im gleichnamigen Erfolgsroman von Goethes Schwager Vulpius, die Amme von ihrer Pflicht ab. Da das Kind auf ihrem Schoß zu schreien beginnt, holt sie mit den Worten „Halt's Maul, Jeheimde Raths Jöhre, un warte, bis Rinaldino dot is!“ zum Schlag aus. „Das leselustige Kindsmädchen. Ein sittengeschichtliches Genrebild nach der Natur gezeichnet" (Der Postheiri, 19. Jg., 1863, Nr. 18, 71; Hanebutt-Benz 1985, Nr. 182 mit Abb.) zeigt ein Kindermädchen, das einen kleinen Jungen (nicht mehr) spazieren fährt: In die Lektüre des Buches „Erzählungen aus der Schweiz“ vertieft, eilt sie ihres Weges und zieht den Wagen hinter sich her, ohne zu bemerken, daß das Kind herausgefallen ist und strampelnd auf dem Weg liegt.

\subsection{Lesen und Vorlesen im Freien}

\subsubsection{Allein Lesende im Freien}

Wie im Mittelalter Maria im Paradiesgärtlein sowie Eremiten und Büßer/innen in der Wüste lesend abgebildet wurden, so ließen sich vom Ende des 17. bis ins 18. Jahrhundert in Frankreich Damen der Gesellschaft als büßende Magdalena im Freien lesend darstellen (vgl. Kap. 4.5). Auch Garrett Morpheys Porträt des jungen John, First Baron Bellew of Duleck, der in der Landschaft unter Bäumen liegend liest, den Kopf in die Hand gestützt, stammt aus dem späten 17. Jahrhundert. ${ }^{3}$ Doch bis in die Mitte des 18. Jahrhunderts gibt es nicht viele Belege von im Freien Lesenden (z.B. Thomas Gainsborough, Sitzendes junges Mädchen in einer Parklandschaft, um 1750, New Haven, Paul Mellon Collection, Zwei Jahrhunderte englische Malerei, Nr. 29 mit Abb.; Martin Knoller, Porträt des Conte Carlo di Firmian, der in einer

2 Karl Zettel: Heidenröslein. Lieder von Liebeslust und Frühlingsfreud'. 21. Auf1. Stuttgart: Greiner \& Pfeiffer [ca. 1902].

3 Katalog Ausstellung 1969/70, Irish Portraits: 1660-1860; London, National Gallery, Nr. 8. 
Ruinenlandschaft Freunden ein geöffnetes Buch zeigt, 1758, Innsbruck, Ferdinandeum). In der zweiten Jahrhunderthälfte werden lesende Damen und Herren besonders in der englischen Kunst ein beliebtes Sujet - was im Zusammenhang mit der Entwicklung des englischen Landschaftsgartens zu sehen ist (z.B. Joseph Wright of Derby, Sir Brook Boothby, der in einer Waldlichtung auf einen Rasenhügel gestützt liegt und von der Lektüre eines Rousseau-Bandes aufblickt; Nicolson, Abb. Nr. 219).

Auf einen eigenen Bildtypus verweist Białostocki (1984, 28 ff.): Seit François Bouchers Bildnis der Madame de Pompadour (1758; London, Viktoria and Albert Museum) vergessen Lesende in der Natur auf ihre Lektüre, um dem Gesang eines Vogels zu lauschen (z.B. Joseph Severn, John Keats lauscht der Nachtigall auf Hampstead Heath, um 1845; Białostocki 1984, Abb. 20). Ein Porträt von AlexandreHyacinthe Dunouy zeigt im Park von La Rochecardon J. J. Rousseau, der sein Buch weglegte, um die Stimme der Natur zu hören (1795; Paris, Musée Marmottan), die beim Vogelsang durch das Ohr unmittelbar zum Herzen geht. Wenn auch viel verschlüsselter im Bild verborgen, zielt Caspar David Friedrichs "Gartenterrasse“ (1811/12, Börsch-Supan/Jähnig 1973, Nr. 199) kritisch auf die durch Lektüre repräsentierte Kultur, welche die Natur nicht achtet. Die rigorose Struktur des Bildes - das von zwei riesigen Kastanien beherrscht wird, die von der Terrassenmauer mit GitterKreuz-Portal hinterschnitten sind - läßt die Leserin, auf die ihr roter Mantel im Gras verweist, fast verschwinden. Sie sitzt am Fuße der rechten Kastanie im Schatten und nimmt, in ihr Buch vertieft, von den sonnigen fernen Hügelketten vor ihr keine Notiz. Wie die nach geometrischen Regeln geordnete Parkpartie und die Steinfigur, verweist (nach Börsch-Supan/ Jähnig 1973, 321 f.) auch die intensiv lesende Frau, die die Natur nicht wahrnimmt, auf die Erstarrung einer verstandesbetonten Kultur.

In der Bedeutungskonstitution des Bildes spielt die Natur seit Ende des 18. Jahrhunderts häufig eine neue Rolle: Sie wird Trägerin einer Stimmung, in der man liest. Goethes „Werther“ (1774) - dessen durchschlagender Erfolg zum kulturgeschichtlichen Ereignis wurde - gab das Vorbild ab für das Lesen in freier Natur, das der Entfaltung der eigenen Individualität und der persönlichen emotionalen Befriedigung dient (Abb. 24). In dieser Lesesituation wird die Natur als Spiegelbild menschlicher Befindlichkeit bzw. als ,Korrespondenz-Landschaft' behandelt (vgl. Jäger 1984, Nr. 16, 17 u. 10). In den Landschaftsgärten bzw. in deren Darstellung im Bild wird Natur so gestaltet, daß sie bestimmten Stimmungen und damit auch Lesesituationen entspricht - es kommt mithin zu einer Ästhetisierung und Subjektivierung der Natur. Darüber hinaus kann die Natur in eine (ideologische, symbolische) Beziehung zu den Figuren, besonders den Frauen, gebracht werden. Ein für weibliches Lesen im Freien typisches Motiv ist die Lektüre im geschützten (Haus)Garten oder Park (z.B. Erasmus Ritter von Engert, Wiener Hausgarten, um 1828/29, Schön 1987/1993, 9; Hans Olde, Unter Blütenbäumen, 1884/85; Kiel, Kunsthalle, vgl. Kähler 1988 mit weiteren Abbildungen). Im 19. Jahrhundert ist mit dem Bildtypus der im Umkreis des Hauses lesenden Frau eine für das bürgerliche Zeitalter spezifische Semantik verbunden: Die Frau wird ideologisch der Natur zugeordnet und rollenspezifisch auf die häusliche Tätigkeit festgelegt. 
Lektüreszenen im Grünen stellten häufig die Impressionisten dar (z.B. JeanBaptiste-Camille Corot, Rêverie bzw. La jeune Grecque, 1868/70; Finocchi 1992, Abb. 4 oder Otto Scholderer, Lesendes Mädchen auf einer Wiese, um 1890, Wiederspahn/ Bode, Abb. S. 141). Die müßige Lektüre der Frauen bürgerlicher Kreise fand statt in Wald und Flur, Park und Garten, am Teich, Bach oder Meer, in Hängematte, Schaukel, Boot etc. Auf Fritz von Uhdes „Sommertag“ (1903; Uhde 1908, 248) unterbricht die Frau ihren Spaziergang im Wald, den sie mit dem Hund unternommen hat, und lehnt sich lesend an einen Baum. Den Lektüresituationen der Mußestunden eng verwandt sind die Motive aus der Sommerfrische sowie von Erhol- und Bildungsreisen. Mädchen oder ihre Mütter lesen Bücher und Journale „Am Strande“, „Weltvergessen“ am Meer (Abb. 32), „Im Freien“, in den Dünen, im Ruderboot (Still ruht der See; Kaiser 1976, 32) etc. Der Herr auf der Kurpromenade, im Straßencafé, allein oder in Gesellschaft, liest meist Zeitung.

\subsubsection{Lesen und Vorlesen im Freien in Gesellschaft}

Im Freien Lesende sieht man auch auf Doppelbildnissen und Genreszenen. Ein frühes Beispiel ist das in der Landschaft bei einem Tempelchen auf der Bank sitzende junge Paar, wo sich der Kavalier - einen Finger der Linken einmerkend im Buch - lebhaft an seine Gefährtin wendet, die den Betrachter anblickt (Thomas Gainsborough, Lady and Gentleman in Landscape - eventuell ein Selbstporträt mit seiner Frau, um 1746/47; Paris, Musée de Louvre), ein anderes Johann Carl Heinrich Koopmanns „Rat Friedrich Schlosser und seine Frau vor Stift Neuburg“ (1832; Heidelberg, Kurpfälzisches Museum). Historisierend gestaltete Arthur von Ramberg seine Genreszene „Vorlesung im Park" (Abb. 37), wo ein junger Mann seiner aufmerksam lauschenden Gefährtin - an einem Bächlein auf der Wiese lagernd und von einem steinernen Pan ,belauscht" - aus einem kleinen Buch vorträgt.

In der zweiten Hälfte des 18. Jahrhunderts, im Zeitalter der Aufklärung und Empfindsamkeit finden sich verstärkt gesellige Lektüreszenen im Park (vgl. das im Salon von 1761 ausgestellte und von Diderot besprochene Bild „La Lecture“ von Carle Van Loo; Leningrad, Eremitage). Auf der Schlußvignette zur ersten Schweizer Ausgabe von Goethes „Werther“ führt Balthasar Anton Dunker (1775, Radierung; Jäger, Abb. 17) am Beispiel einer, gemischten Gesellschaft" auf einer Bank im Park die unterschiedlichen Rezeptionsweisen vor Augen: um eine junge Vorleserin sind geschart eine ältere gerührte Dame, ein junger lümmelnder Kavalier und ein zweiter, der der Gesellschaft den Rücken kehrt; zwischen Bank und Gebüsch ein ältliches Paar sie scheinheilig betrübt, er lüstern-neckisch. Und das kleine Mädchen links außen veranschaulicht mit theatralischer Komik seine Version der „Werther“-Handlung: sie, eine Lotte en miniature, ersticht ihre Puppe im Werther-Zeitkostüm mit einem Messer. Während hier ein übertriebenes und veräußerlichtes Gefühlsverhalten verspottet wird, fehlen solche karikierenden Züge auf anderen Lesebildern, wie z.B. der Radierung von Chodowiecki zu W. G. Beckers „Taschenbuch zum geselligen Vergnügen“, 6. Jg., 1796, in der sich eine Gruppe von Erwachsenen und Kindern um den Vorlesenden in einem Lustwäldchen schart (Hanebutt-Benz 1985, Nr. 128 mit Abb.) oder Thomas Rowlandsons „A Summer Idyll“ (Abb. 23), wo in einem Park vor gotischer Kirche zwei Pärchen bei Lektüre und Flötenspiel neben Schafen lagern. 
Das episodenreiche Genrebild "Sonntagnachmittag in einem schwäbischen Dorfe“ (1873; Koch, Abb. 61) von Theodor Schüz vereinigt die üblichen Leseszenen ländlicher Sittenschilderungen. Es zeigt eine Bauernfamilie im Freien vor ihrem Haus: Die Großmutter liest bei der Wiege, nah dabei hört die große Schwester die kleine mit Hilfe eines Büchleins ab, der Bruder liest bäuchlings, der Jüngere schreibt auf der Tafel, während der Vater sich das sonntägliche Treiben im Dorf beschaut, wo u.a. der Lehrer unter der Kirchhoflinde aus der Zeitung vorliest. Schüz ländliche Schilderungen führen den Umgang der dörflichen Bewohner mit der Bibel, dem Gebet- und Gesangbuch sowie den kindlichen Sing- und Lesebüchern etc. - im protestantischen Bereich und ausschließlich im Freien - beispielhaft vor und wurden oft in mehreren Fassungen und im Stich etc. weit verbreitet (vgl. die Abbildungen bei Koch 1985).

\subsection{Lesen und Vorlesen zu zweit oder in Gruppen (Innenraum)}

\subsubsection{Familien- und Gruppenbildnisse}

Bei Leseszenen zu zweit oder mit mehreren Personen ist zunächst zu unterscheiden, ob es sich um gemeinsame Lektüre in einem Buch oder um unabhängiges Lesen bzw. Studieren in verschiedenen Büchern im selben Raum handelt; bei letzterem können die Leser völlig isoliert voneinander ihren Leseinteressen nachgehen. Zu solchen Leseszenen kommt es etwa in der Bibliothek, im Lesekabinett (z.B. Johann Peter Hasenclever, Das Lesekabinett) und Lesecafé (z.B. Gustav Taubert, Im Lesecafé, 1832, verso steht: „Alles ließt alles“; Hanebutt-Benz 1985, Nr. 163 mit Abb.).

In Familienbildnisse ist das Lesemotiv häufig integriert. Besonders gerne verwenden es Künstler in Darstellungen mit ihrer Familie, so Chodowiecki in seiner Graphik „Cabinet d'un peintre“ (1771; Bürgerliches Leben 1978, Nr. 3 mit Abb.) oder Anton Graff „Die Familie des Künstlers“ (1785; Winterthur, Stiftung Oskar Reinhart), wo die Mutter die kleine Tochter im Buch auf ihrem Schoß unterweist, während die Söhne sich selbst beschäftigen und der Vater hinten malt. Arbeits- und Familienbereich sind zwar räumlich integriert, doch kompositorisch voneinander abgehoben - vorbildhaft formuliert in Darstellungen der Heiligen Familie (z.B. von Wilhelm von Schadow, Heilige Familie unter dem Portikus, 1818; München, Bayerische Staatsgemäldesammlungen). Das Lesen bzw. Bücher-Anschauen ist dem durch die Mutter repräsentierten familialen Raum zugeordnet. Wie nach einem Photo gemalt wirkt Carl Bäuerles „Familienszene“ von 1871 (Abb. 42): Das große aufgeschlagene Bilderbuch verbindet die in einer Reihe auf dem Sofa sitzenden zwei Töchterchen und die Mutter - wobei nur die Kleinste hineinschaut, die anderen den Betrachter anblicken; der Vater hinterfängt als dunkler Kontrast die helle, bewegte Gruppe, die Rechte über ein Buch gelegt, während der Mutter die Pflanze - wie den Kindern das Spielzeug - beigeordnet ist.

Meist folgen die Kompositionen den geschlechterspezifischen Rollenzuweisungen und Sozialisationsmustern der Zeit, indem der Sohn dem Vater, die Tochter der Mutter beigeordnet wird (modellhaft vorgeführt auf Friedrich Kaulbachs Bildnis der Kgl. Familie von Hannover, 1858-60), der Sohn zu einer höheren schulischen Bildung bestimmt ist usw. Auf Georges Desmarées Familienporträt „Leibarzt Hofrat Erhard Winterhalter mit seiner Familie“ (1762, München, Bayerische Staatsgemälde- 
sammlungen; Kronberger-Frentzen, 1940, Abb. S. 23) z.B. liest der kleine, an den Vater gelehnte Knabe, während das Töchterchen auf dem Schoß der Mutter gehalten wird; ganz ähnlich auf einem Familienbildnis von Friedrich Wasmann (Nathan 1954, A 563, Abb. 113), wo neben dem Vater auch der zweitälteste Sohn ein Buch hält und eine Tasche umgehängt hat, was wohl heißt, daß er zur weiteren Unterrichtung demnächst fortreist. Zum Idealbild einer glücklichen Familie gehört die Lektüre als bildender, unterhaltender und gemeinschaftsstiftender Faktor wie das Buch zur Individuation in der Gruppe.

Weitaus häufiger als die Gruppenporträts oder Genredarstellungen mit vielen Personen - von Kultgemeinschaften und Vereinen wie von Familien- und Freundeskreisen werden Kleingruppen dargestellt, die sich zur gemeinsamen Lektüre finden. Allüberall und aufs vielfältigste variiert sind - im Innenraum wie im Freien - die Bildmotive von Mutter und Kind(ern) oder Großmutter und Enkel(i)n bei der Lektüre (vgl. Kap. 4.1 bis 4.4) sowie von Kindern, die sich um ein Bilderbuch scharen oder es neben sich und unter ihrem Spielzeug, den Puppen, Tieren etc. liegen haben (z.B. Christoffer Wilhelm Eckersberg, Die Holm'schen Kinder, um 1830; Dänische Maler 1911, Abb. S. 9 oder Johann Georg Meyer von Bremen, Das genesende Schwesterchen, 1864; Alexander 1910, Abb. 93. G.).

Zahlreiche Zweiergruppen jugendlicher LeserInnen erfüllen die Kriterien der Empathiegemeinschaft (Schön 1987/1993, 202 f.): Es sind Freundschaftsbeziehungen oder geschwisterliche Verhältnisse von großer Zärtlichkeit und Zuneigung. Prototypisch stehen dafür die ein Buch oder eine Zeitschrift gemeinsam lesenden Mädchen (vgl. z.B. Ferdinand Balzer, Mädchen-Doppelbildnis, 1898; Wiederspahn/Bode 1982, 289; Gerhard Marcks, Lesende Mädchen, Bronze, 1944). Doch solch vertraute LeseGrüppchen bilden auch Geschwister (z.B. Defregger, Geschwister beim Lesen, 1873, Hanfstaengeldruck, Defregger 1983, Bd. 1, Abb. S. 94).

\subsubsection{Von der, autoritativen 'zur, assoziativen' Lesesituation}

Die Gruppenbildungen, zu denen das Vorlesen Anlaß gibt, lassen sich (mit Schön 1987/1993, 194-204) idealtypisch unterscheiden. Die ,autoritative Interaktionssituation" verbindet die Autorität des Vorlesers - Hausvater oder Hausmutter, Pfarrer, Schulmeister usw. - mit der Autorität des Buches: im Frömmigkeitsbereich die Bibel, der Katechismus oder ein Erbauungsbuch, im Erziehungsbereich das ABC- oder ein anderes Schulbuch. Die Verteilung der Vorleserrolle an Hausvater und -mutter richtet sich im bürgerlichen Zeitalter in der Regel nach deren sozialen Funktionen: Wo der ganzen Familie oder dem, ganzen Haus “ - mit Einschluß der Dienstboten, Knechte und Mägde - vorgelesen wird, dominiert der Hausvater, der dem Haus vorsteht und es nach außen vertritt. Anders ist es im familiären Binnenraum des Hauses, wo die Mutter den Kindern vorliest und ihnen den ersten Unterricht erteilt (vgl. Kap. 4.2). Im Verlauf des 18. Jahrhunderts tritt neben die ,autoritative“ verstärkt die ,assoziative Interaktionssituation“" in Form geselliger Kreise. In diesen dezentralisierten Gruppen, deren Teilnehmer durch Verwandtschaft, Freundschaft oder Bekanntschaft verbunden sind, ist „,der gesellige Austausch der Zweck, die Literatur das Mittel“ (Schön 1987/1993, 204). 
Als handlungsleitende Idee beherrschte die assoziative Interaktionssituation das bürgerliche Zeitalter von den Moralischen Wochenschriften der ersten Hälfte des 18. bis zu den Familienblättern und Kalendern der zweiten Hälfte des 19. Jahrhunderts. Für die Familienblatt-Redaktionen wurden Haus und Familie zum schichtenübergreifenden Orientierungsmerkmal: „Bewußt an einer kleinen Gruppe orientiert, das Familienideal als Leitbild vor Augen, sprach das Familienblatt den Leser nicht als Individuum, sondern als Mitglied der familiären Gemeinschaft an“ (Barth 1974, 207). Der ursprüngliche, später vielfach variierte Titelkopf der maßstabsetzenden „Gartenlaube“ (1853-1944; Barth 1975, Abb. 7) zeigt eine Großfamilie mit Kindern in der Laube. Ein Mann liest vor, während der zweite ihm über die Schulter schaut und interessiert auf eine Stelle weist. Die Frauen beschäftigen sich mit den Kindern, eine Dienstbotin trägt Essen auf. Vergleichbare Bildprogramme finden sich in anderen Familienblättern. Die Jahrgangsillustration des „Daheim“ (1864-1944), der protestantischen Gegengründung, nutzt 1861 ihren Titel wie die „Gartenlaube“ zu einer selbstbezüglichen Inszenierung: Zwei Putti hissen die Schrifttafel „Daheim“ zum Richtfest. Der Storch auf dem Dach weist auf die Kinder, die das Haus bevölkern werden. In einem Blumen- und Früchtekranz deuten Katze und Tauben, das Spinnrad, das aufgeschlagene Buch mit eingelegter Brille auf häusliches Beisammensein. $\mathrm{Da} \beta$ dabei auch vorgelesen wird, erhellt die Titelillustration des ersten Heftes dieses Jahrgangs (Barth 1975, Abb. 11): Das Triptychon zeigt im Mittelbild eine Familie mit drei Kindern, Großvater und Hund. Der Vater liest sitzend vor, der Älteste steht hinter ihm und schaut ihm über die Schulter ins Heft. Großvater raucht Pfeife, die Mutter ist mit dem Jüngsten beschäftigt. Das linke Bild zeigt die Ankunft von Freunden oder Nachbarn, im rechten Bild werden Früchte im Garten geerntet, die ein Dienstmädchen im Mittelbild hereinträgt. Die Titelillustrationen der Familien-, Haus- und Volkskalender zeigen analoge häusliche Lesesituationen, wobei in aller Regel das Buch in Händen des Mannes, des Vaters oder Großvaters, ist (zahlreiche Beispiele bei Wiedemann 1984).

Diese Titelbilder fassen die charakteristischen Elemente der bürgerlichen wie bäuerlichen Lesesituation zusammen: Lesen ist Teil der Häuslichkeit und organisiert eine Geselligkeit, die mehrere Generationen, beide Geschlechter und die Freunde des Hauses umfaßt. Das Wort kommt in Gesellschaft dem Mann zu, die Frauen sind mit den Kindern oder Handarbeiten beschäftigt, von der Küchenarbeit jedoch durch Dienstboten entlastet, so daß sie an Information und Geselligkeit teilhaben können. Diese Lesesituation schafft die ,gut-deutsche Gemütlichkeit“, die das Programm der „Gartenlaube“ aufruft, und öffnet das Haus den Freunden gegenüber und zur Natur hin.

\subsubsection{Vorleseszenen}

Wie die Darstellungen von Leseszenen finden sich auch die Schilderungen von Vorlese-Situationen in allen Milieus. Das Vorlesen in der Familie, die häufig noch aus drei Generationen besteht, oder im bäuerlichen Bereich vor allen Hausangehörigen übernahmen in der Regel die Familien- bzw. Hausväter (vgl. Kap. 5.6.2). Die Frau ist während der Lektüre mit Handarbeiten, den Kindern etc. beschäftigt, jedoch kann die Vorleserrolle im bürgerlichen Milieu auch auf sie oder ein Kind übergehen. In höfisch-adeligen und großbürgerlichen Kreisen obliegt die Aufgabe des Vorlesens Hof- 
leuten oder Angestellten (Hauslehrer, Gouvernante), manchmal auch der Ehefrau oder Tochter. Auf dem Dorf ist es der Lehrer oder Pfarrer, der im größeren Kreis - auch in der Wirtsstube - aus der Zeitung, dem Kalender, einem Flugblatt etc. vorliest. In allen Gesellschaftsschichten findet sich zudem der joviale, extrovertierte Selbstdarsteller, der sich mit Vorliebe an die weibliche Zuhörerschaft wendet. Ein eigenes Thema bilden Dichter-Lesungen, wie sie sich seit Jean Francois de Troys „MolièreLesung“" (um 1728, Cholmondeley, Cheshire; Keller 1971, Abb. 350) dargestellt finden (vgl. das Bildmaterial in Dichter lesen).

Ins adelig-bürgerliche Milieu führt Chodowieckis Titelkupfer fürs „,Jahrbuch zur belehrenden Unterhaltung für junge Damen“ von J. J. Ebert (1795), wo der Verfasser unterm Kronleuchter neun um einen Tisch sitzenden Damen aus (s)einem Buch vorliest (Bürgerliches Leben, Abb. 126) oder Johannes Spricks Gemälde „Familie von Twickel beim Tee“ (um 1840; Westhoff-Krummacher 1990, Abb. 78), das außer den vier pfeifenrauchenden männlichen Familienmitgliedern am Tisch die Hausfrau und die Tochter zeigt, vor denen Bücher und Zeitungen liegen; die Mutter hält ein Intelligenzoder Anzeigenblatt in der Hand, auf das sie den Betrachter eigens verweist; die Tochter häkelt. Ein ähnlich genrehaft biedermeierliches Familienbild ist auch Karl Heinrich Arnolds „Im Familienkreis“ (um 1850; Kronberger-Frentzen 1940, Abb. S. 79), wo ebenfalls am Teetisch, jedoch abends unter der Petroleumlampe, die Großmutter mit Enkelkind auf dem Sofa sitzt und vorliest, wobei auch der pfeifenrauchende Großvater im Lehnsessel seine Zeitung sinken ließ, um zuzuhören und sogar die junge Frau, die mit ihrem Mann am offenen Fenster steht, sich halb umwendet, um die Lesung nicht zu versäumen. In all diesen Bildern wird „Das häusliche Glück“ geschildert (so der Titel eines Almanach-Kupfers von Chodowiecki, 1795; Bürgerliches Leben 1978, Abb. 161), wo die Familie traut beisammensitzt und die gemeinsame Lektüre alle noch enger verbindet: Hier ist es das Töchterchen, das im Licht stehend in der einfachen Stube den Eltern vorliest, die - mit dem Baby gegenüber am Tisch sitzend - sich zärtlich umarmen.

Bis weit ins 19. Jahrhundert werden Knaben oder Mädchen, die durch die Schule im Lesen geübt sind und für andere häusliche Tätigkeiten noch nicht taugen, als Vorleser/innen eingesetzt. Besonders im bäuerlichen Bereich, in dem die Erwachsenen zum sekundären Analphabetismus tendierten, werden Kinder zum Vorlesen bei der Hausandacht, der Näharbeit und beim Spinnen - bevorzugt an Sonn- und Feiertagen - herangezogen. Schon um 1735 sieht man auf dem Gemälde des Giacomo Ceruti „Frauen bei häuslicher Tätigkeit“ (Padernello bei Brescia; Keller 1971, Abb. 324) ein kleines Mädchen zwischen jungen Spitzenklöpplerinnen stehen, denen sie konzentriert vorliest. Auf Genrebildern wird häufig vorgelesen der handarbeitenden oder kranken Mutter (z.B. Johann Georg Meyer von Bremen, Häusliche Andacht, 1872; Alexander 1910, Abb. 113 P., oder Johan Julius Exner, Interieur, um 1870; Dänische Maler 1911, Abb. S. 51). In der „Handarbeitsstunde“ und im „Heimgarten“, der dörflichen Zusammenkunft unverheirateter Mädchen (Alexander Drechsler, Frühling im Winter; Gartenlaube, 1895, Nr. 9, 144 f.), werden die älteren Mädchen als Vorleserinnen tätig, wie diese Rolle bei einer Kranken die Freundin oder Schwester übernimmt. 
Jutta Assel / Georg Jäger

\subsection{Das Buch als Kuppler}

Variantenreich ist ein Bildtypus, der die Anbahnung einer Beziehung schildert, bei der Buch oder Lektüre die Funktion eines Katalysators zukommt. Häufig sitzt die junge Frau allein - oder z.B. das Kindermädchen mit seinen Schützlingen - auf einer Bank im Freien oder im Zimmer am Fenster und liest oder hat das Buch neben sich abgelegt, um etwas zu nähen - während der ,Kavalier' Kontakt sucht: er pfeift, zieht den Hut, reicht oder wirft Blumen durchs Fenster, überrascht sie, kitzelt sie (z.B. „Schachmatt“, Brückner 1973, Abb. 127). Besonders auf Bild- und Photopostkarten um die Jahrhundertwende sind Lektüreszenen mit Verliebten beliebt, die ,zusammenkommen wollen ' - häufig ergänzt durch Gedichtstrophen: müßig Lesende locken den Anbandlungswilligen (Kaiser 1976, 121, 122, 177). Während des gemeinsamen Lesens stellt der Liebende die „Stumme Frage“ oder auch eine eindeutigere (Kaiser 1976, 25 u. 124) - so ruft auf einer Photokarte ein junges Mädchen mit geöffnetem Buch aus ihrem Fenster einem unten auf der Straße schmachtenden Jüngling zu: „Komm an mein Herz. Soll ich hier alleine bleiben, einsam und betrübt? ..."Auf einer anderen Photokarte illustriert ein Paar - neben einem Tischchen mit Büchern und Leselampe - die „Bücherweisheit. Was man sich schwarz auf weiß läßt sagen, kann man getrost nach Hause tragen. So sagt ein Spruch: Doch Mund auf Mund tut mehr als Himmelswonnen kund.“

Buch und Lektüre begleiten Verliebte und Liebende von den ersten Anfängen ihrer Beziehung an: „Der Beginn eines Romans“ von Louis Schmidt-Constant (Holzstich, um 1890) geht mit dieser Bildformulierung witzig um, indem er sich die Doppelsinnigkeit des Wortes Roman zunutze macht: Herr und Dame sitzen auf Bänken im sonnigen Park weitmöglichst auseinander, sind aber kompositorisch aufeinander bezogen. Sie kehrt sich demonstrativ ab, hat aber das offene Buch, in dem sie bisher gelesen hat, neben sich gelegt, so daß der ,Roman des Lebens' beginnen kann. Carl Spitzwegs „Nachhilfestunde“ oder „Die Lektüre“ betiteltes Gemälde (Wichmann 1991, 88-105) leitet zum nächsten Kapitel über: In Gottes freier Natur sitzt zwischen Kürbispflanzen und Weinreben, deren Ranken fast eine Laube bilden, ein junges Mädchen neben einem Jesuitenpater, der ihr eine Lektion - jedoch im Küssen - erteilt. Er umhalst sie innig und küßt sie, während sie das Buch immer noch vor sich in Händen hält. Die durch einen Gärtnerburschen „Belauschten Liebenden“ zeigen das gleiche Paar, jedoch ist die Kennzeichnung durch den Jesuitenhut weggefallen.

\subsection{Erotische Leseszenen}

Die Gefahren nicht-religiöser Lektüre - hauptsächlich des Romans - werden nicht allein im Müßiggang und der Zerstreuung gesehen, sondern vor allem in der Aufreizung der Sinnlichkeit durch Phantasiebilder, zu der die Texte die Anregung bieten. Die Szenen, in denen Buch und Lesen beim Anbandeln und Einfädeln einer Beziehung eine Rolle spielen (vgl. Kap. 5.7), sind bereits mehr oder weniger mit erotischen Konnotationen durchzogen. Die Einzelleser, die über dem Buch ins (Tag)Träumen kommen, werden häufig sinnlich affiziert dargestellt (vgl. Kap. 5.3). Dies kommt - neben entsprechendem Ambiente - in der Augen- und Körpersprache zum Ausdruck, 
wird aber z.B. auch durch Tiere angezeigt, die erotisch konnotiert sind: der den Schuh apportierende Schoßhund, die Schnäbelei mit einer Taube (Philippe Auguste Cattelain, Radierung, um 1870) o.ä. Hatten Künstler des 18. Jahrhunderts (Boucher, Debucourt, Watteau) auf die Legitimation durch mythologische oder biblische Verbrämungen (vgl. Magdalenen-Darstellungen Kap. 4.5) verzichtet, um die entblößte oder nackte Frau in intimen Schilderungen bei der Toilette, im Bad und im Bett zu zeigen, so wurde bald das Motiv der allein (nächtlich) ein Buch Lesenden hinzugefügt.

Eine gleitende Skala der Entblätterung führt vom Kleid zum Negligé bis zu völliger Nacktheit der Lesenden: Modelliert bei dem über ihrem Buch den Betrachter lächelnderwartungsvoll anblickenden „Lesenden Mädchen im Korbstuhl“ (Philipp Rumpf; Wiederspahn/Bode, Abb. S. 86) das Licht weich die blusenbedeckte Schulter und Busen, so führen nackte Schultern (z.B. Kaiser 1976, 36, 114, 120, zu Hasenclever „Die Sentimentale“ s. Kap. 5.3), entblößter Busen (z.B. Achille Devéria, Le Roman du jour, 1832; Auguste Toulmouche, Junges Mädchen mit Buch, 1857; Gustave Courbet, La liseuse d'Ornans, 1868-72; Bergman-Carton 1995, Abb. 61, 63, 77), und lässige oder laszive Haltung zur halbnackt im zerwühlten Bett oder ganz nackt als Akt gemalten Lesenden, deren Blick häufig verschleiert oder verschwimmend und deren Mund oft lächelnd geöffnet ist (vgl. die Postkarten bei Kaiser 1976, 99, 130, 174). Eine Postkarte zeigt eine junge Frau unter'm Blütenbaum auf einer Wiese mit angewinkelten Beinen, die den Betrachter mit leicht geöffneten Lippen einladend anschaut - auch sie hat das offene Buch weggelegt - und der Titel läßt sie sagen: „A présent il ne manque que toi“ (Jetzt fehlst nur du) (Kaiser 1976, 154, 151).

Das nachhaltig wirkungsvollste Bildmotiv für die Verführung durch das/über dem Buch liefern die Verse aus Dantes „Die Göttliche Komödie“ (Die Hölle, 5. Gesang, V. 73-142) über das Liebespaar Francesca und Paolo: Francesca da Rimini, zur Beilegung eines Familienzwistes dem lahmen und häßlichen Giovanni Malatesta angetraut, faßt eine leidenschaftlich erwiderte Liebe zu dessen Bruder Paolo. Über der gemeinsamen Lektüre einer Liebesszene zwischen Ginevra und „Lancelot“ - so der Titel des Ritterromans - kommt es zum Ehebruch: „Verführer war das Buch und der's geschrieben“ (V. 137). Das Schicksal der beiden, die vom Bruder bzw. Gatten getötet wurden, ist ein rührendes Sinnbild für die Macht der Liebe - und der Literatur - und das am häufigsten in der bildenden Kunst aufgegriffene Motiv aus der „Divina Commedia“. Die Liebes- und Lektüre-Szene wird im späten 18. (u.a. Flaxman, Joseph Anton Koch) und 19. Jahrhundert mehrfach dargestellt (vgl. Locella 1913), u.a von J. Auguste Dominique Ingres (1818), Giuseppe Frascheri (1836), William Dyce (1837), Achille Devéria (1838), Dante Gabriel Rossetti (1849); Gustave Doré (etwa 1860), Anselm Feuerbach (1863 und 1864), Amos Cassioli (um 1870, Abb. 33) sowie Josef Danhausers „Dichterliebe. Francoise da Rimini“ (gestochen von Josef Axmann; Prämienblatt des Österreichischen Kunstvereins, um 1845). In den teils im Innenraum, teils im Freien spielenden Szenen wird der zündende Augenblick und Umschlag vom Lesen zum Lieben zärtlich oder leidenschaftlich gestaltet: Francesca hält das Buch noch in Händen oder es liegt aufgeschlagen auf ihrem Schoß, während Paolo sich ihr zuwendet, seinen Arm um sie legt und sie küßt; sie hat den Arm mit 
dem Buch gesenkt, aber mit dem Finger noch die Seite eingemerkt, an der die Lektüre unterbrochen wurde; sie läßt das Buch fallen bei der stürmischen Umhalsung, oder es liegt bereits am Boden. Auf Rossettis Bild, bei der Francesca ihren Liebsten umarmt, verbindet beide das große Buch - mit einer Seite auf ihrem Schoß, mit der anderen von ihm abgestützt - auch körperlich.

Zeitlich vor diesen Bildern hat bereits Nikolaus Daniel Chodowiecki (Werther, Kupferstich von Daniel Berger, 1775; Jäger 1984, Abb. 13, mit Beschreibung von Assel 99 f.) eine vergleichbare Szene aus Goethes „Leiden des jungen Werthers“ (1774) mit dem Buch als corpus delicti wie delectans illustriert: Der zum Sterben entschlossene Werther geht ein letztes Mal zu Lotte, liest ihr aus den von ihm übersetzten Gesängen Ossians vor und rührt sie damit so sehr, daß es zu der einzigen leidenschaftlichen Umarmung zwischen ihnen kommt. Unter dem Titelkupfer mit Werthers Idealporträt zeigt Chodowiecki in einer Miniaturszene Werther und Lotte im Kuß vereint. Werther, links von Lotte knieend, umschlingt diese, sie mit seiner Rechten zu und an sich ziehend, bevor Lotte ihn abwehrt und aufspringt. Das Schnupftuch in Lottes ausgestreckter Rechten verweist auf die vorangegangene bewegte Tränenszene, das Buch ist bei der Umarmung aus Werthers linker Hand geglitten und liegt nun aufgeschlagen an der vorderen Bildkante. Diese Bildformulierung wird nicht nur von den Darstellungen der Leseszenen mit Francesca und Paolo, sondern auch von Romanlektüre-Szenen aufgenommen.

Eine Reihe von Bildern illustriert die Kritik an den sinnlich aufreizenden Romanen oder die Bilder von Frauen bei der Romanlektüre wurden produziert, um sinnlich aufzureizen. Da die belletristische Lektüre als Domäne der Frauen gilt und ihre (Nackt-) Darstellung sich als Sujet für Voyeure besser eignet, betrifft dies fast ausschließlich Leserinnen: Im Ansturm der Gefühle hat die nackte junge Frau auf Ernest Martens „La dernière page du Roman“ (Abb. 35) sich die Handlung derart zu eigen gemacht, daß sie ihre Liegestatt so zerwühlte, daß Decke und Kissen herabgeglitten sind und sie selbst aufgewühlt - das fast geschlossene Buch in der Linken, die Rechte aufgestützt - sich dem Betrachter preisgibt. In dem großformatigen Ölbild „La Liseuse de roman“" (1853, 1,25 x 1,55 m, Abb. 36) setzt Antoine Wiertz die Topoi der Romankritik um: Die einen Roman, verschlingende ' nackte Frau räkelt sich lüstern im Bett. Der Maler wählte die Darstellung so, daß der Betrachter am Fußende ihres Bettes steht und ihren Körper in raffinierter Verkürzung - und mit Hilfe des großen Spiegels vollkommen - überblickt. Der Teufel, vom linken Bettvorhangsrand überschnitten, kauert im Dunkeln und legt eine Reihe neuer Bücher aufs Laken - A. Dumas, Erfolgsautor historischer Liebes- und Abenteuerromane, ist auf einem Titel zu entziffern -, um sie vollends ins Verderben zu führen, nach dem Motto: Sie las Romane Tag und Nacht und das hat sie zu Fall gebracht. Der Spiegel ermöglicht nicht nur dem Betrachter, sondern der Frau selbst den pornographischen Blick und verweist damit auf die onanistische Selbstbezüglichkeit, die diesen - den Text in einen inneren Film mit eigener Hauptrolle umsetzenden - Leseakt kennzeichnet. 


\section{Zur Ambivalenz in der Bewertung des Buches}

Wie die Geschichte der Lese(r)bilder demonstriert, ist die Bewertung des Buches von einer grundsätzlichen Ambivalenz geprägt. Das religiöse Buch wird zwar gemeinhin der Frömmigkeit und Sitte assoziiert, doch führen die Darstellungen der büßenden Magdalenen die Möglichkeit des Umschlagens vor Augen: Die Bekehrung der Sünderin hat zur Folge, daß die Heilige Schrift, ihr Attribut, zur Legitimation ,nackter Tatsachen ' benutzt werden kann. Das weltliche Buch erfährt von vornherein unterschiedliche Bewertung, je nachdem ob es bildet oder zerstreut, belehrt oder aufreizt - und dies besonders in Bezug auf die Frau.

Dies belegen Bilder in der Tradition der Gegenüberstellung von Tugend und Laster. In der Nachfolge von Hogarth waren seit Ende des 18. Jahrhunderts in Kalendern, Almanachen etc. (vgl. Wunderlich/Klemt-Kozinowski 1985, Nr. 29 u. 30) Einzelblätter, Gegenstücke oder Folgen mit parallelen Lebensläufen beliebt. Illustratoren wie Chodowiecki oder Ernst Ludwig Riepenhausen stellten den für „das häusliche und öffentliche Glück “4 verderblichen Einfluß der Lesesucht auf der einen und die tugendhafte hausfraulich-mütterliche Beschäftigung auf der anderen Seite heraus. So führt Wilhelm Jury in zwei Kupferstichen „Kinderstube“ die Folgen der weiblichen Leselust (um 1800) warnend vor Augen: Der ihr Kind innig stillenden jungen Mutter im gut gelüfteten, gepflegten Kinderzimmer opponiert die in äußerst unordentlicher Stube mit ihrem Hündchen auf dem Schoß sitzende Lesende, die den Betrachter anschaut, jedoch keinen Blick auf die Wiege hinter sich und die vielen Arzneifläschchen auf dem Fenstersims verschwendet.

Programmatisch kontrastiert Victor Orsels Diptychon „Le Bien et le Mal“ (1832; Bergman-Carton 1995, Abb. 66) ein lesendes Mädchen, das vom Erzengel Michael mit Schild und Schwert beschützt wird, einem anderen Mädchen, dessen Buch unter ihrem Fuß am Boden liegt und dem der Teufel ins Ohr bläst. Oberhalb sind unter dem Titel „Beatitudo“ und „Damnatio“ die Erlösten und die Verdammten zur Rechten bzw. Linken Gottes zu sehen. Die Lithographie von Carel Frederik Curtenius Bentinck nach Joseph Guillaume Bourdet (Die Versuchung, um 1840, Romantische liefde, Abb. 5) zeigt das Mädchen in der Entscheidungssituation: Zu ihrer Rechten der Engel, der auf die aufgeschlagene Bibel weist, zu ihrer Linken der Satan, der ihr ein Leben in Luxus und Reichtum verspricht und hinter dem Vorhang, der die Zukunft verbirgt und den er ein Stück weit aufhält, ein Ballfest erstrahlen läßt.

Die grundlegende Ambivalenz in der Bewertung des Buches gilt auch für die Darstellung von Lesern. Sie geht wohl zurück auf die eingezogene und weltabgewandte Lebensweise des Gelehrten. In negativer Sicht wird aus ihm ein lebensfremder und -untauglicher Stubenhocker und „Büchernarr“ (vgl. z.B. den allegorischen Kupferstich „Der Büchernarr vom Tode besucht“ aus dem 18. Jahrhundert: Die einstürzende Bibliothek erschlägt den Gelehrten; Reicke 1900/1924, Abb. 120, sowie zusammen-

4 Vgl. Johann Gottfried Hoche: Vertraute Briefe über die jetzige abentheuerliche Lesesucht und über den Einfluß derselben auf die Verminderung des häuslichen und öffentlichen Glücks. Hannover 1794. 
fassend Hanebutt-Benz, 1985, 180-184). Unter der erotischen Graphik von Thomas Rowlandson ${ }^{5}$ findet sich die satirische Darstellung eines Astronomen, der in seiner Gelehrtenstube inmitten von Schriften und Folianten mit dem Fernrohr die Sterne beobachtet, während im Nebenzimmer der Liebhaber mit seiner Frau schläft. Dem Gegensatz zwischen Buch und Leben hat auch Carl Spitzweg in bekannten Bildern Ausdruck gegeben: Auf „Der verbotene Weg“ (um 1845; Wichmann 1990, Nr. 14 mit Abb.) hält der Jesuitenpater, das aufgeschlagene Brevier in der Hand auf dem Rücken, vor einer Weggabelung inne. Der rechte Weg führt zur Kirche, den linken, den eine Schranke mit dem Schild „Verbotener Weg“ versperrt, hat ein Husar mit seiner Liebsten gewählt. „Rosenduft-Erinnerung“ (um 1840/48; Wichmann 1990, Nr. 35 mit Abb.) zeigt einen gleichfalls in freier Natur mit seinem Brevier wandelnden Pater. Er genießt den Duft der Rosen, hinter deren Busch und dem Zaun sich ein Liebespaar verbirgt. Wird hier das zölibatäre Dasein der Liebe gegenübergestellt, so auf anderen Bildern der ,Bücherwurm' in seinen weltabgewandten Studien in einsamer Stube dem freien und lichten Leben der Natur. Charakteristischerweise konnte Spitzweg das Motiv des Vogels, der als Bote der Natur am offenen Fenster das Bücherstudium stört, auf den Mönch wie auf den Gelehrten beziehen (Wichmann 1991, 78 f.). Der Opposition von Buch und Leben (für die Kulturkritik der Romantik vgl. C. D. Friedrich, Gartenterrasse, Kap. 5.5.1) steht das Buch als Kuppler zwischen Liebenden und Medium der Sinnlichkeit gegenüber (vgl. Kap. 5.7 und 5.8). Diese gegensätzliche Besetzung des Buches wird auf die Frau ,als Weib' projiziert: Auf der einen Seite repräsentiert sie die durch das (geistliche, gelehrte) Bücherleben ausgeschlossene Natur, auf der anderen Seite Erotik und Sexualität, zu der das Buch den Zutritt eröffnet.

Die Ambivalenz in der Bewertung des Buches geht in die kulturelle Konstruktion der Geschlechter ein, aber sie geht keineswegs darin auf. In der Opposition von heiliger und teuflischer Schrift nimmt das Buch die paradoxe Struktur auf, die dem abendländischen Rationalismus in seinem binären Denken eigen ist. Das Buch repräsentiert beide Seiten der Moral, die jeweils als richtig und gut geltende (ausschließende) wie auch die als falsch und verderblich angesehene (ausgeschlossene) Seite. Die Gegenstücke zur Heiligen Schrift und ihren säkularisierten Analoga bilden die - je nach ideengeschichtlichen Frontstellungen unterschiedlich definierten - ketzerischen Bücher. 


\section{Literatur}

\section{Lesebilder als Quelle für die Lese(r)geschichte- Lexika, Überblicksdarstellungen, Einzelaspekte und Methodologisches}

Als Westfalen lesen lernte. „Von den Musen wachgeküßt ...“. Katalog: Walter Gödden und Annette Drees-Hüttemann. Paderborn 1990.

Barth, Dieter: Das Familienblatt - ein Phänomen der Unterhaltungspresse des 19. Jahrhunderts. Beispiele zur Gründungs- und Verlagsgeschichte. In: AGB (Archiv für Geschichte des Buchwesens) X (1970) 15 (1975); S. 121-316.

Barth, Dieter: Zeitschrift für alle. Das Familienblatt im 19. Jahrhundert. Münster 1974 (Arbeiten aus dem Institut für Publizistik der Universität Münster, 10).

Brückner, Wolfgang: Die Bilderfabrik. Dokumentation zur Kunst- und Sozialgeschichte der industriellen Wandschmuckherstellung zwischen 1845 und 1973 am Beispiel eines Großunternehmens. Frankfurt/Main, Historisches Museum 1973.

Dichter lesen. Bd. 1: Von Gellert bis Liliencron. Bd. 2: Jahrhundertwende. Hg. von Reinhard Tgahrt. Marbach a. N. 1984-89. [reiches Bildmaterial]

Hanebutt-Benz, Eva-Maria, unter Mitarbeit von Monika Estermann: Die Kunst des Lesens. Lesemöbel u. Leseverhalten vom MA bis zur Gegenwart. Frankfurt/Main: Museum für Kunsthandwerk 1985.

Jäger, Georg: Die Leiden des alten und neuen Werther. Texte, Kommentare, Abbildungen, Materialien zu Goethes „Leiden des jungen Werthers“ und Plenzdorfs „Neuen Leiden des jungen W." Mit einem Beitrag zu den Werther-Illustrationen von Jutta Assel. München 1984 (Hanser Literatur-Kommentare, 21). [Abbildungsteil]

Kaiser, Bruno: Bücher ohne Titel. Ein Postkartenalbum. Düsseldorf 1976. [Sammlung von Lesebildern]

Leser und Lesen im 18. Jahrhundert. Colloquium der Arbeitsstelle Achtzehntes Jahrhundert Gesamthochschule Wuppertal. Heidelberg 1977. [Leserstiche, S. 153-187]

Locella, Guglielmo: Dantes Francesca da Rimini in der Literatur, Bildenden Kunst und Musik. Hg. von Marie Locella. Esslingen 1913. [umfassende Bildbelege]

Neubert, Franz: Vom Doctor Faustus zu Goethes Faust. Mit 595 Abbildungen. Leipzig 1932.

Nies, Fritz: ,... bis Rinaldo dot is“. Bildgewordene Lektüre von Massenliteratur des 19. Jahrhunderts, oder warum wir ein Bildarchiv der Lesergeschichte brauchen. In: Romanistische Zeitschrift für Literaturgeschichte 15 (1991b); S. 452-464.

Nies, Fritz: Bahn u. Bett u. Blütenduft. Eine Reise durch die Welt der Lesebilder. Darmstadt: Wiss. Buchgesellschaft 1991(a). [einzige Monographie, Abbildungsteil, Verzeichnisse von identifizierbaren Büchern und Periodika auf Lesebildern, Erschließung der Bildinhalte im Sachregister]

Noltenius, Rainer (Hg.): Alltag, Traum und Utopie. Lesegeschichten - Lebensgeschichten. Essen 1988. [Lese-Situationen. Eine Bilderreise, S. 9-19]

Plaul, Hainer: Illustrierte Geschichte der Trivialliteratur. Leipzig 1983.

Romantische liefde. Een droombeeld vereeuwigd. Redaktion: Marjan Rinkleff. Nijmegen 1985.

Schenda, Rudolf: Bilder vom Lesen - Lesen von Bildern. In: IASL (Internationales Archiv für Sozialgeschichte der deutschen Literatur) 12 (1987); S. 82-106.

Schön, Erich: Der Verlust der Sinnlichkeit oder Die Verwandlung des Lesers. Mentalitätswandel um 1800. Stuttgart 1987 (Sprache u. Geschichte, 12)/Neuausgabe 1993 (GreifPaperback). [Abbildungsteil]

Wiedemann, Inga: „Der Hinkende Bote“ und seine Vettern. Familien-, Haus- und Volkskalender von 1757 bis 1929. Katalog der Kalendersammlung des Museums für Deutsche Volkskunde. Berlin 1984 (Schriften des Museums für Deutsche Volkskunde Berlin, 10). 
Jutta Assel / Georg Jäger

\section{Porträtsammlungen (Auswahl)}

Allgemeines Historisches Porträtwerk. Nach Auswahl von Woldemar von Seidlitz. 6 Bde. München 1884-1890.

Brucker, Jacob/Johann Jacob Haid: Bilder-sal (!) heutiges Tages lebender, und durch Gelahrtheit berühmter Schrift-steller (!); in welchem derselben nach wahren Original-malereyen entworfene Bildnisse in schwarzer Kunst, in natürlicher Aehnlichkeit vorgestellet ... werden. 10 Lieferungen. Augsburg 1741-55.

Die Porträtsammlung der Herzog August Bibliothek Wolfenbüttel. Bearb. von Peter Mortzfeld. Bd. 1 ff., München u.a. 1986 ff. [Umf.]

\section{Kunstgeschichte}

Albert Anker. Katalog der Gemälde und Ölstudien. Hg. vom Berner Kunstmuseum. Bern 1962. [Lesende Mädchen, Bibelleser, Zeitung lesende Bauern, Schulgenre, Vorlesesituationen, Bildnisse]

Alexander, Fr. W.: Johann Georg Meyer von Bremen. Das Lebensbild eines dt. Genremalers. Leipzig 1910. [reiches Spektrum an Lesebildern mit Mädchen und Frauen, Schulgenre]

Antoine Wiertz 1806-1865. Paris u.a. 1974. [Romanleserin]

Barlach: s. Ernst Barlach.

Beckmann: s. Max Beckmann.

Belting, Hans: Bild und Kult. Eine Geschichte des Bildes vor dem Zeitalter der Kunst. Nachdruck der 2. Aufl. München 1991.

Belting, Hans: Das Bild und sein Publikum im Mittelalter. Form und Funktion früher Bildtafeln der Passion. 2. Aufl. Berlin 1995.

Berenson, Bernard: Lorenzo Lotto. Complete Edition. London 1956. [Hieronymus in der Wildnis, junge Männer und Studierende, Porträts]

Bergmann, Gustav: Buchtitel als Sprachelemente auf Gemälden. 2 Tle. In: Philobiblon 18 (1974); S. 256-271 u. 20 (1976); S. 28-45.

Białostocki, Jan: Bücher der Weisheit und Bücher der Vergänglichkeit. Zur Symbolik des Buches in der Kunst. Heidelberg 1984 (Abhandlungen der Heidelberger Akademie der Wissenschaften. Philosophisch-histor. Klasse 1985, 5. Abh.).

Boehn, Max: Faust und die Kunst. Berlin 1924.

Börsch-Supan, Helmut/Karl Wilhelm Jähnig: Caspar David Friedrich. Gemälde, Druckgraphik und bildmäßige Zeichnungen. München 1973.

Bürgerliches Leben im 18. Jahrhundert. Daniel Chodowiecki 1726-1801. Zeichnungen und Druckgraphik. Städelsches Kunstinstitut und Städtische Galerie Frankfurt am Main. Frankfurt/Main 1978.

Bürgerliches Wandbild 1840-1920. Populäre Druckgraphik aus Deutschland, Frankreich und England. Katalog: Christa Pieske. Göttingen, Kunstverein 1975.

Büttner, Frank Olaf: Mens divina liber grandis est. Zu einigen Darstellungen des Lesens in spätmittelalterlichen Handschriften. In: Philobiblon 16 (1972); S. 92-126.

Clark, Anthony M.: Pompeo Batoni. A Complete Catalogue of his Works with an Introductory Text. Hg. von Edgar Peters Bowron. Oxford 1985. [Büßende Magdalena, Verkündigung und lesende Maria, zahlreiche Männerporträts]

Dänische Maler von Jens Juel bis zur Gegenwart. Arbeit/Brot und Friede. Düsseldorf u.a. 1911

Defregger, Hans Peter: Defregger 1835-1921. Rosenheim 1983. Ergänzungsbd. 1991. [zahlreiche Lesende aus dem bäuerlichen Milieu]

Die Reichsdrucke. Eine Sammlung von Kupferstichen, Radierungen, Holzschnitten, Gemälden, Aquarellen und Pastellen in Nachbildungen der Reichsdruckerei zu Berlin. Berlin 1928.

Eberlein, Johann K.: Miniatur und Arbeit. Das Medium Buchmalerei. Frankfurt/Main 1995.

Ernst Barlach. Das plastische Werk. Bearb. von Friedrich Schult. Hamburg 1960. [Mönche, Klosterschüler, Buchleser] 
Fantin-Latour. Paris: Éditions de la Réunion des musées nationaux 1982. [Frauenporträts, lesende Mädchen und Frauen]

Fuhri Snethlage, H.: In het licht van het lezen. De rol van het book in de beeldende kunst. Zwolle, Haarlem: Frans Halsmuseum 1992.

Geismeier, Willi: Daniel Chodowiecki. Leipzig 1993.

Gerard Dou. Des Meisters Gemälde. Hg. von W. Martin. Stuttgart 1913 (Klassiker der Kunst in Gesamtausgaben, 24). [Büßende Magdalenen, Einsiedler, lesender alter Mann (,Rembrandts Vater“) u. lesende alte Frau (,Rembrandts Mutter“), lesende Greise, Astronomen, Ärzte, junge Gelehrte und Studenten]

Gibbs, Robert: Tomaso di Modena. Painting in Emilia and the March of Treviso, 1340-80. Cambridge u.a. 1989.

Gibson, Frank: The Art of Henri Fantin-Latour: His Life and Work. London o.J. [Frauenporträts, lesende Mädchen und Frauen]

Greuze: s. Jean-Baptiste Greuze.

Grimm: s. Ludwig Emil Grimm.

Hugelshofer, Walter: Schweizer Kleinmeister. Zürich 1943. [Leseszenen im bäuerlichen und bürgerlichen Milieu, lesende Mädchen und Frauen]

Jean-Baptiste Greuze 1725-1805. Katalog: Edgar Munhall. Musée de Dijon, Palais des États de Bourgogne 1977. [Porträts, Lesende, Magdalena]

Jean-Louis-Ernest Meissonier. Ses souvenirs - ses entretiens. Precédés d'und étude sur sa vie et son œuvre par M. O. Gréard. Paris 1897. [Werkverzeichnis, zahlreiche Leser in historischem Kostüm]

Keller, Harald: Die Kunst des 18. Jahrhunderts. Berlin 1971.

Koch, David: Theodor Schüz. Ein Maler für das deutsche Volk. Stuttgart 1905. [Leseszenen auf dem Lande im Freien]

Koetschau, Karl: Rheinische Malerei in der Biedermeierzeit. Düsseldorf 1926.

Kronberger-Frentzen, Hanna: Das deutsche Familienbildnis. Leipzig 1940.

Laabs, Rainer (Hg.): Nicht für den Tag. Vier Jahrhunderte Zeitung in der Kunst. Frankfurt/Main u.a. 1987. [Bildband]

Leselust. Niederländische Malerei von Rembrandt bis Vermeer. Hg. von Sabine Schulze. Katalog der Schirn Kunsthalle Frankfurt am Main. Stuttgart 1993.

Ludwig Emil Grimm. Zeichnungen und Gemälde. Hg. von Ingrid Koszinowski/Vera Leuschner. 2 Bde. Marburg 1990. [Frauen- und Männerporträts, u.a. von Clemens Brentano; zahlreiche lesende Frauen, unter ihnen Bettine Brentano; studierende Männer, u.a. Jacob Grimm; Trachtenbilder]

Mann, Heinz Herbert: Augenglas und Perspektive. Studien zur Ikonographie zweier Bildmotive. Berlin 1992 (Studien zur profanen Ikonographie, 1). [Buch und Brille, S. 31-41]

Max Beckmann. Das Portrait. Gemälde, Aquarelle, Zeichnungen. Katalog: Klaus Gallwitz. Karlsruhe, Badischer Kunstverein 1963.

Nathan, Peter: Friedrich Wasmann. Sein Leben und sein Werk. München 1954. [Porträts lesender Frauen]

Nicolson, Benedict: Joseph Wright of Derby. Painter of Light. 2 Bde. London 1968. [viele Frauen- und Männerporträts, Lesen im Freien]

Pauli, Gustav: Die Hamburger Meister der guten alten Zeit. München 1925. [Bildnisse, Interieurs]

Polleross, Friedrich B.: Das sakrale Identifikationsporträt. Ein höfischer Bildtypus vom 13. bis zum 20. Jahrhundert. Worms 1988 (Manuskripte zur Kunstwissenschaft in der Wernerschen Verlagsgesellschaft, 18).

R. S. Zimmermann. Der Genremaler Reinhard Sebastian Zimmermann 1815-1893. Mit Texten von Maren Coseriu u.a. Friedrichshafen 1986 (Kunst am See, 16). [Bibelleser, Zeitungsleser im Wirtshaus, Mönchs- und Schulgenre]

Schneider, Cornelia: Leseglück im Spiegel der Kunst. Eine Spurensuche. In: Bellebaum, Alfred/Ludwig Muth (Hg.): Leseglück. Eine vergessene Erfahrung? Opladen 1996; S. $115-150$. 
Schneider, Norbert: Porträtmalerei. Hauptwerke europäischer Bildniskunst 1420-1670. Köln 1994.

Schnell, Werner: Georg Friedrich Kersting (1785-1847). Das zeichnerische u. malerische Werk mit Euvrekatalog. Berlin 1994. [Studium bei Lampenlicht, lehrende Maria, Maria Magdalena, lesender Hirte, Kindergenre]

Soiné, Knut: Johann Peter Hasenclever. Ein Maler im Vormärz. Neustadt/Aisch 1990. [Analysen von „Die Betschwester“, „Der Politiker“ (Zeitungsleser), „Das Lesekabinett“, „Die Sentimentale“, „Jobs als Schulmeister“" „Die Versuchung“ u.a.]

The Drawings of Thomas Rowlandson in the Paul Mellon Collection. Catalogue compiled by John Baskett and Dudley Snelgrove. New York 1978.

The Genius of Venice 1500-1600. Ed. by Jane Martineau and Charles Hope. London, Royal Academy of Arts 1983.

Uhde. Des Meisters Gemälde. Hg. von Hans Rosenhagen. Stuttgart u.a. 1908 (Klassiker der Kunst in Gesamtausgaben, 12). [Leserinnen im Freien, Schulgenre, Bilderbuch]

Valentiner, Wilhelm R.: Nicolaes Maes. Berlin u.a. 1924. [lesende Frauen, die nachdenkliche und eingeschlafene Alte; Gelehrter, Bildnis]

Weisberg, Gabriel P.: Francois Bonvin. Paris 1979. [Nonnen, insbesondere als Lehrerinnen; lesende Mädchen und Frauen, auch in der Kirche; Schüler]

Weisberg, Gabriel P.: The Realist Tradition. French Painting and Drawing 1830-1900. Cleveland, The Cleveland Museum of Art 1980.

Wentworth, Michael Justin: James Tissot. Catalogue Raisonné of his Prints. Minneapolis, Minnesota 1978. [lesende Frauen in unterschiedlichen Situationen, auch im Freien, in Hängematte, als Zeitungsleserin]

Wichmann, Siegfried: Carl Spitzweg. Kunst, Kosten und Konflikte. Frankfurt/Main u.a. 1991.

Wichmann, Siegfried: Carl Spitzweg. München 1990. [Eremiten, Geistliche, „Bücherwurm“, Antiquar, Zeitungsleser, Lesen im Freien und im Spazierengehen]

Wiederspahn, August/Helmut Bode: Die Kronberger Malerkolonie. Ein Beitrag zur Frankfurter Kunstgeschichte des 19. Jahrhunderts. Frankfurt/Main 1982.

Wiener Biedermeier. Malerei zwischen Wiener Kongreß und Revolution. Hg. von Gerbert Frodl/Klaus Albrecht Schröder. München 1992. [Leserinnen, Frauen in der Kirche, Lesen in der Bauernstube, Dorfschule, Romanlektüre, lesender Knabe u.a.]

Wiertz: s. Antoine Wiertz.

Wildenstein, Georges: Chardin. Revised and enlarged Ed. Greenwich, Conn. 1969. [Æuvrekatalog; häuslicher Unterricht durch die Frau, Lesebilder von Frau und Mann]

Wunderlich, Heinke/Gisela Klemt-Kozinowski: Leser u. Lektüre. Bilder u. Texte aus zwei Jahrhunderten. Dortmund 1985.

Wunderlich, Heinke: „Buch“ u. „Leser“ in der Buchillustration des achtzehnten Jahrhundert. In: Die Buchillustration im 18. Jahrhundert. Heidelberg 1980 (Beiträge zur Geschichte der Literatur u. Kunst des 18. Jahrhundert, 4); S. 93-123.

Zimmermann: s. R. S. Zimmermann.

Zimmermann, Antje: Studien zum Figurenbild bei Corot. Phil. Diss. Köln 1986 [Motiv des Lesens].

Zwei Jahrhunderte englische Malerei. Britische Kunst und Europa 1680 bis 1880. München, Haus der Kunst 1980.

\section{Bücher und Lesende in der christlichen Ikonographie}

Braun, Joseph: Tracht und Attribute der Heiligen in der deutschen Kunst. 4. Aufl. Berlin 1992. [Buch als Attribut]

Ehrenstein, Theodor: Das Alte Testament in Bilde. Wien 1923.

Lexikon der christlichen Ikonographie. Hg. von Engelbert Kirschbaum u.a. 8 Bde. Freiburg u.a. S. 1968-76. [Wilhelm Messerer: Lesen, Lesende, Bd. 3, 89 f.]

Meiss, Millard: Francesco Traini. Edited with an Introduction by Hayden B. J. Maginnis. Washington, D.C. 1983 (Art history series, 6). 
Schiller, Gertrud: Ikonographie der christlichen Kunst. Bd. 1 ff. Gütersloh 1969 ff.

Van Winckel, A. W./F. van Goethem (Hgg.): S. Thomas van Aquino. Bijdragen over zijn Tijd, zijn Leer en zijn Verheerlijking door de Kunst. Brüssel u.a. 1927. [Darstellung in der Malerei, S. 143-223, mit großem Bildanhang, auch mit Schulszenen]

\section{Mann und Buch}

Eremiten u. Eremitagen in der Kunst vom 15. bis zum 20. Jahrhundert. Katalog der Öffentlichen Kunstsammlung Basel. Redaktion: Rudolf Velhagen. Basel 1983. [Teil II. Der heilige Hieronymus als Büsser in der Wildnis, III: Der heilige Hieronymus als Gelehrter im Gehäuse]

Hartau, Johannes: Don Quijote in der Kunst. Wandlungen einer Symbolfigur. Berlin 1987. [reiches Bildmaterial]

Hofmann, Werner (Hg.): Luther u. die Folgen für die Kunst. Katalog der Hamburger Kunsthalle. München 1983.

Luther im Porträt. Druckgrafik 1550-1900. Bad Oeynhausen u.a. 1983.

Ost, Hans: Einsiedler und Mönche in der deutschen Malerei des 19. Jahrhunderts. Düsseldorf 1971 (Bonner Beiträge zur Kunstwissenschaft, 11).

Reicke, Emil: Der Gelehrte in der deutschen Vergangenheit. Leipzig 1900 (Monographien zur deutschen Kulturgeschichte, 7). 2. Aufl. Jena 1924.

Reicke, Emil: Lehrer und Unterrichtswesen in der deutschen Vergangenheit. Leipzig 1901 (Monographien zur deutschen Kulturgeschichte, 9).

Schramm, Petra: Die Alchemisten. Gelehrte - Goldmacher - Gaukler. Ein dokumentarischer Bildband. Taunusstein 1984.

Warnke, Martin: Das Bild des Gelehrten im 17. Jahrhundert. In: Neumeister, Sebastian/Conrad Wiedemann (Hgg.): Res Publica Litteraria. Die Institutionen der Gelehrsamkeit in der frühen Neuzeit. Tl. 1. Wiesbaden 1987 (Wolfenbütteler Arbeiten zur Barockforschung, 14); S. 1-31. [Abbildungen]

\section{Frau und Buch}

Bardon, Francoise: Le thème de la Madeleine penitente au XVIIème siècle en France. In: Journal of the Warburg and Courtauld Institutes 31 (1956); 274-306.

Bergman-Carton, Janis: The woman of ideas in French art, 1830-1848. New Haven u.a. 1995. [Kap. 4 über die Frau, ihren Körper und das Buch]

Fastner, Herbert: „Oh, heilige Mutter Anna, hilf!“ Eine vergessene Heilige in ihrer Verehrung u. in der Volkskunst. Grafenau 1986. [Hinterglasbilder]

Finocchi, Anna: Lettrici immagini della donna che legge nella pittura dell'Ottocento. Nuoro 1992.

Ingenhoff-Danhäuser, Monika: Maria Magdalena. Heilige u. Sünderin in der italienischen Renaissance. Studien zur Ikonographie der Heiligen von Leonardo bis Tizian. Tübingen 1984.

Kähler, Ingeborg: Blühende Schönheit. Betrachtungen zu einem Mythos, ausgehend von einem Frauenbildnis Hans Oldes d. Ä. In: Nordelbingen 57 (1988); 85-110.

Kleinschmidt, Beda: Die Heilige Anna. Ihre Verehrung in Geschichte, Kunst u. Volkstum. Düsseldorf 1930.

La Maddalena tra Sacro e Profano. Da Giotto a De Chirico. Ausstellungskatalog Florenz. Florenz 1986. [geordnet nach Bildtypen, u.a. „Vanitas“, „Estasi“, „La Penitente“, mit Ausblick auf das 19. Jahrhundert]

Marienlexikon hg. im Auftrag des Institutum Marianum Regensburg e.V. von Remigius Bäumer u. Leo Scheffczyk. 6 Bde. St. Ottilien 1988-94.

Schreiner, Klaus: Marienverehrung, Lesekultur, Schriftlichkeit. Bildungs- und frömmigkeitsgeschichtliche Studien zur Auslegung u. Darstellung von „Mariä Verkündigung.“ In: Frühmittelalterliche Studien 24 (1990); 314-368.

Westhoff-Krummacher, Hildegard: Lesende Frauen auf westfälischen Bildnissen. Weibliche Existenz zwischen Strickstrumpf u. Gebetbuch. In: Als Westfalen lesen lernte (s. dort), S. 67-93. 


\section{Abbildungsteil: Ikonographie des Lesens}

\section{Seite [4]}

1 Evangelist Matthäus, Cutbercht-Evangeliar, um 770

Wien, Österreichische Nationalbibliothek

Adolph Goldschmidt: Die deutsche Buchmalerei. Bd.1: Die karolingische Buchmalerei. Firenze, München 1928, Taf. 1.

2 Louis de Laval beim Gebet. Heures de Louis de Laval, um 1480-1489

Jean Porcher: Französische Buchmalerei. Recklinghausen 1959, Taf. LXXXVI.

3 Jan van Eyck (um 1390-1441) und Werkstatt, Der Hl. Hieronymus im Gehäuse (,portrait historié “ des Kardinals Niccolò Albergati ?), um 1435, datiert 1442

The Detroit Institute of Arts

Julia P. Henshaw: 100 Masterworks from the Detroit Institute of Arts. New York 1985.

4 Gerlach Flicke, Archbishop Thomas Cranmer, 1546

London, National Portrait Gallery

\section{Seite [5]}

5 Benozzo Gozzoli (1420-1497), Der Hl. Augustin übergibt den Mönchen die Regel, Fresko, 1465

Chiesa S.Agostino, S. Gimignano

6 Wilhelm von Löwenstern, Dr. Martin Luther, Lithographie, 2. Viertel des 19. Jh. Luther im Porträt. Druckgrafik 1550-1900. Bad Oeynhausen u.a. 1983, Nr. 52 [ recte 53].

7 Ludger torn Ring d. A. (1496-1547), Bildnis des Dichters Vergil Münster, Westfälisches Landesmuseum für Kunst und Kulturgeschichte

8 Johann Kemmer (ca. 1495-1554), Bildnis einer Patrizierin/Fürstin, 1534 Leipzig, Museum der bildenden Künste

\section{Seite [6]}

9 Daniel Nikolaus Chodowiecki (1726-1801), Brustbild eines alten lesenden Bauern, Radierung, 1757 (E 2.)

Daniel Nikolaus Chodowiecki. Das druckgraphische Werk. Die Sammlung Wilhelm Burggraf zu Dohna-Schlobitten. Hannover 1982, Nr.4.

10 Reinhard Sebastian Zimmermann (1815-1893), Bibelleser, Gouache, um 1840

Der Genremaler Reinhard Sebastian Zimmermann. Friedrichshafen, 1986, S.133.

11 Jean-Louis-Ernest Meissonier (1815-1891), Le Liseur Blanc, 1857

Jean-Louis-Ernest Meissonier. Ses souvenirs - ses entretiens. Paris 1897.

12 Georg Friedrich Kersting (1785-1847), Leser bei Lampenlicht, 1814

Winterthur, Stiftung Oskar Reinhart

Werner Schnell: Georg Friedrich Kersting. Berlin 1894, A 61.

\section{Seite [7]}

13 Raffaello Santi (1483-1520), Madonna mit Kind, Federzeichnung (Vorderseite), um 1505 Wien, Albertina

14 Julius Schnorr von Carolsfeld (1794-1872), Maria mit dem Kinde, 1820

Köln, Wallraf-Richartz-Museum 
15 Anna und Maria, Stahlstich (Probeabzug Carl Mayer, Nürnberg ?), um 1850

16 Das Abendgebet, Stahlstich von dell'Argine nach August Noack (1822-1905), um 1850

\section{Seite [8]}

17 Die Erziehung der Jungfrau durch ihre Mutter Anna, Miniatur einer englischen Handschrift, 2. Hälfte des 14. Jh.

Paris, Bibliothèque Nationale

Le livre dans la vie quotidienne. Bibliothèque Nationale. Paris 1975, Nr. 181.

18 Die Erziehung des Achilles, Lithographie von Guido Gohr, um 1900 (Ausschnitt)

\section{Seite [9]}

19 Josef Obwexer (1828-1875), Die hl. Familie bei der Unterweisung Marias, gouachierte Zeichnung, um 1850

20 Mutter und Töchterchen bei gemeinsamer Lektüre - vom Vater belauscht, kolorierte Fotopostkarte, R \& K 5744/2., um 1900

21 Mädchenbildnis, Holzstich von Knesing X.A. nach Georg Jacobides (1853-nach 1920), um 1900

22 Hans Jakob Oeri (1782-1868), Knabenbildnis, Zeichnung, um 1820

Walter Hugelshofer: Schweizer Kleinmeister. Zürich 1943, Taf. 73.

\section{Seite [10]}

23 Thomas Rowlandson (1756-1827), A Summer Idyll, aquarellierte Federzeichnung, um 1800 The Drawings of Thomas Rowlandson in the Paul Mellon Collection. Catalogue compiled by John Baskett and Dudley Snelgrove. New York 1978, Nr.54.

24 Johann David Schubert (1761-1822), Werther, Aquarell, 1787/88

Wolfgang Pfeiffer: Die Wertherillustrationen des J.D. Schubert. Weimar 1933.

\section{Seite [11]}

25 Lesende Nonne. Ludolf von Sachsen, Das Leben Christi, Schwaben 1472-1476. Eva-Maria Hanebutt-Benz: Die Kunst des Lesens. Frankfurt a.M. 1985, Abb. S.39.

26 Maurice Quentin de la Tour (1704-1788), Mademoiselle Ferrand meditiert über Newton, 1753, Pastell

München, Alte Pinakothek

27 Friedrich Wasmann (1805-1886), Minna W., Schwester des Künstlers, 1822

Hamburg, Kunsthalle

Peter Nathan: Friedrich Wasmann. Sein Leben und sein Werk. München 1954.

28 Georg Schrimpf (1889-1938), Lesende am Fenster, 1925

Mannheim, Städtische Kunsthalle

\section{Seite [12]}

29 Johann Anton Ramboux (1790-1866), Mädchen in der Kirche, um 1830 Heidelberg, Kurpfälzisches Museum

30 Leopold Schmutzler (1864-nach 1930), Interessante Lektüre, Farbpostkarte, Berlin, Moderner Kunst-Verlag, um 1900

31 Der dritte Band, Holzstich, um 1880

32 Weltvergessen, Holzstich, um 1890 


\section{Seite [13]}

33 Amos Cassioli (1832-1891), Francesca da Rimini (Dante), um 1870

34 Foto, um 1910

Rainer Noltenius (Hg.): Alltag, Traum und Utopie. Essen 1988.

\section{Seite [14]}

35 Ernest Martens (1865-nach 1911), La dernière page du Roman, Fotopostkarte, um 1890, Salons de Paris, SPA 466

36 Antoine Wiertz (1806-1865), La Liseuse de romans, 1853, Postkarte NELS Bruxelles, Musée Wiertz

\section{Seite [15]}

37 Vorlesung im Park, Stahlstich nach Arthur von Ramberg (1819-1875), um 1860 (Ausschnitt)

38 Ich liebe Dich!. Fotopostkarte, koloriert, um 1900, L.J.S.F.F. 2660/2

39 Emanuel Spitzer (1844-1919), Heimliche Lektüre. Holzstich von Richard Bong in Berlin, um 1900. Photographieverlag der „Photographischen Union“ in München

40 Heitere Lektüre, Holzstich von F. Feldweg nach Federico Andreotti (1847-1930), um 1890

\section{Seite [16]}

41 Eduard Pistorius (1796-1862), Der Vater liest der Familie aus der Bibel vor, Umrißradierung, um 1835

42 Familienportrait, 1871. Adolf Wagenmann (1839 - nach 1890) nach Carl Wilhelm Friedrich Bauerle (1831-1912), Stahlstich, Verlag von Carl von Jaminet in Berlin 


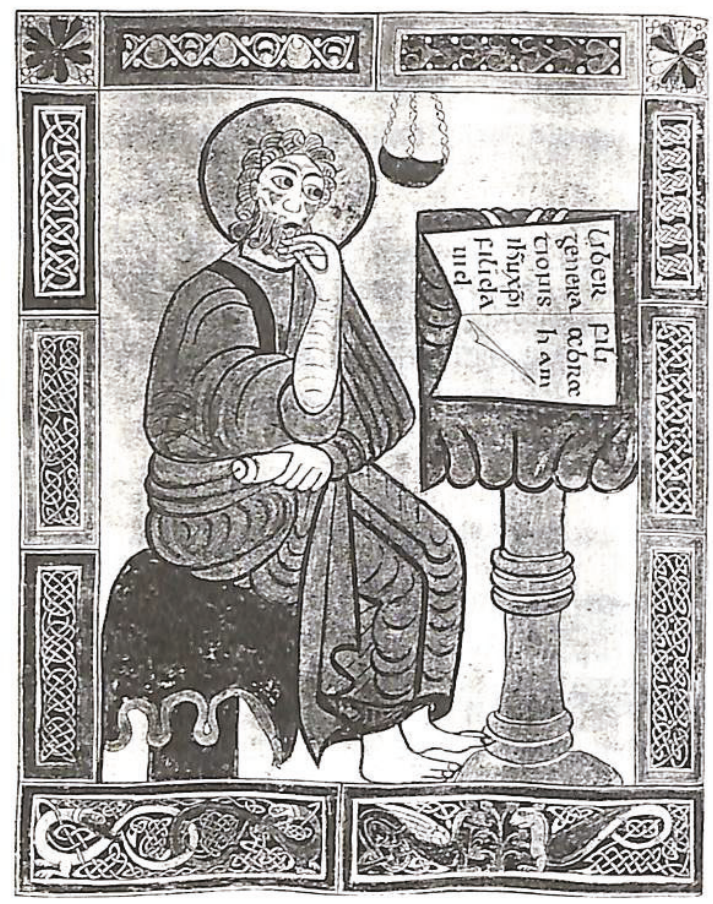

(1)

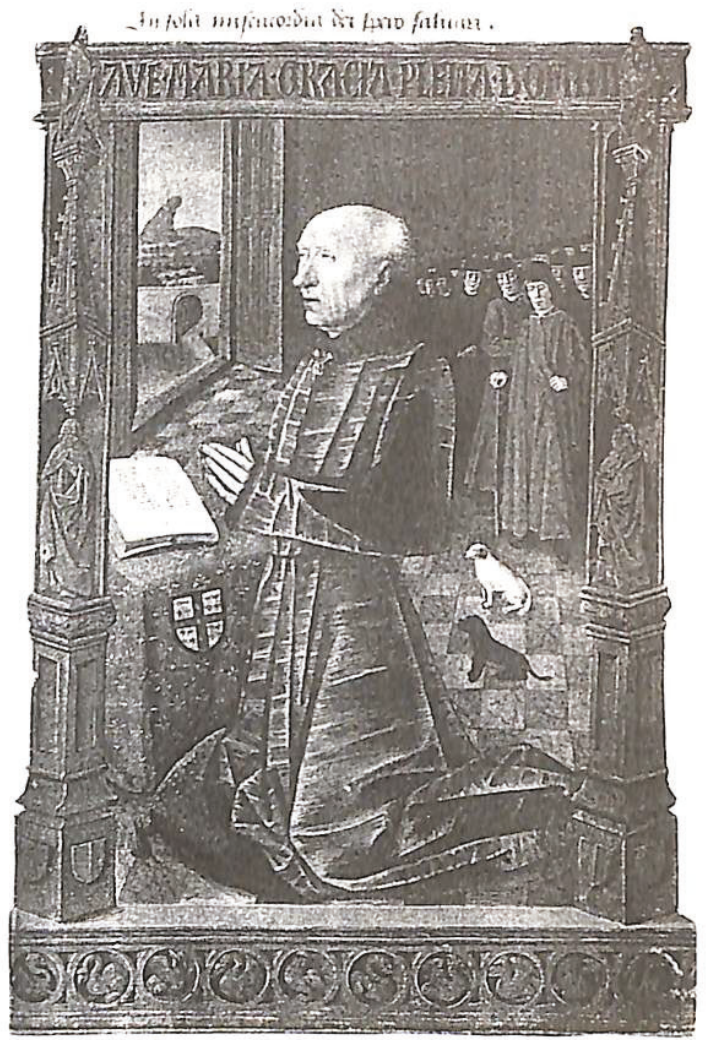

(2)

(3)

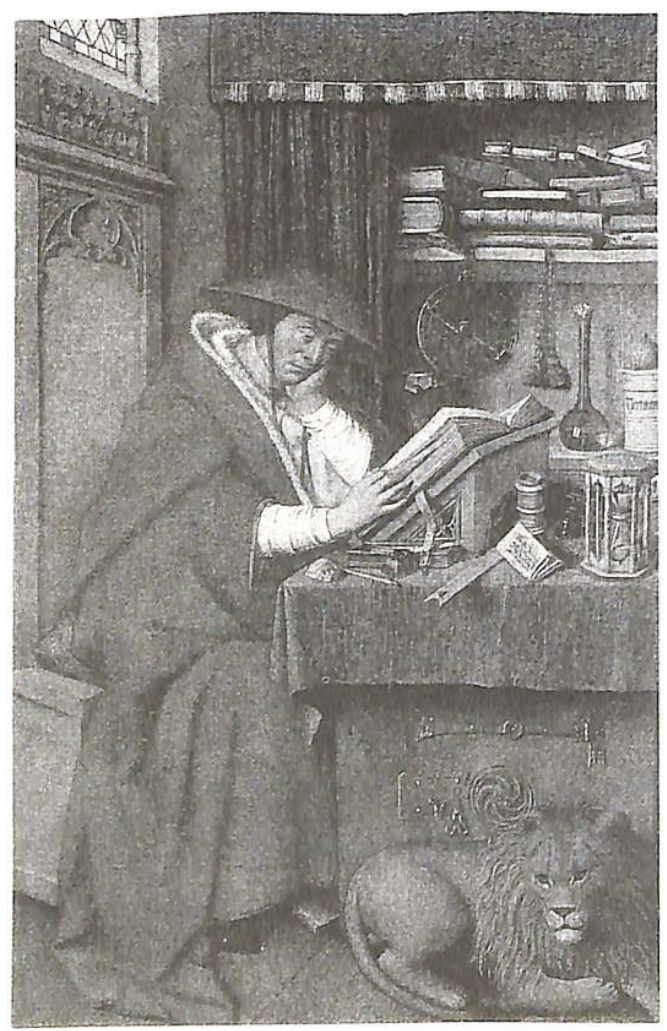

(4)

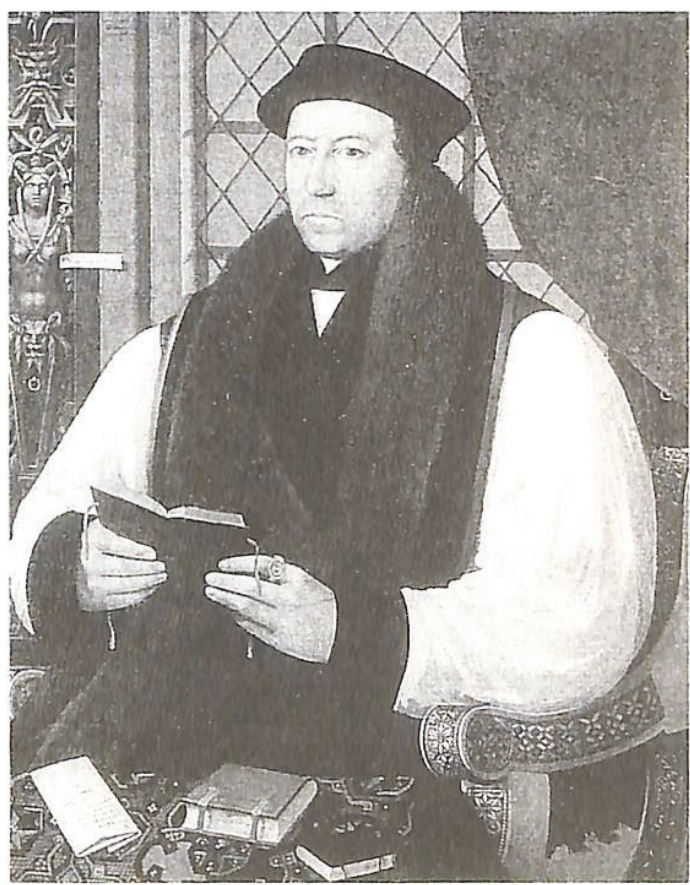




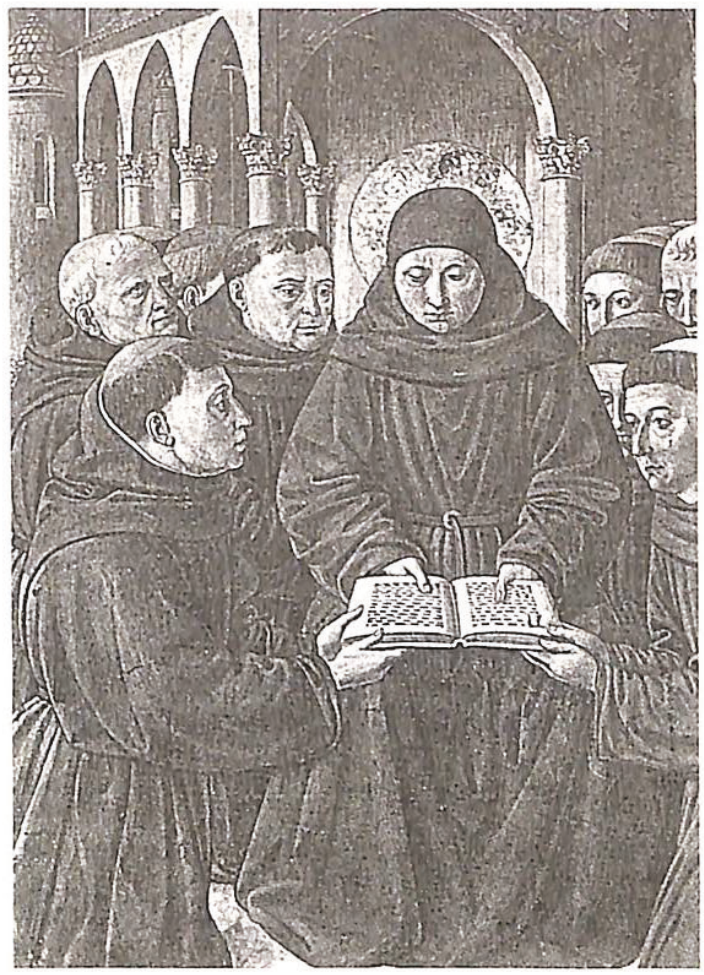

(5)

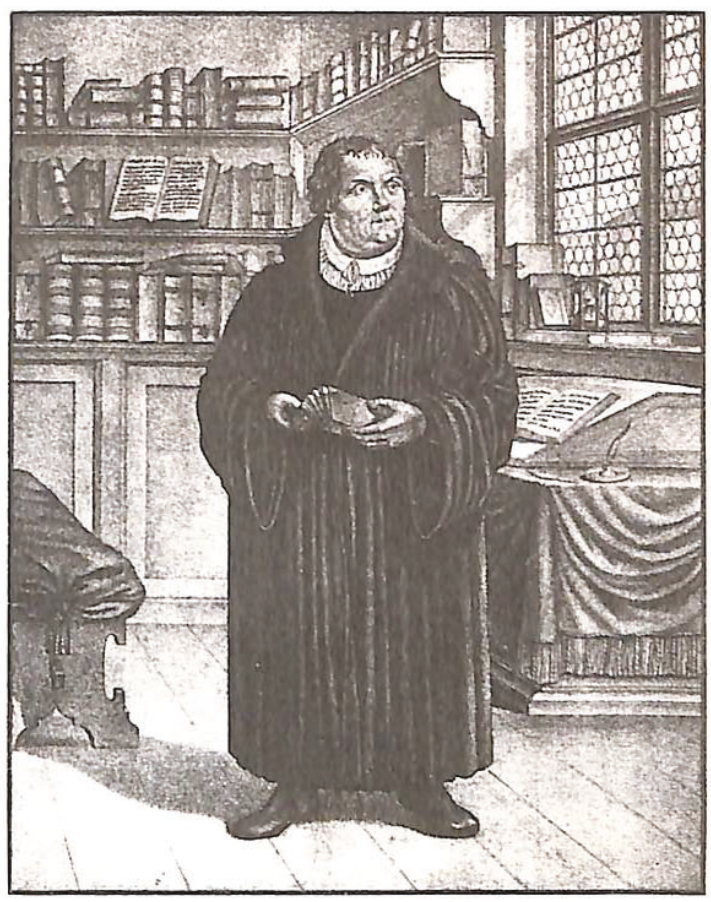

(6)

(7)
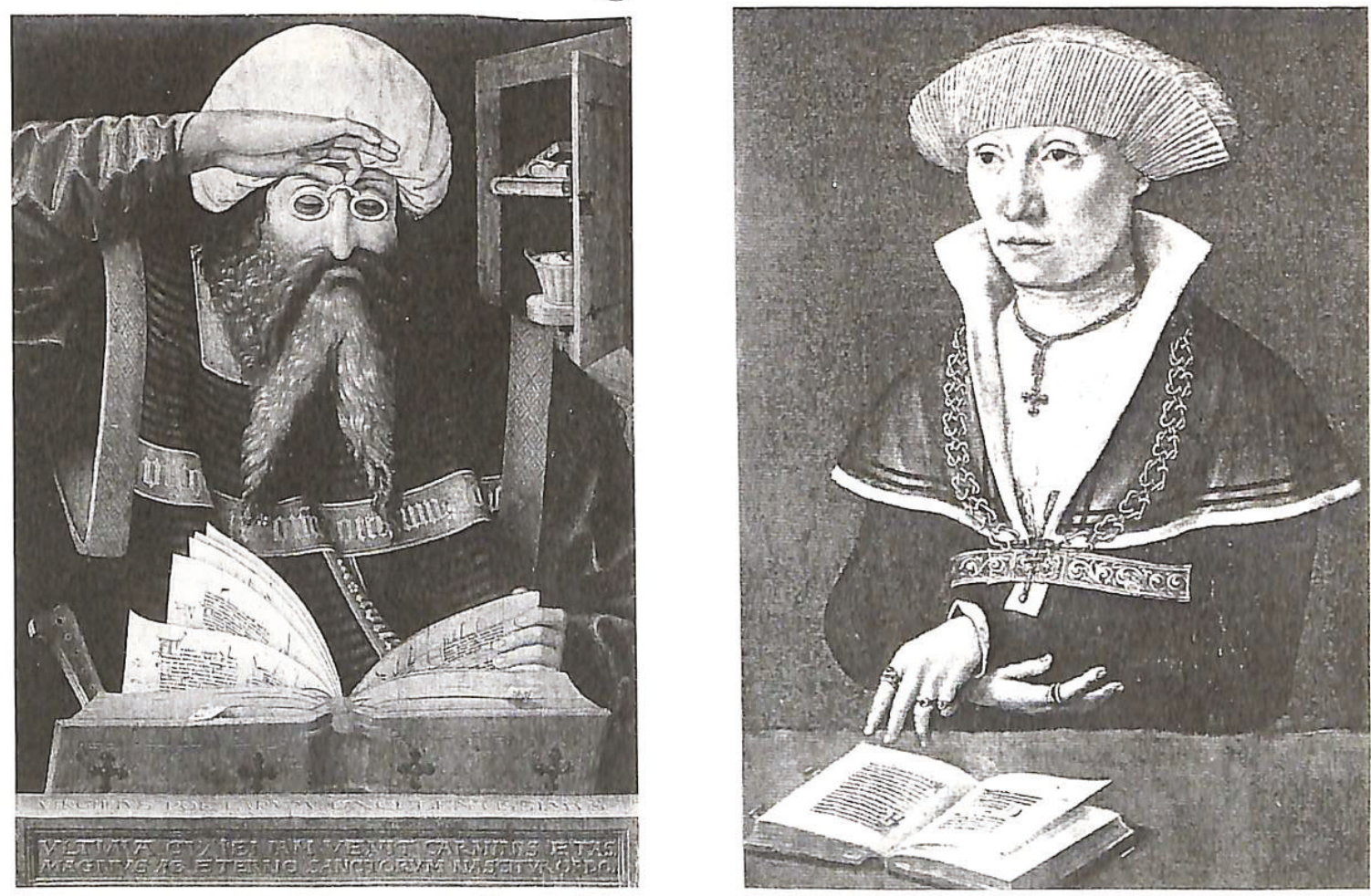


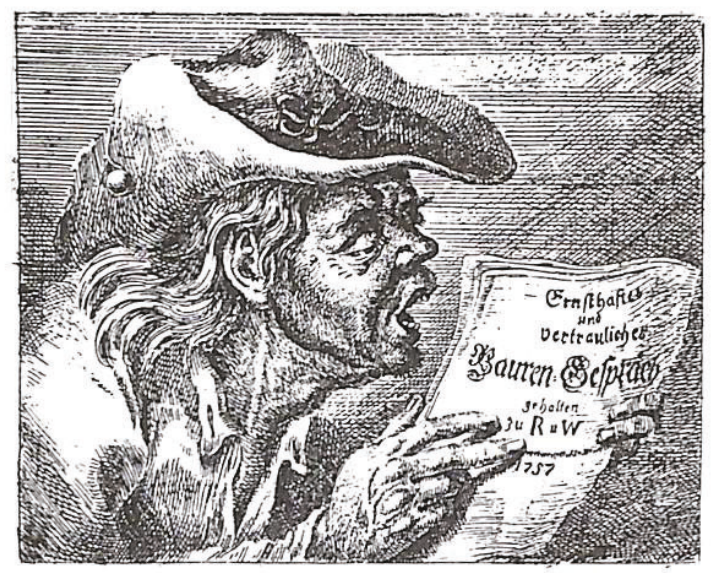

(9)

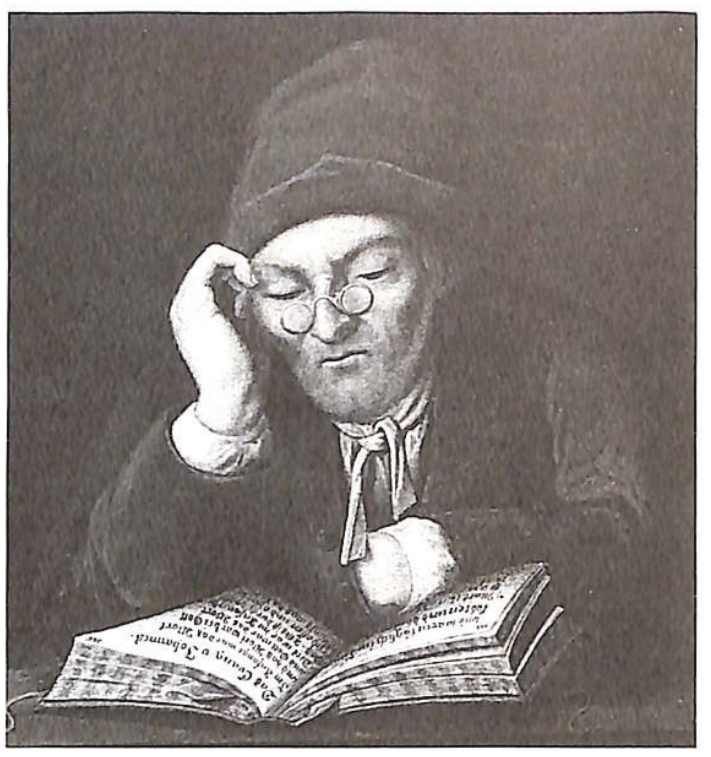

(10)

(11)

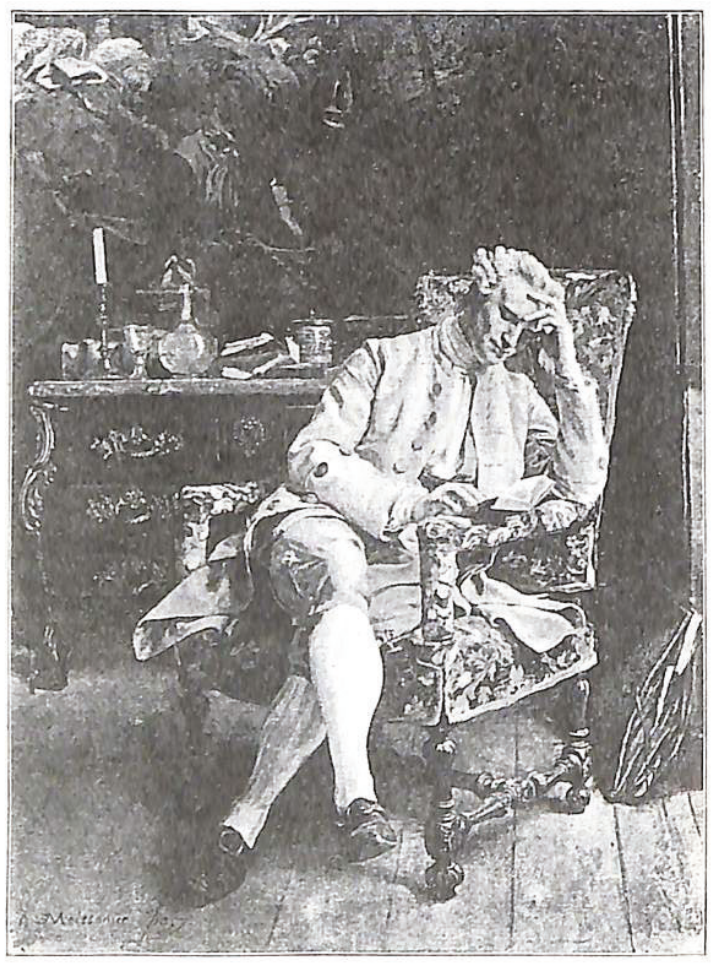

(12)

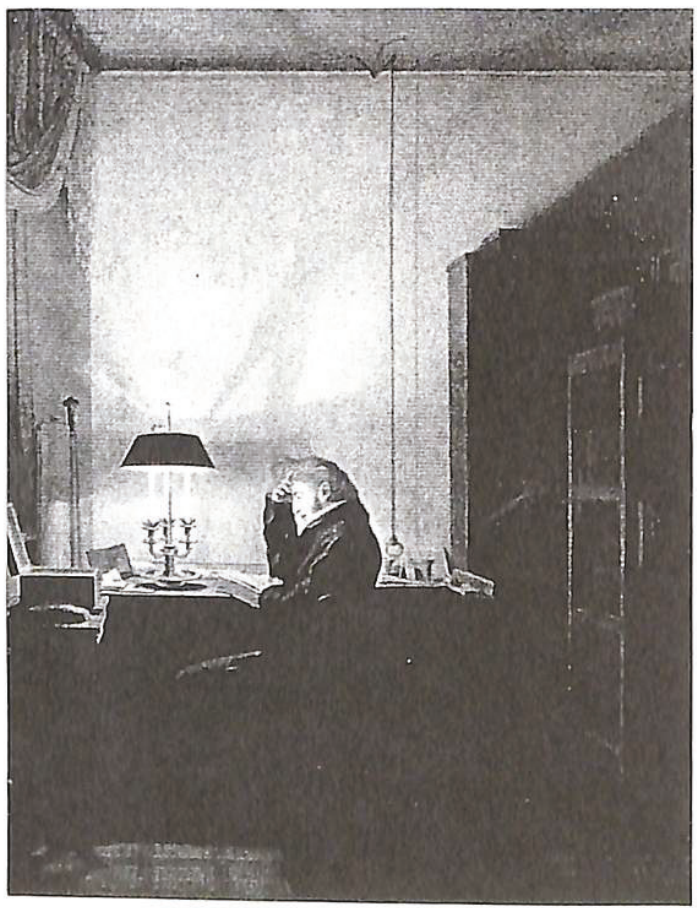




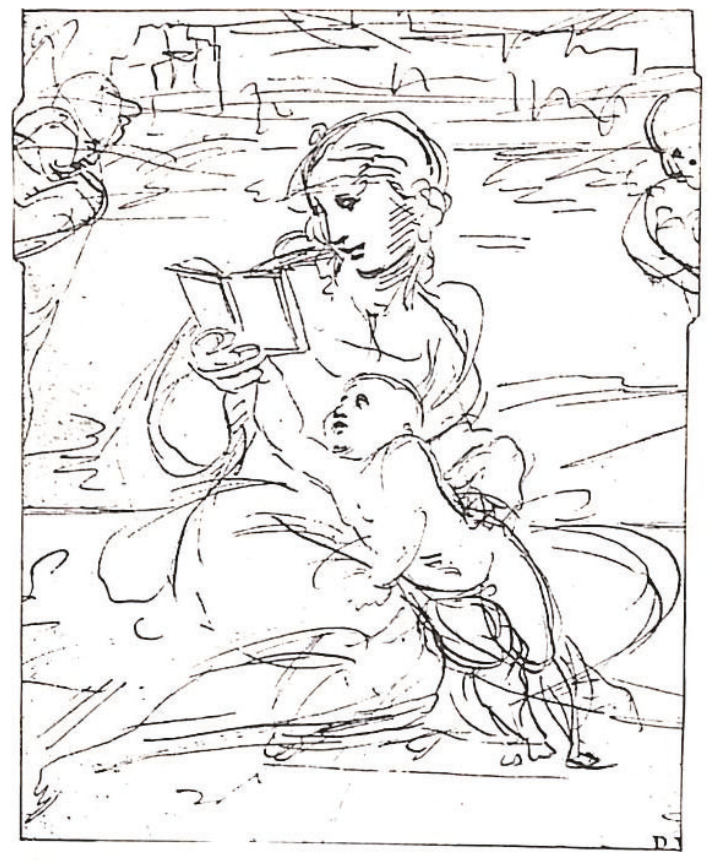

(13)

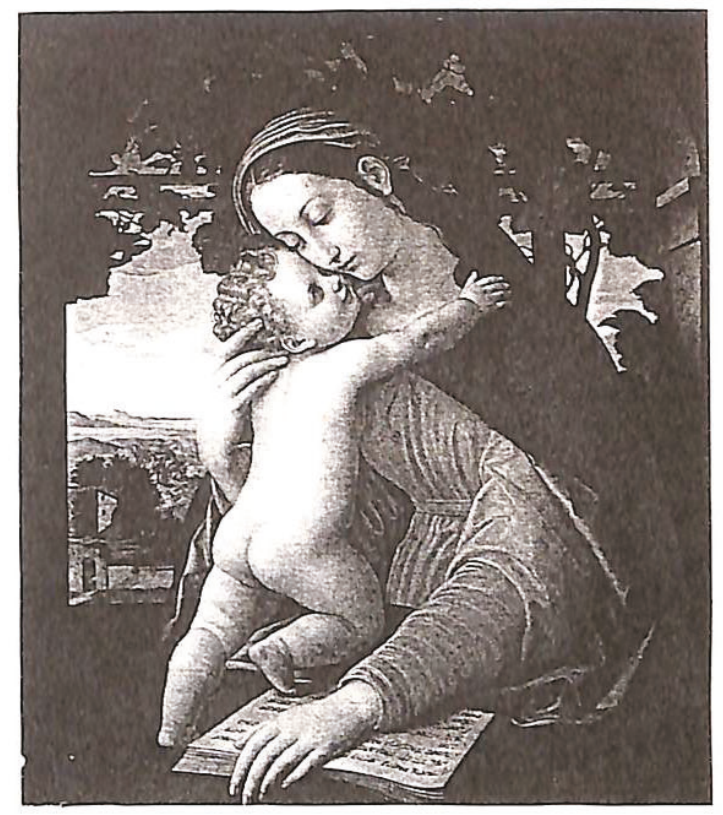

(14)

(15)

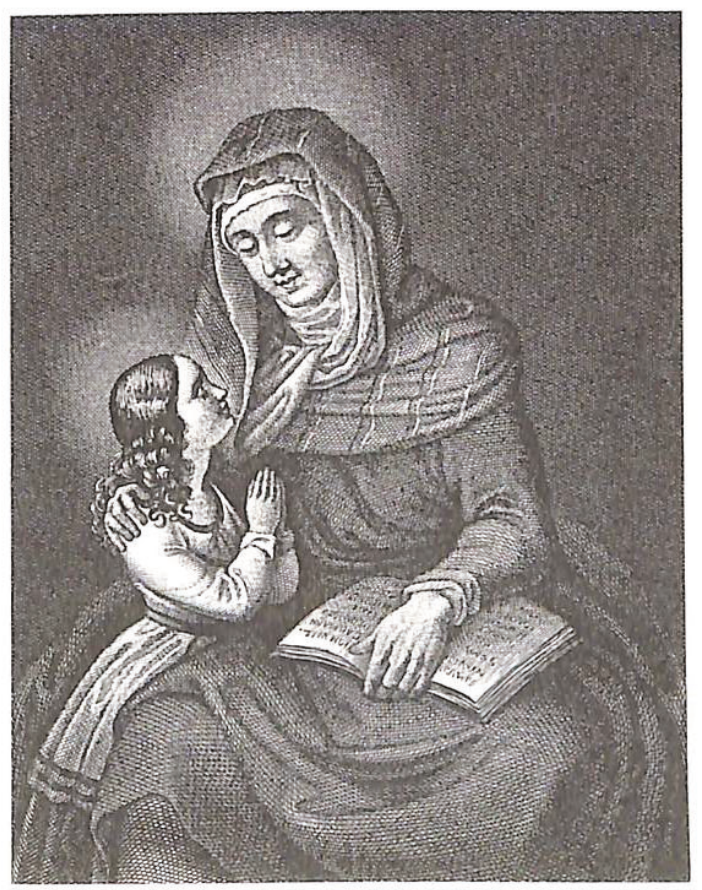

(16)

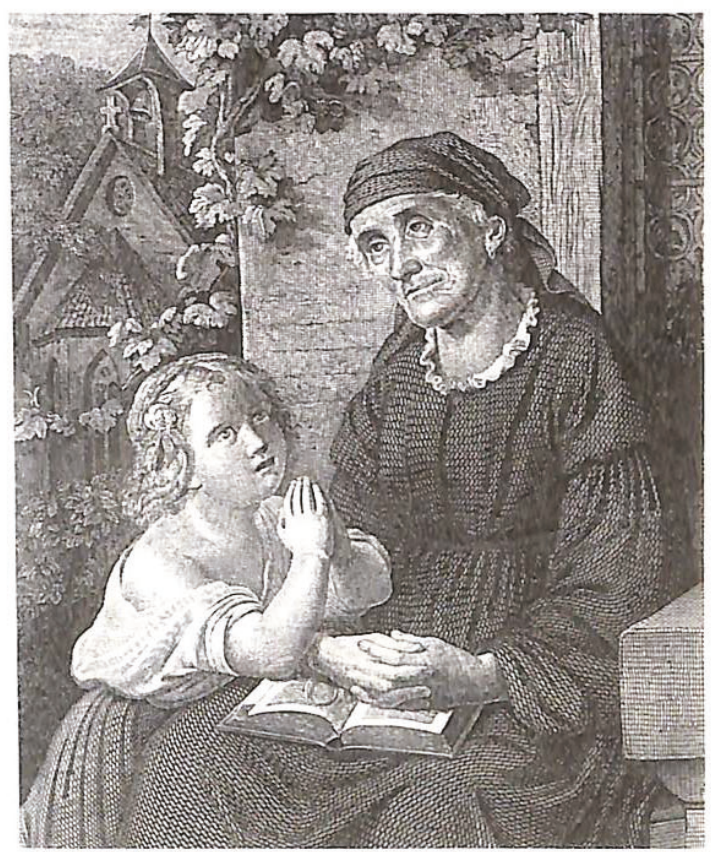


Futice funt 028 pro nobis.
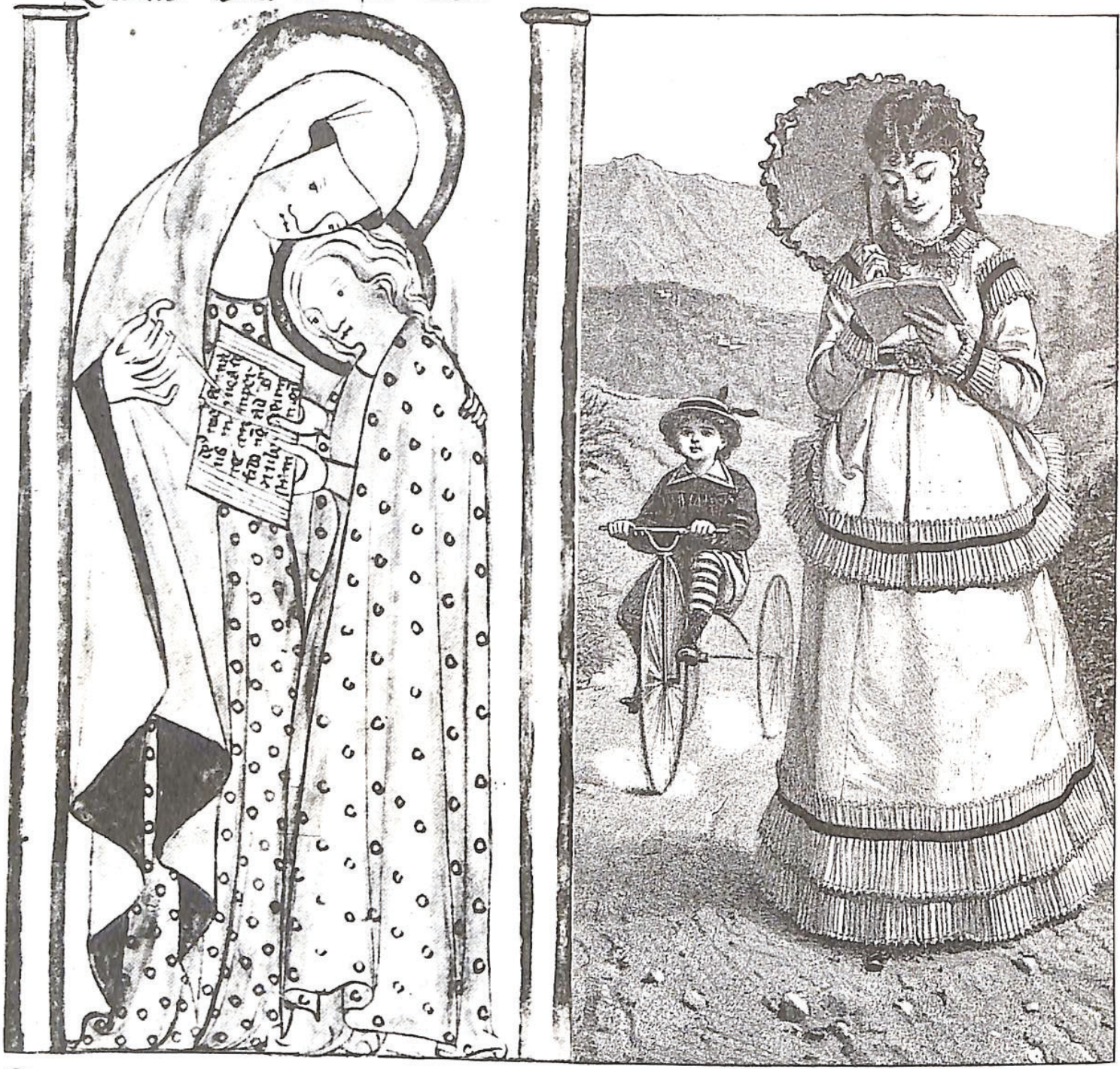

(17)

(18) 


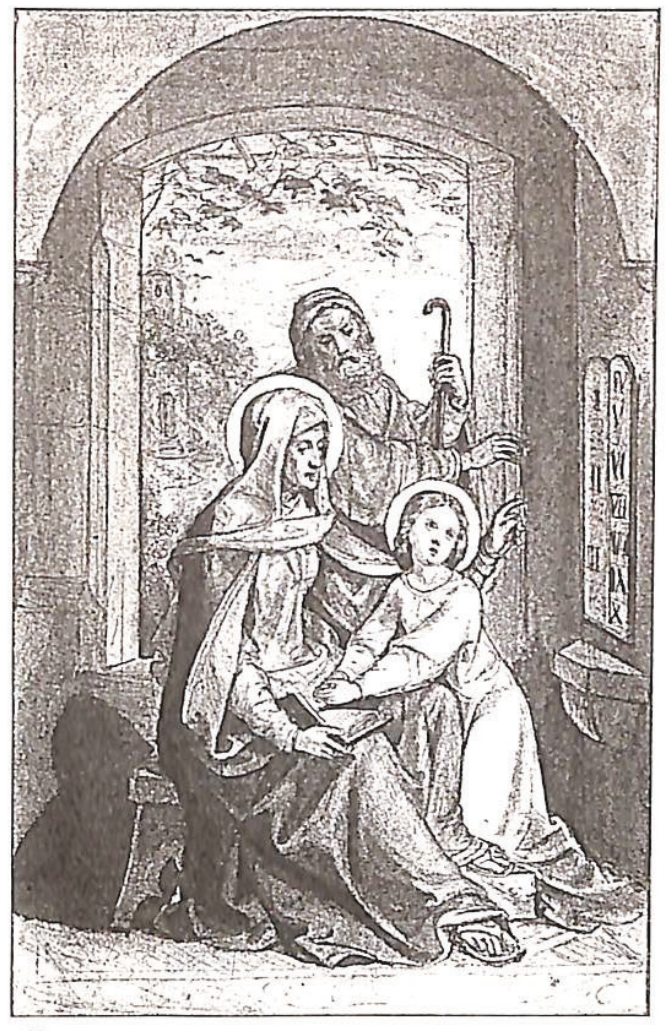

(19)

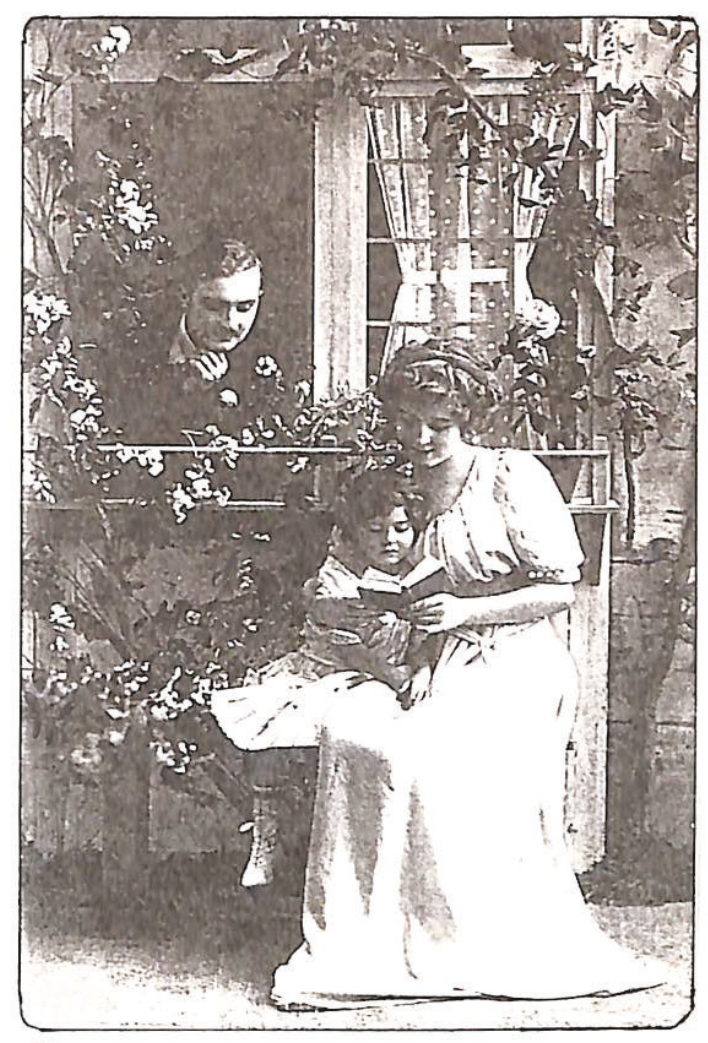

(20)

(21)
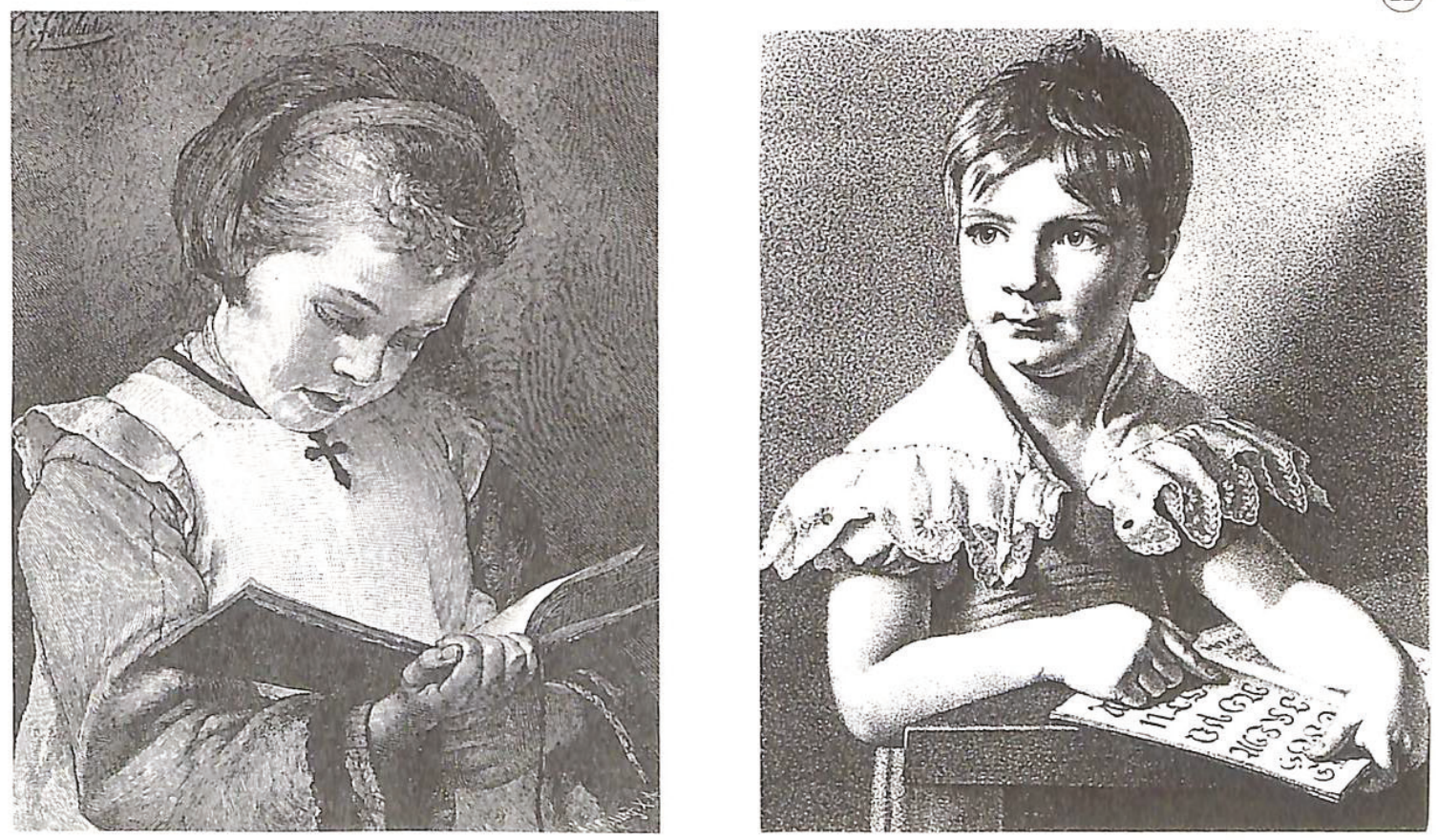


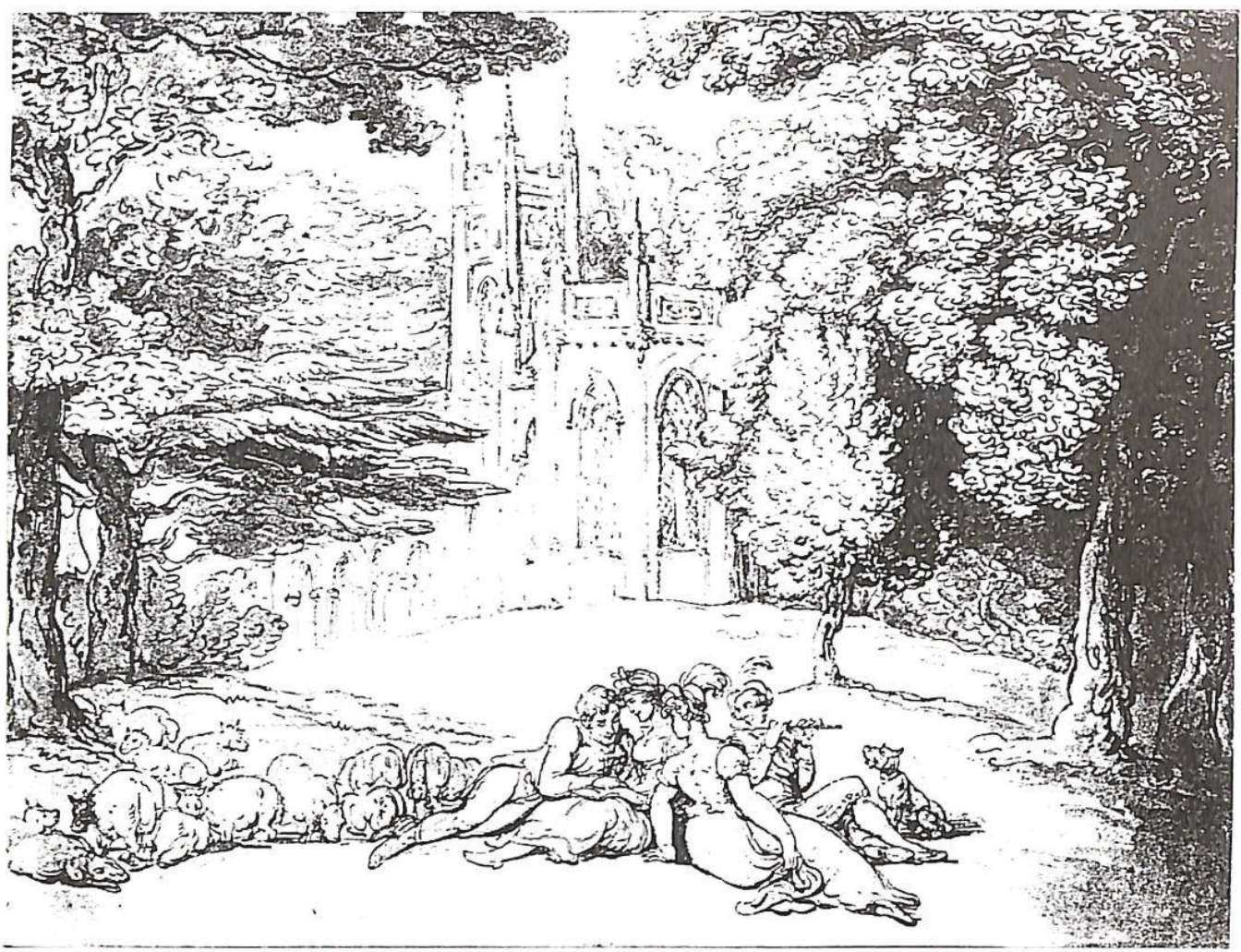

(23)

(24)

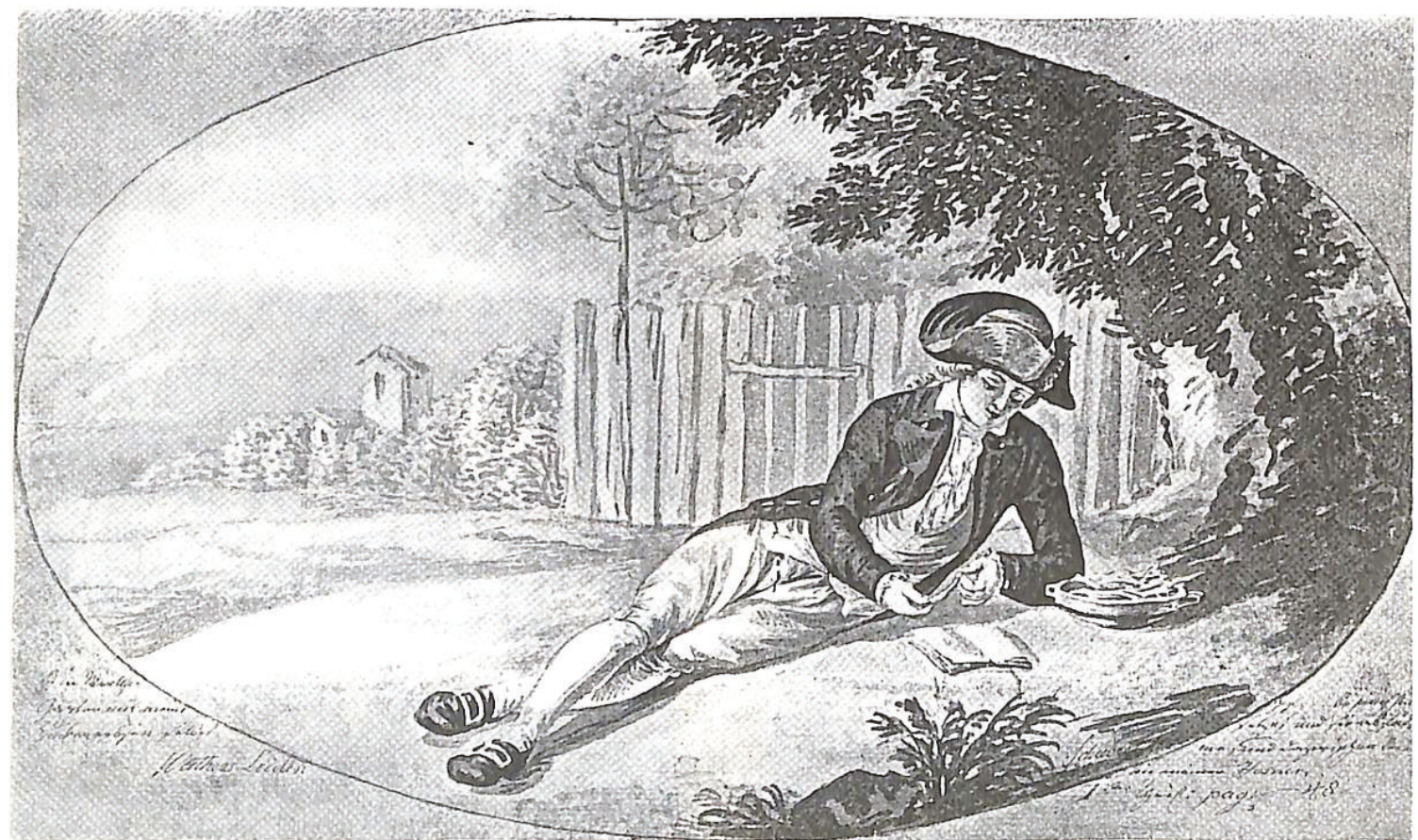




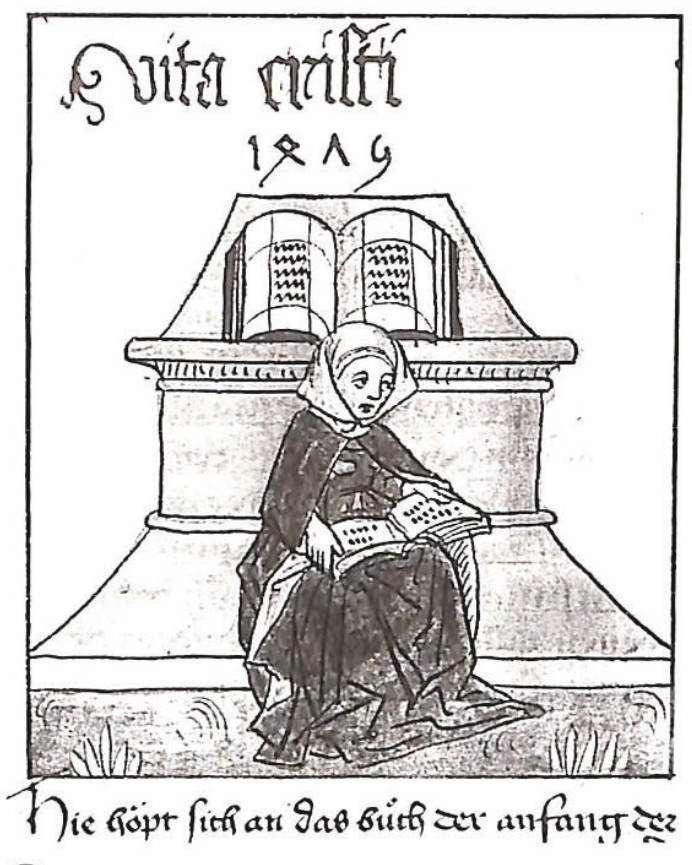

(25)

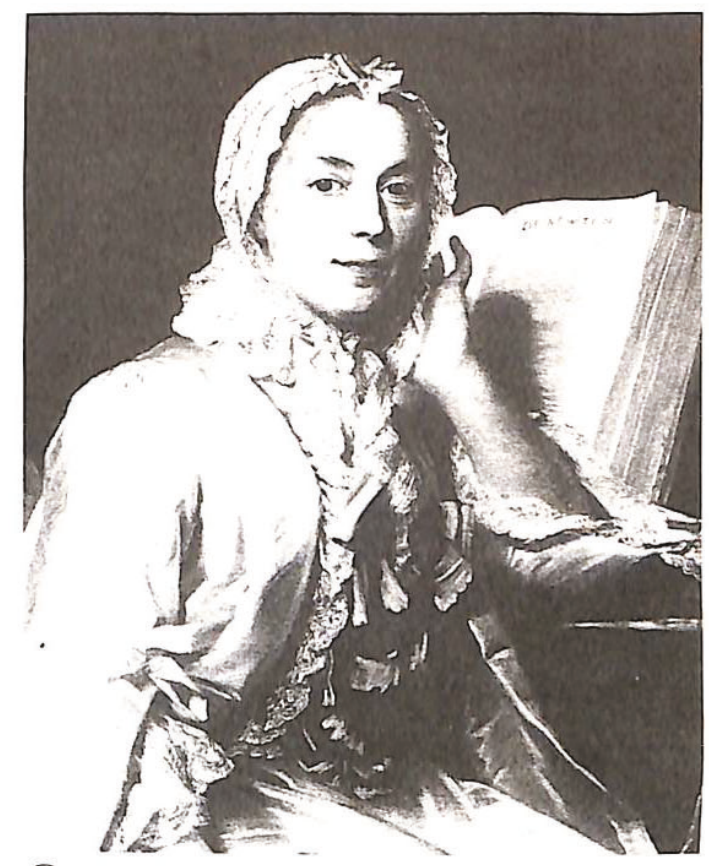

(26)

(27)

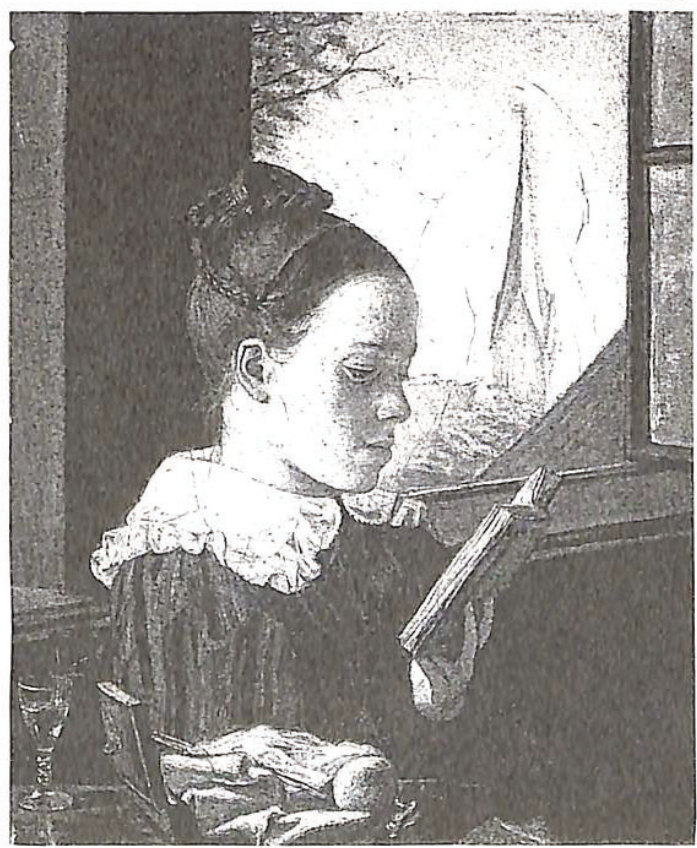

(28)

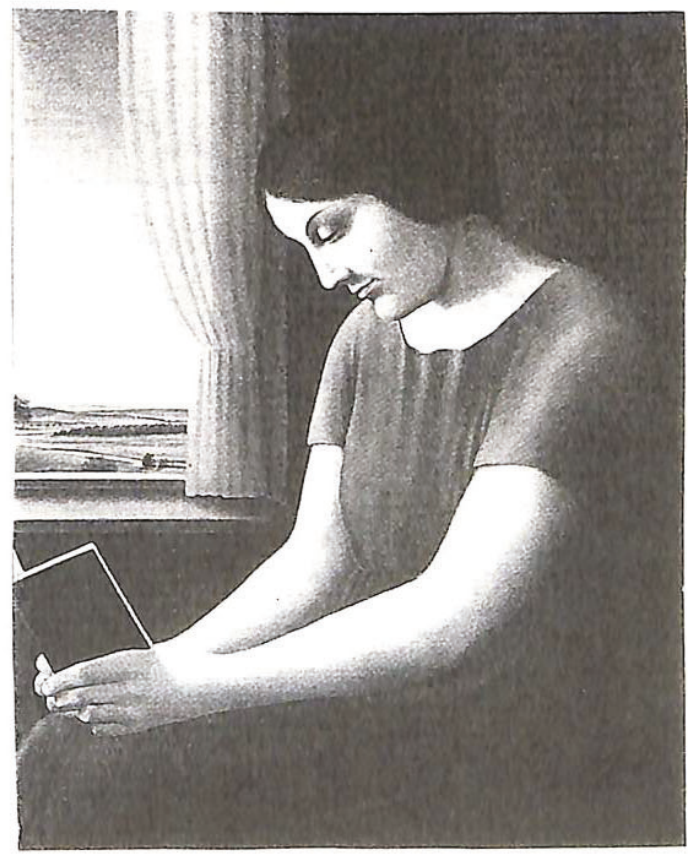




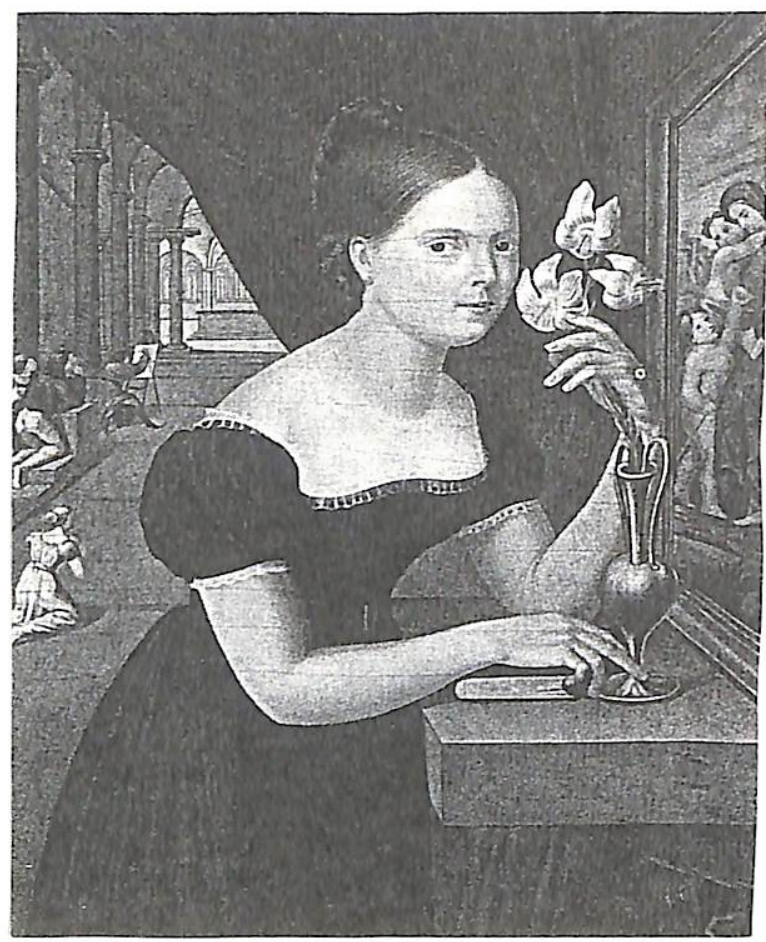

(29)

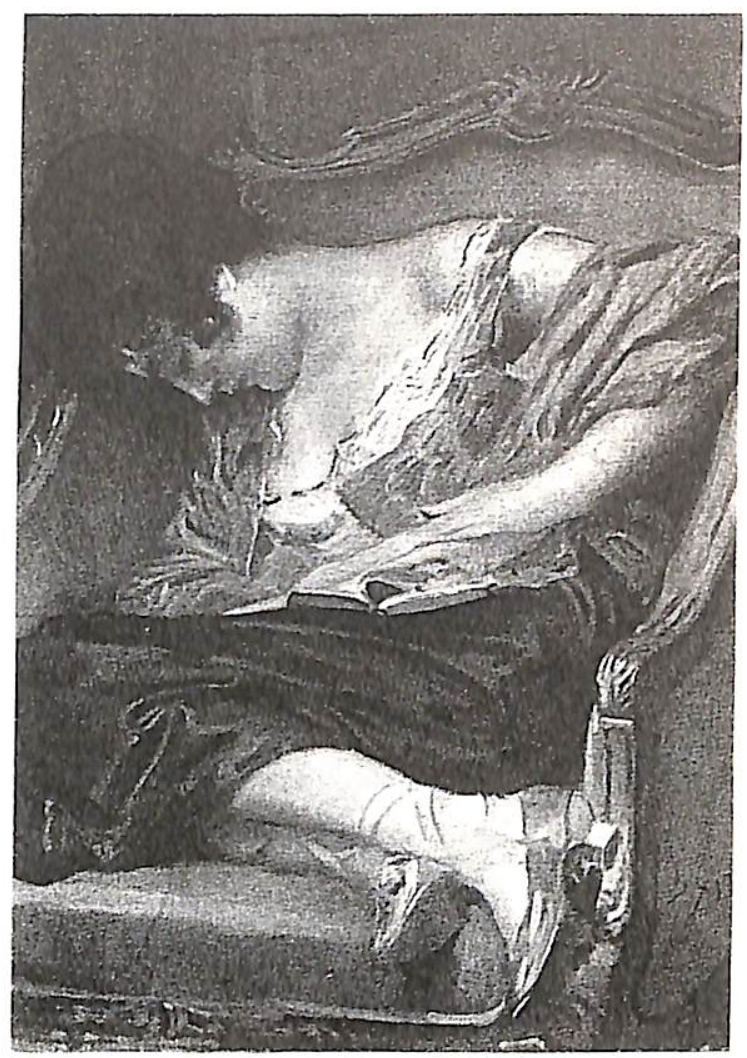

(30)

(32)

(31)
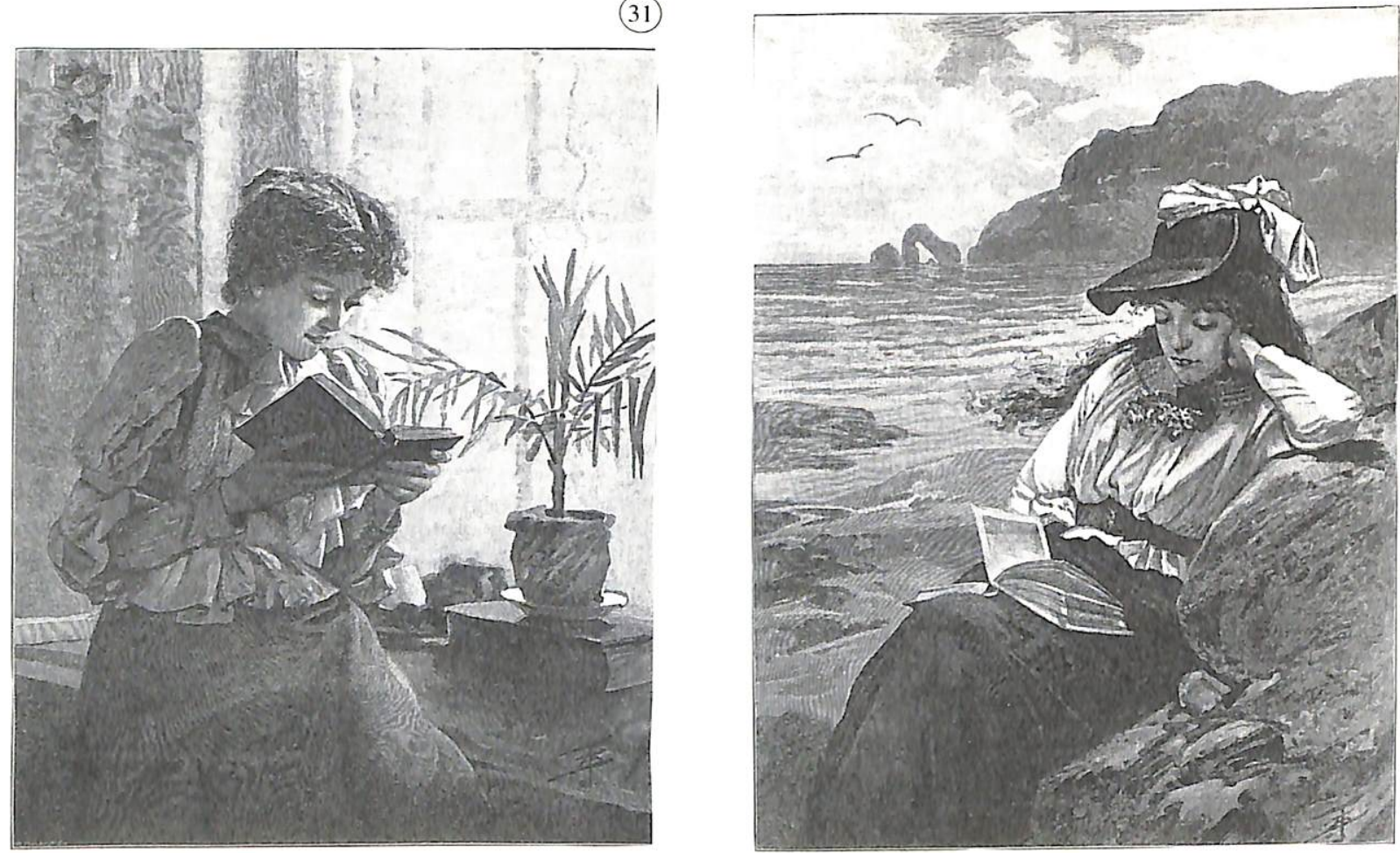


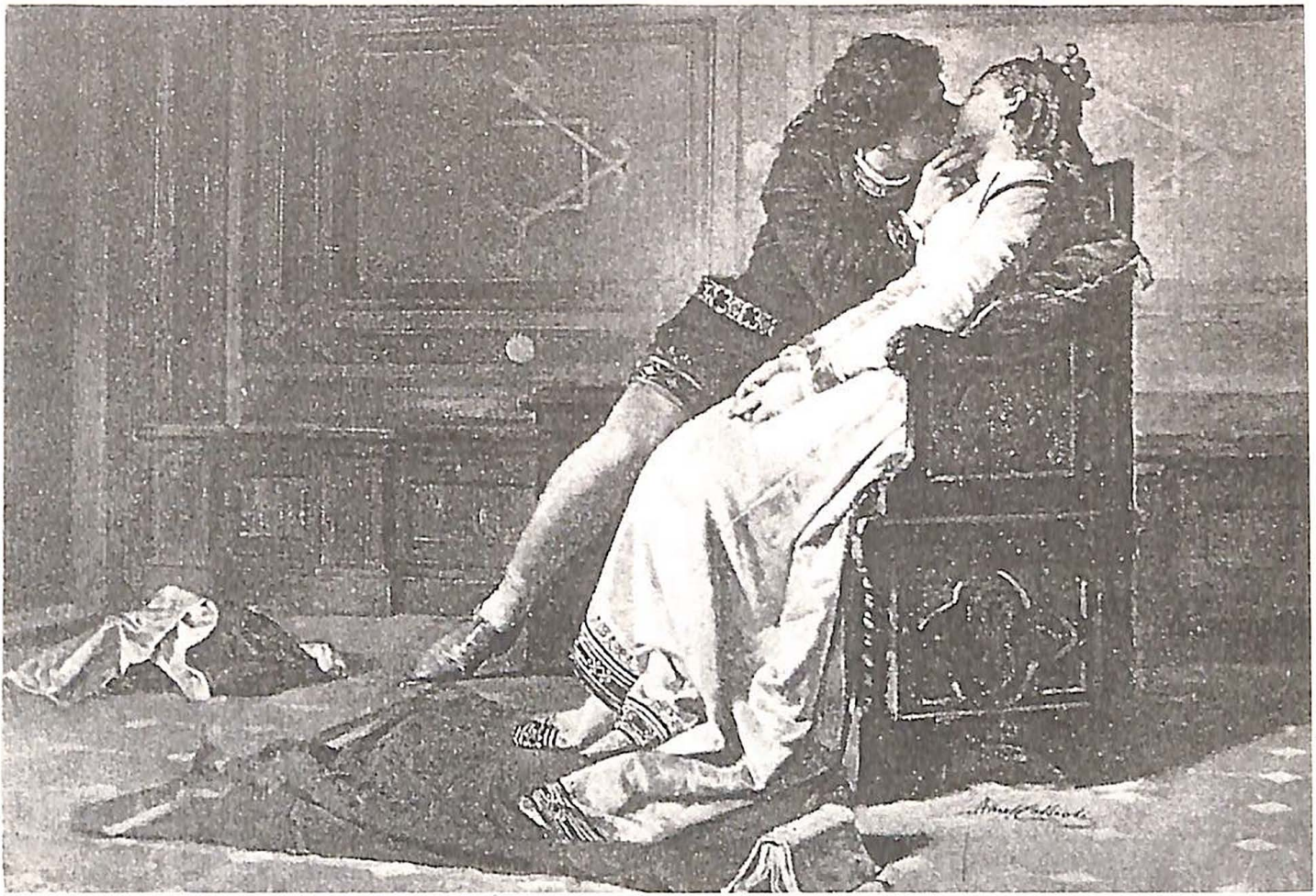

(33)

(34)

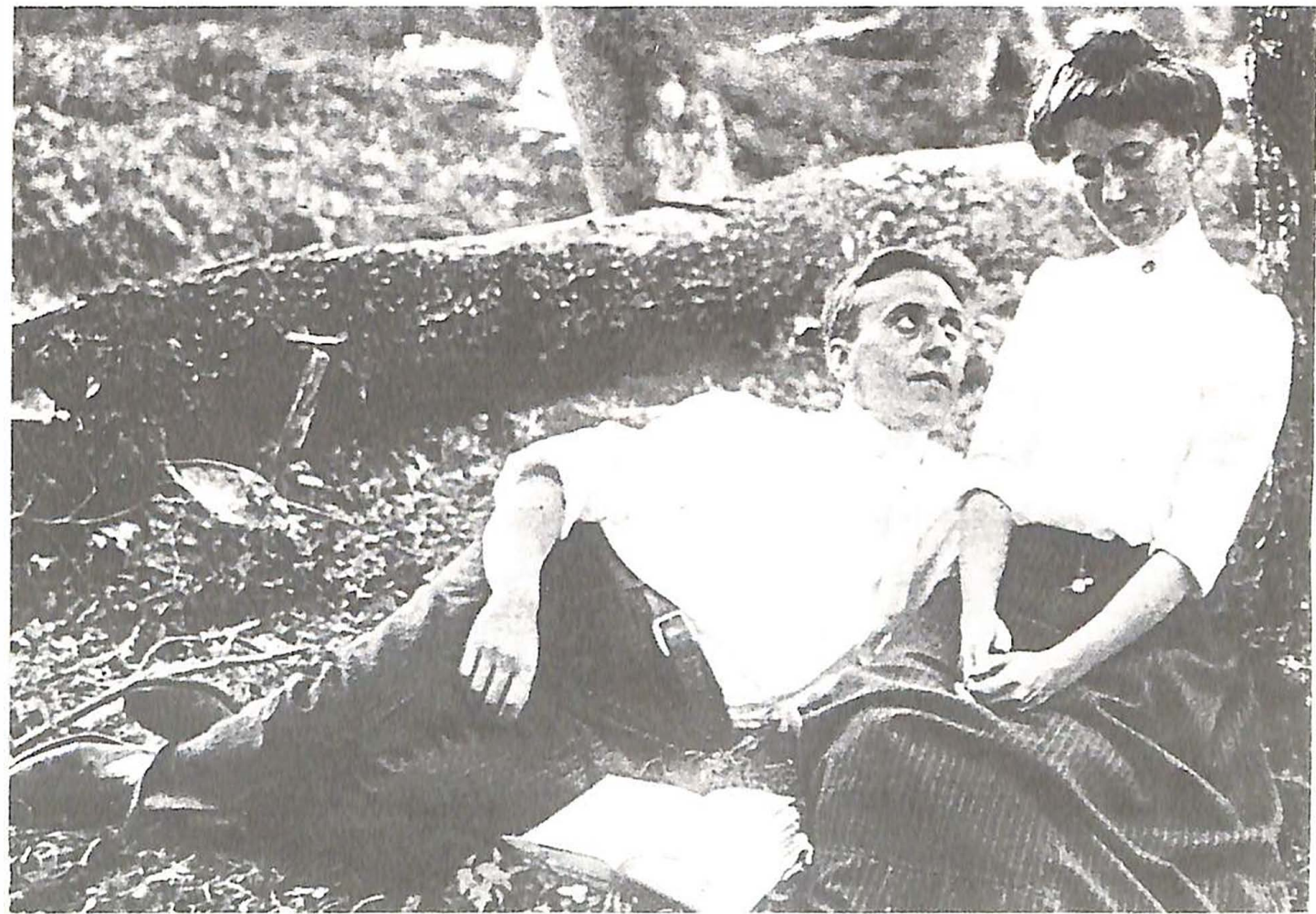




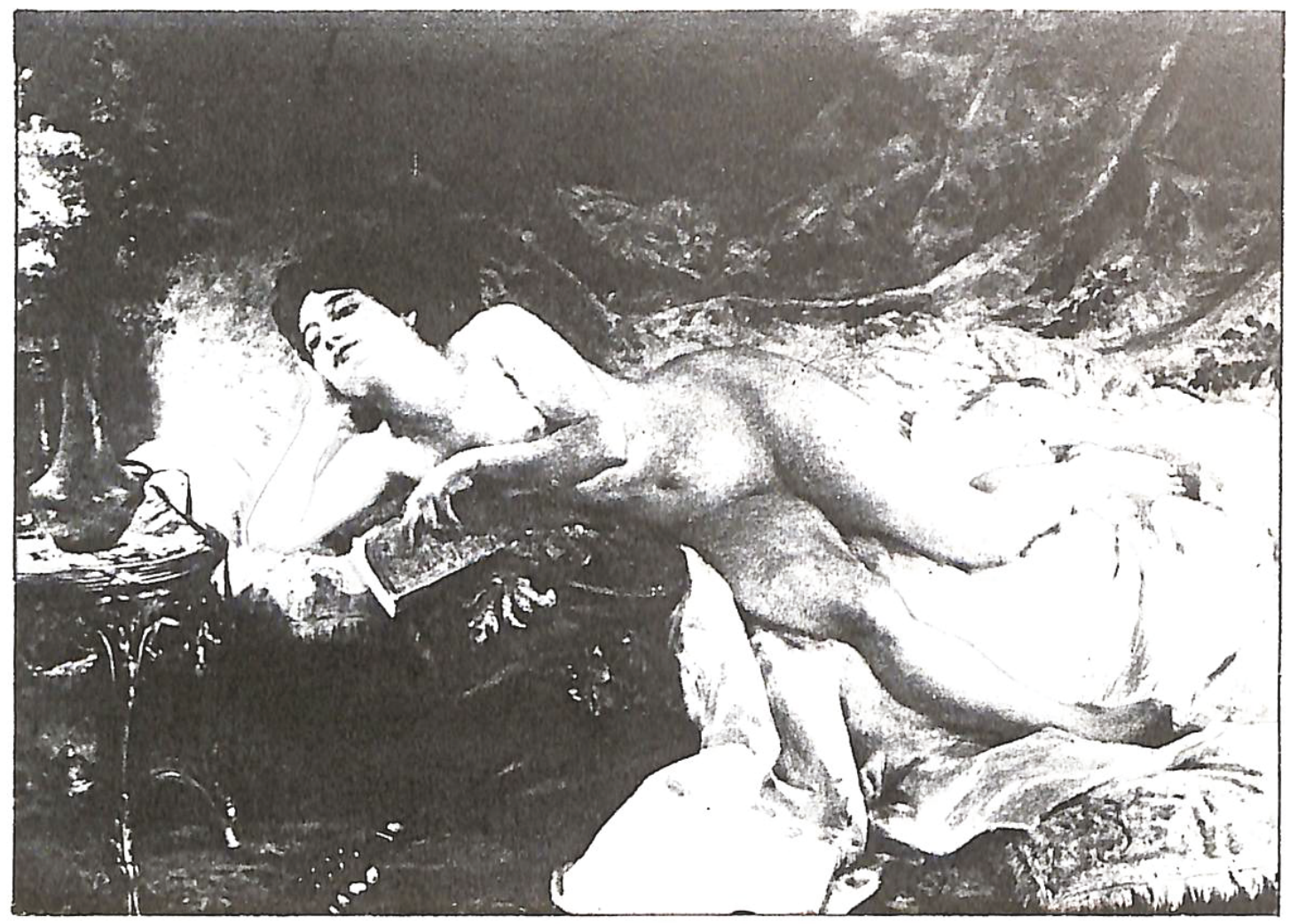

(35)

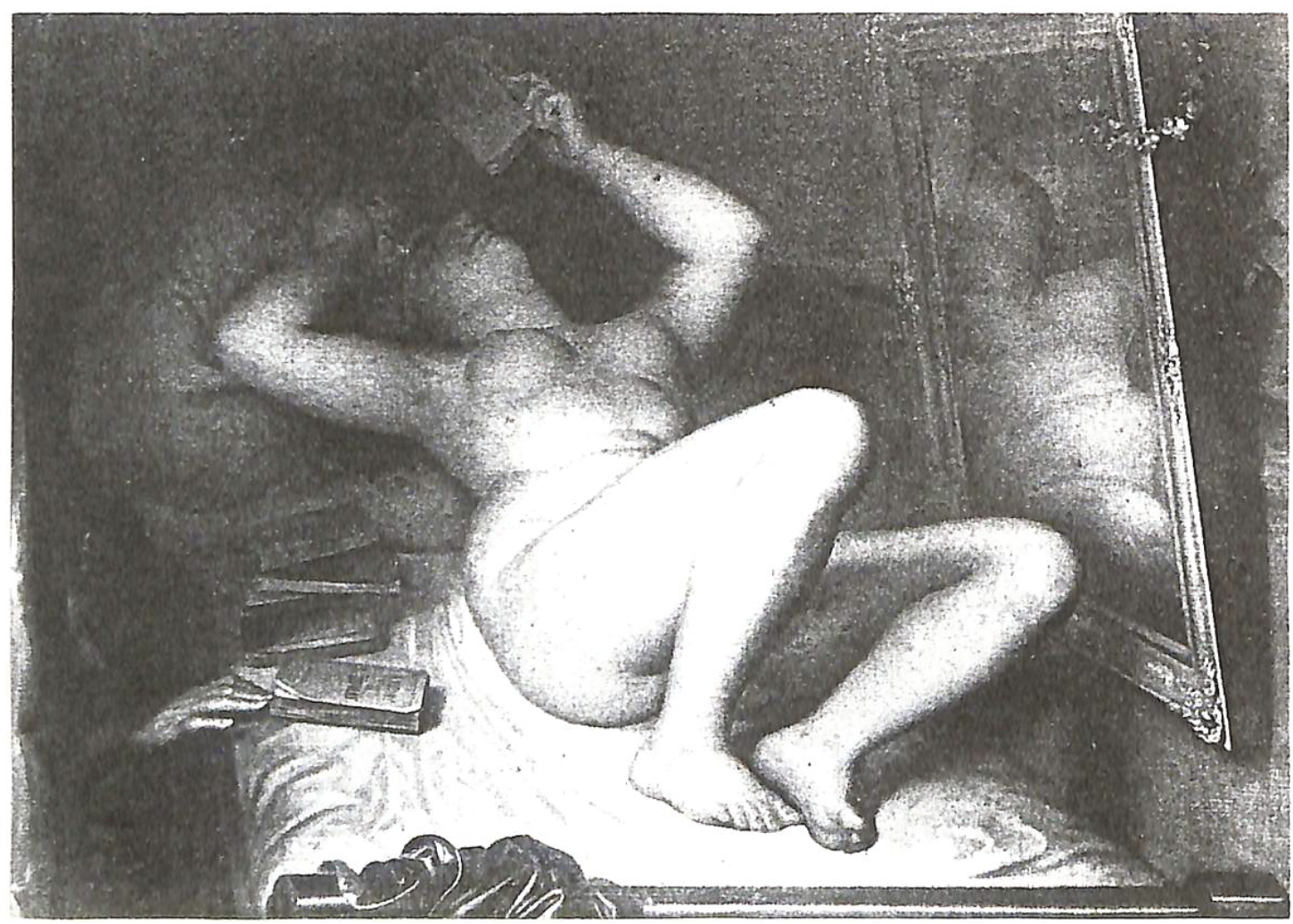




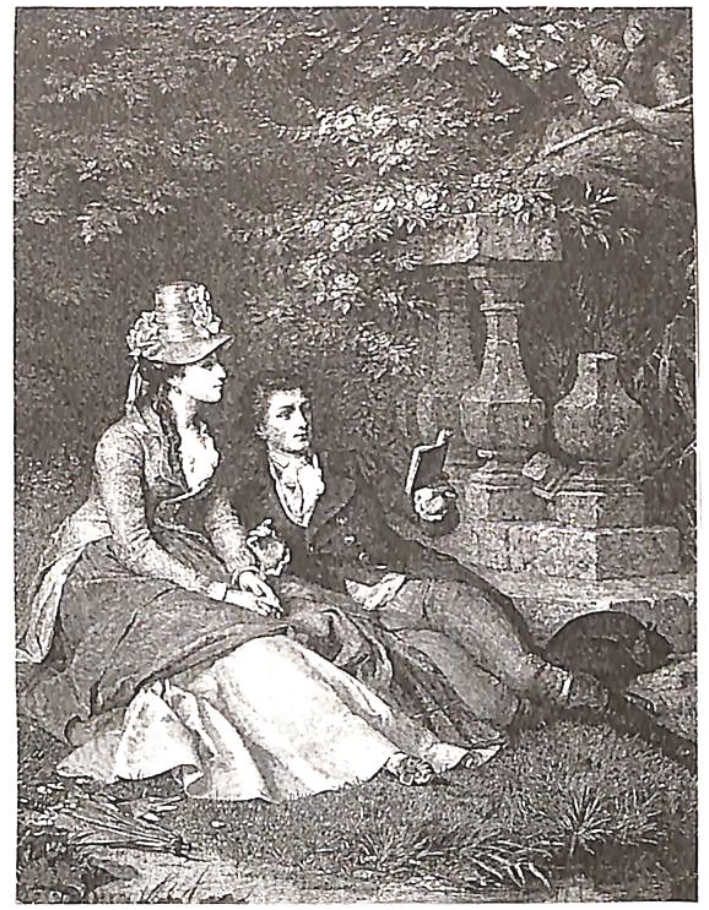

(37)

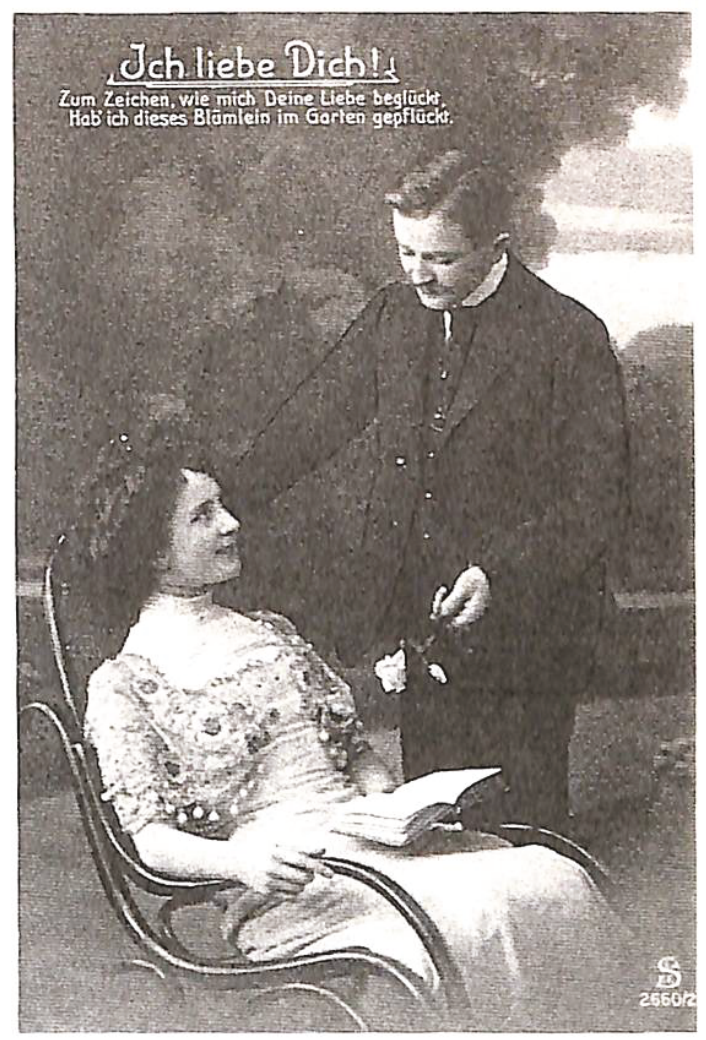

(38)

(39)
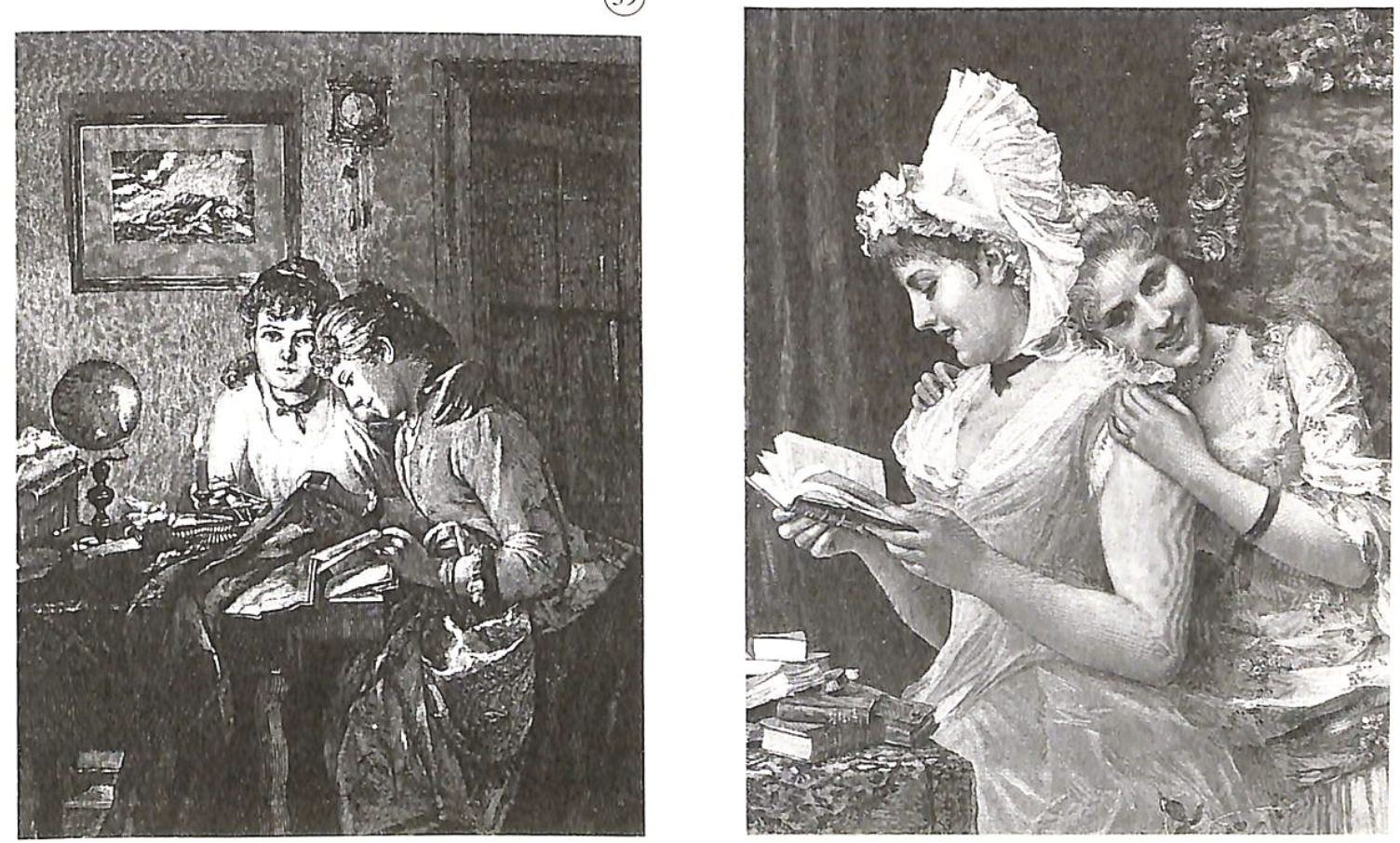


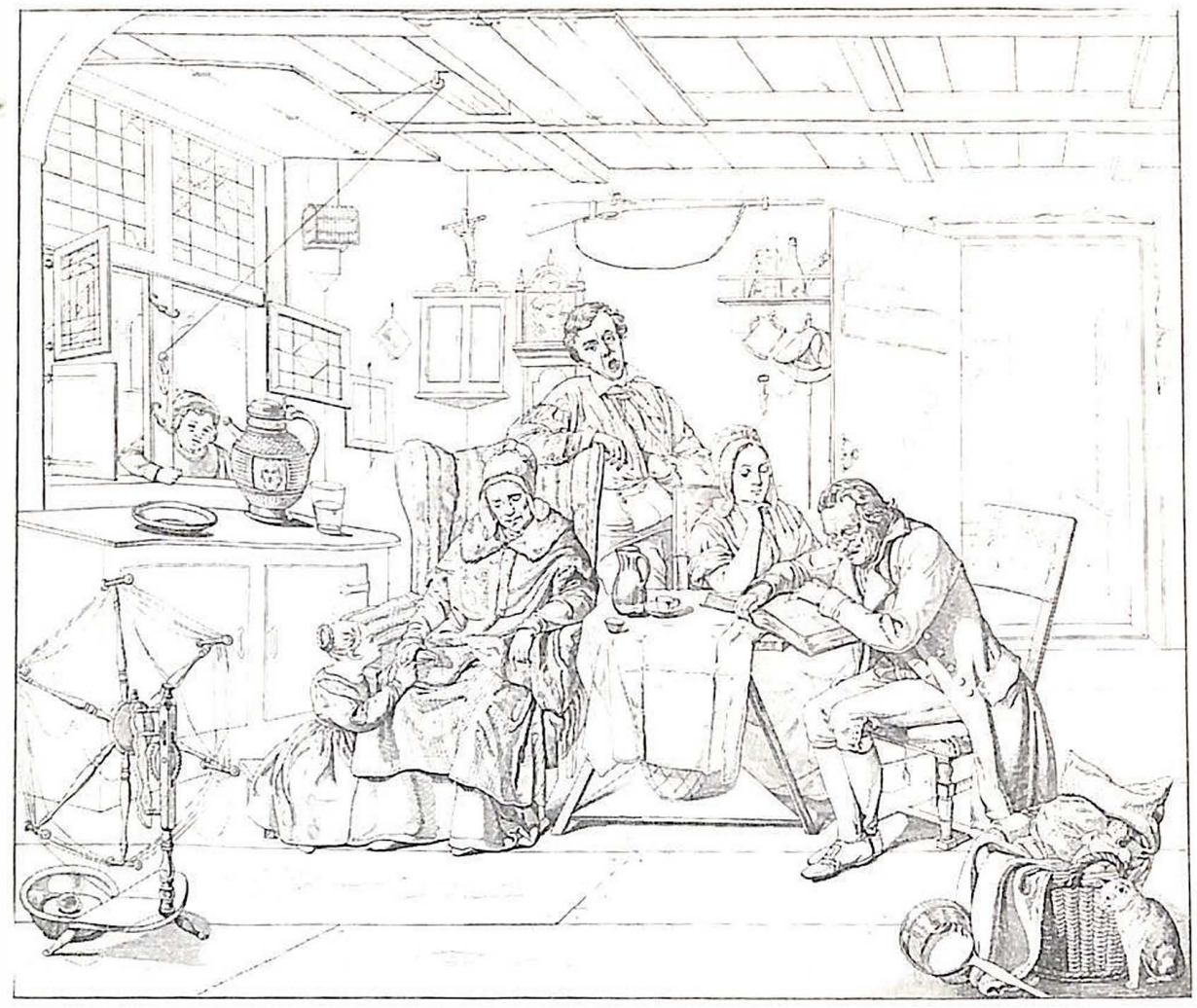

(41)

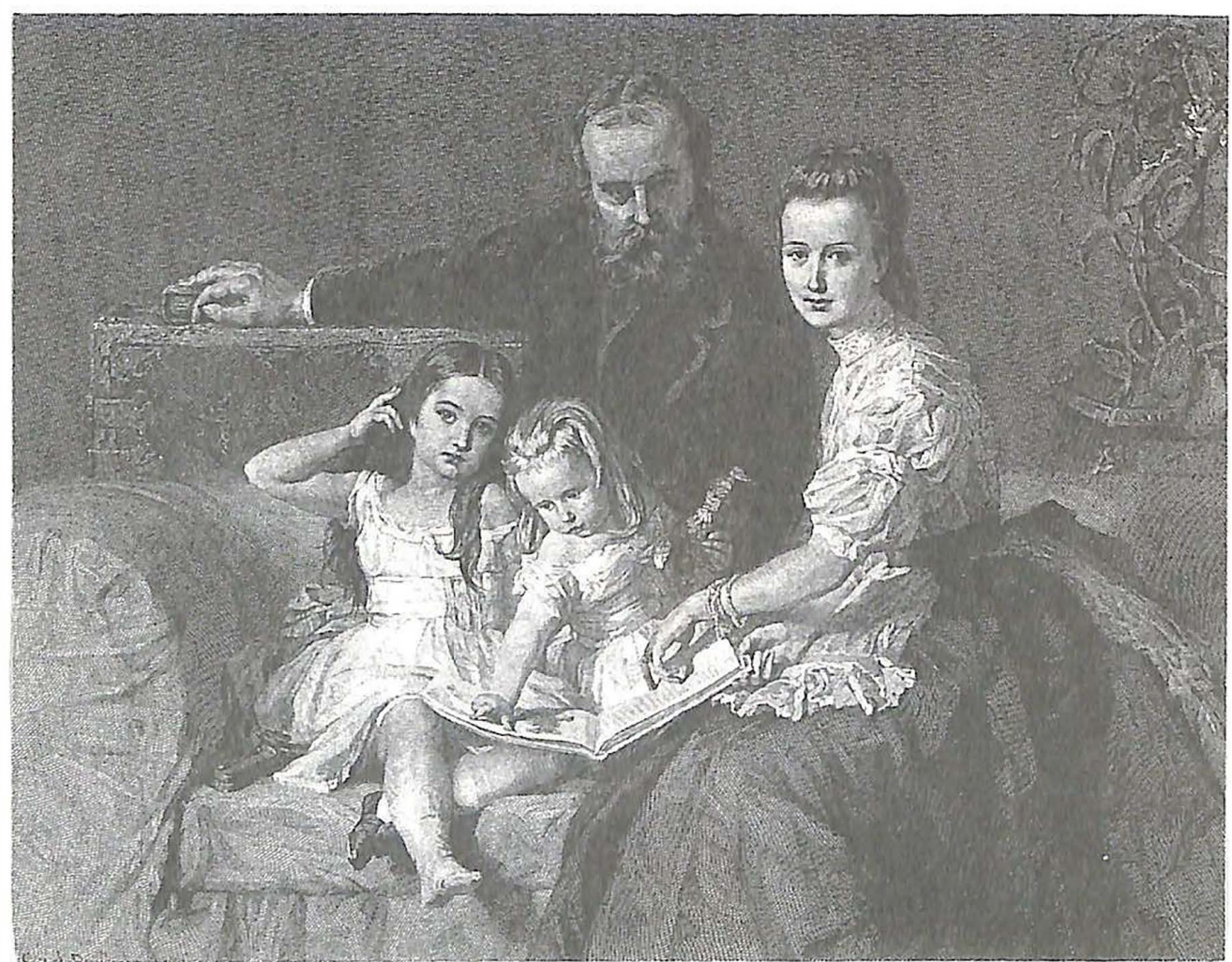

